\title{
Taxonomy and morphology of Cladochaeta Coquillett, 1900 in Brazil (Diptera: Drosophilidae: Drosophilinae)
}

\author{
Taxonomia e morfologia de Cladochaeta Coquillett, \\ 1900 no Brasil (Diptera: Drosophilidae: Drosophilinae)
}

GABRIELA PIRANI IGNÁCIO

Dissertação apresentada à Faculdade de Filosofia,

Ciências e Letras de Ribeirão Preto da USP, como parte das exigências para a obtenção do título de Mestre em Ciências, Área: ENTOMOLOGIA

RIBEIRÃO PRETO, SP 


\title{
Taxonomy and morphology of Cladochaeta Coquillett, 1900 in Brazil (Diptera: Drosophilidae: Drosophilinae)
}

\author{
Taxonomia e morfologia de Cladochaeta Coquillett, \\ 1900 no Brasil (Diptera: Drosophilidae: Drosophilinae)
}

\author{
GABRIELA PIRANI IGNÁCIO \\ Orientador: Dalton de Souza Amorim
}

Dissertação apresentada à Faculdade de Filosofia,

Ciências e Letras de Ribeirão Preto da USP, como parte das exigências para a obtenção do título de Mestre em Ciências, Área: ENTOMOLOGIA

RIBEIRÃO PRETO, SP 
Autorizo a reprodução e divulgação total ou parcial deste trabalho, por qualquer meio convencional ou eletrônico, para fins de estudo e pesquisa, desde que citada a fonte.

Ignácio, Gabriela Pirani

Taxonomy and Morphology of Cladochaeta Coquillett, 1900 in Brasil (Diptera: Drosophilidae: Drosophilinae)

$75 \mathrm{pp}$.

Dissertação de Mestrado, apresentada à Faculdade de Filosofia, Ciências e Letras de Ribeirão Preto/USP. Área de concentração: Entomologia.

Orientador: Amorim, Dalton de Souza.

1. Cladochaeta. 2. Drosophilidae. 3. Taxonomy. 4. Morphology. 5. Brazilian Fauna 


\section{Acknowledgments}

First of all, I would like to thank my advisor, Prof. Dr. Dalton de Souza Amorim for the guidance and willingness to help me in understanding important issues about Taxonomy, Systematics, Diptera morphology and also education, human values, spirituality and many other subjects that slowly and gradually changed my way of thinking.

To all my friends of Diptera Lab., for countless lessons patiently taught every day and for all the great and funny moments shared. They all contribute to my scientific and personal growth by different reasons. Maria Isabel P. A. Balbi for the help with the dissections and material preparations in general, for all the advices and for the kindness and docility that she dealt with everything that I asked her. Marco for important contributions to the improvement of the text of this dissertation, for all the talks about many scientific or not topics and for the great moments. Diego, for all the help with all the softwares, particularly the Quantum Gis, for the help in constructing the key to species, formatting advices, and many other things, for all the funny momments. Caleb, Paula and Renato for several important discussions and tips in various topics. Danilo for all the long and repeated talks about male terminalia homology, for being the first to teach me how to use photoshop and illustrator and for helping me always in many different ways. To all colleagues from LBCA, especially Fabio Oliveira for reading some sections of the text and for the countless pleasant moment together.

To Dr. Marco Silva Gottschalk for the long time partnership, being who thought me how to properly identify drosophilid genera, to understand many morphologic issues of the group, for helping with the improvement of dissecting techniques and for receiving me in his Lab. at UFPel last year for the second time.

To Dr. David Grimaldi, for kindly receiving me at the AMNH, allowing me to have access to a great load of material to be studied in colaboration in a near future, for all the great and extremely important talks about morphology and systematics of Cladochaeta and Drosophilidae as a whole and many insights of future possible studies, giving me a broader context about the group.

To Dr. Carlos J. E. Lamas, Diptera Curator of the Museu de Zoologia da USP (MZUSP) that provided the loan of an important part of the material studied here from the BIOTA Diptera (FAPESP Grant 2003/10274-9) and Dr. Angelica Maria Penteado 
Martins Dias (UFSCAR), who made another great part of the material available by the project Hymenoptera Parasitóides da Região Sudeste Brasileira (INCT- HYMPAR Sudeste) (FAPESP Grant 2008/57949-4; CNPQ Grant 573802/2008-4). To Dr. Eduardo Almeida, José Amílcar Tavares Filho and Daércio Adam Lucena (Faculdade de Filosofia Ciências e Letras, Universidade de São Paulo) who collected in Ceará and provided us 3 of the described species.

To my Family for all the support and patience during all the Msc, specially my mother Lilian, for the inconditional love and comprehension given in the harder momments, for taking care of my health and for the pleasant companion during some lonely weekends working.

To the Faculdade de Filosofia Ciencias e Letras de Ribeirão Preto and The Entomology postgraduate program of Universidade de São Paulo for providing the structure which enabled this work. This study was funded by FAPESP Proc. 2013/07433-0. 


\begin{abstract}
Drosophilidae is a very diverse family of acalapytrate flies comprising more than 4,000 described species, worldwide in distribution, occupying a large range of ecological niches and with high morphological variability. Despite the huge number of papers published on different aspects of the genus Drosophila Fallen, 1823 and especially $D$. melanogaster Meigen, 1830, the group as a whole can still be considered poorly known, since some taxa within it have historically gained more attention than others. As one of the examples of a very speciose but unsatisfactorily studied group, is the drosophiline genus Cladochaeta Coquillet, 1900, with more than 100 described Neotropical and some few southern Nearctic species, but still with a large number of species to be described. In this study the Brazilian fauna of the genus is revised, with the description of 16 new species based on males-Cladochaeta sp. 1, nov. sp., C. sp. 2, nov. sp., $C$. sp. 3, nov. sp., C. sp. 4, nov. sp., C. sp. 5, nov. sp., C. sp. 6, nov. sp., C. sp. 7, nov. sp., C. sp. 8, nov. sp., C. sp. 9, nov. sp., C. sp. 10, nov. sp., C. sp. 11, nov. sp., C. sp. 12, nov. sp., $C$. sp. 13 , nov. sp., $C$. sp. 14 , nov. sp. and $C$. sp. 15 , nov. sp. The descriptions include photographs for each species and detailed illustrations of the male terminalia in different views. A synopsis about the taxonomy and natural history of the genus, a key for the Brazilian species, and a distributional map of the genus in Brazil are provided. Some comments about relationships between some of the species of the genus are made, as well as a discussion about male terminalia sclerite homology, and the issue of association between males and females.
\end{abstract}

Key words: Cladochaeta, Drosophilidae, Taxonomy, Morphology, Brazilian Fauna. 


\section{Resumo}

Drosophilidae é uma família extremamente diversa de moscas acaliptradas, compreendendo mais de 4.000 espécies descritas e distribuição mundial, ocupando uma grande variedade de nichos ecológicos e apresentando alta variabilidade morfológica. Apesar do grande número de publicações sobre diversos aspectos do gênero Drosophila Fallen, 1823 e, em especial, sobre D. melanogaster Meigen, 1830, o grupo como um todo ainda é relativamente pouco conhecido. Um exemplo de um grupo muito especioso e insatisfatoriamente estudado é o gênero Cladochaeta Coquillett, 1900 de Drosophilinae, com mais de 100 espécies descritas da região Neotropical e do sul da região Neártica. A fauna brasileira foi revista, resultando na descrição de 16 novas espécies baseadas em machos-Cladochaeta sp. 1, nov. sp., C. sp. 2, nov. sp., C. sp. 3 , nov. sp., $C$. sp. 4, nov. sp., $C$. sp. 5, nov. sp., $C$. sp. 6, nov. sp., $C$. sp. 7, nov. sp., $C$. sp. 8, nov. sp., $C$. sp. 9, nov. sp., $C$. sp. 10, nov. sp., $C$. sp. 11, nov. sp., $C$. sp. 12, nov. sp., $C$. sp. 13, nov. sp., $C$. sp. 14 , nov. sp. e $C$. sp. 15, nov. sp. As descrições incluem fotografias para cada espécie e ilustrações detalhadas das terminálias masculinas em diferentes vistas. São apresentados uma sinopse sobre a taxonomia e história natural, uma chave para as espécies brasileiras e um mapa de distribuição do gênero no Brasil. Alguns comentários são feitos sobre hipóteses de relacionamento entre algumas das espécies, bem como uma discussão a respeito de questões de homologia de escleritos da terminália masculina e a questão da associação entre machos e fêmeas nas espécies do gênero.

Palavras Chave: Cladochaeta, Drosophilidae, Taxonomia, Morphologia, Fauna Brasileira. 


\section{Summary}

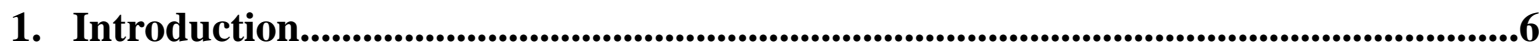

2. Material and methods........................................................................................................12

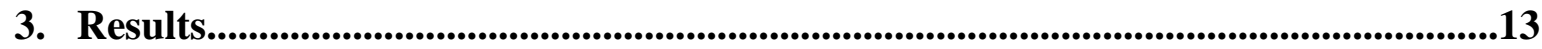

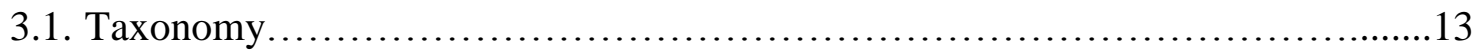

3.2. Distributional map of Cladochaeta in Brazil..................................62

3.3. Identification key to species of Cladochaeta based on adult males (except for $C$.

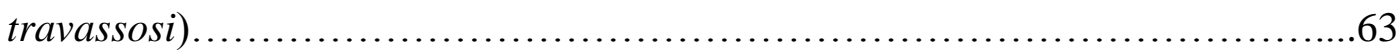

4. Discussion..............................................................................65

4.1. Species richness in Cladochaeta and morphospecies known only from females...65

4.2. Male terminalia sclerites and homology....................................67

4.3. Groups of species and relationships within the genus Cladochaeta .................70

4.4. The already described species of Cladochaeta from Brazil........................71

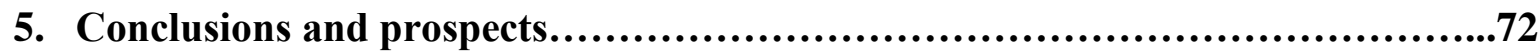

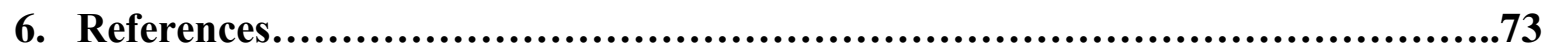




\section{Introduction}

The family Drosophilidae has 4,279 described species worldwide (Bächli, 2015), comprising small, from 1 to 7 millimeters long acalyptrate flies, with a considerably large diversity of biologies, colors and shapes. The species of the family can be recognized by the incomplete Sc, the presence of both, humeral and subcostal breaks on $\mathrm{C}$, and three frontoorbital setae, the anterior one proclinate and the posterior ones, reclined (Grimaldi, 2010). The Acalyptratae are a large Schizophora grade which, according to McAlpine (1989), is classified into ten superfamilies (e.g., Nerioidea, Diopsoidea, Conopoidea, Tephritoidea, Lauxanioidea, Sciomyzoidea, Opomyzoidea, Sphaeroceroidea, Carnoidea, Ephydroidea). The family Drosophilidae fits into the Ephydroidea and, according to Grimaldi (1990), has the Curtonotidae as its sister group.

The Drosophilidae are traditionally divided into two subfamilies, Steganinae and Drosophilinae. The first author to formally propose this subdivision of the family was Okada (1989) in a phenetic classification, later revised by Grimaldi (1990) in a phylogenetic context - which is the classification of subfamilies that we adopt here. Remsen \& O'Grady (2002) reanalyzed Grimaldi's (1990) data and also provided their own phylogenetic analysis with morphologic and molecular data. There are some differences in the topologies of the trees, but the monophyly of both subfamilies was corroborated. More recently, several other authors published phylogenetic analyses of the Drosophilidae, most of which dealing solely with Drosophila and closely related genera. Van der Linde et al. (2010) and Yassin (2013) had a considerably wide taxon sampling to test the monophyly of Steganinae and Drosophilinae, recovering both as monophyletic sister groups.

Currently, the Steganinae comprises 919 species in 30 genera, while the Drosophilinae comprises 3,358 species in 44 genera (Bächli, 2015). There are 21 monotypic genera in the classification of the family, two of which - Apacrochaeta Duda, 1927 and Sphyrnoceps de Meijere, 1916- are incertae sedis at the subfamily level (Bächli, 2015). The Drosophilinae were divided by Grimaldi (1990) into two tribes, the Cladochaetini with 163 speciesincluding the genera Diathoneura Duda, 1924 (39 species) and Cladochaeta Coquillett, 1900 (124 species) - and the Drosophilini with 3,195 species, comprising the remaining genera of the subfamily. The Cladochaetini are entirely restricted to the New World. Drosophila 
(Lordiphosa) ripa (Okada), 1961 from Nepal was originally described as Diathoneura, but was later on transferred by Okada (1984) to the genus Drosophila.

The genus Drosophila has historically received more attention relative to other drosophilid genera. The reason is evidently that D. melanogaster Meigen, 1830 and some other Drosophila species were largely used as biological models, mostly due to its short lifecycle and easy laboratory breeding (Okada, 1977). The use of D. melanogaster in studies concerning fundamental biological processes, as mutation, linkage, crossing-over, sex-linked inheritance, among others, contributed to the beginning of modern genetics (DeSalle e Grimaldi, 1991). This eventually led to the development of the synthetic theory of evolution (Grimaldi, 1990). Other genera of the family have received far less attention, despite their species richness and interesting evolutionary problems.

A significant number of drosophilid species has been recorded for Brazil. The real dimension of the drosophilid fauna in Brazil, however, is still unknown. Brown (2009) estimates that the number of existing species for some fly genera may be up to 10 times the present number of described species, what most likely may apply to Cladochaeta.

Cladochaeta Coquillett, 1900 is a primarily Neotropical genus, with 124 described species, seven of which from North America-e.g. C. floridana (Malloch, 1924); C. inversa (Walker, 1861); C. sturtevanti Wheeler \& Takada, 1971; C. wilhansoni Grimaldi \& Nguyen, 1999; C. dracula Grimaldi \& Nguyen, 1999; C. heedi Grimaldi \& Nguyen, 1999; C. florinversa Grimaldi \& Nguyen, 1999. The species of the genus have been arranged by Grimaldi \& Nguyen (1999) in ten species groups-e.g., nebulosa species group, inversa species group, sororia species group, dikra species group, diminuta species group, unca species group, simplex species group, armata species group, tripunctata species group and bomplandi species group_-, in a monographic paper by far the most important study ever published on the genus. The paper includes the description of 105 new species and new distributional and biological data for the group. Before that revision, Cladochaeta was basically known from the original descriptions of some few known species.

The taxonomic history of Cladochaeta is considerably complicated. The genus was described by Coquillett (1900) in a paper on the Diptera from Puerto-Rico, including on a single species, C. nebulosa Coquillett, 1900, a fly with brownish-yellow clouded wing and an arista bearing only one basal dorsal branch. Malloch (in Malloch \& McAtee, 1924) erected the genus Clastopteromyia Malloch, 1924 for C. inversa (Walker, 1861), previously in the genus Drosophila. Malloch \& McAtee (1924) dealt with various drosophilid genera, 
including Cladochaeta; the aristal branching described for Clastopteromyia would include species that now fit Cladochaeta and Diathoneura. In the same year, Duda (1924) mentioned the genera Diathoneura in a key to drosophilid genera, but did not describe it formally. Duda (1925) referred to the genus again, with a brief description and adding some species to it, but did not indicate the type-species-designated only in Malloch (1934) as Diathoneura taeniatipennis Duda, 1924.

The three aforementioned names were used in parallel until the Frota-Pessoa's (1947) attempt to synonymize Diathoneura with Clastopteromyia, suppressing Diathoneura. He considered that the characters showed by the authors to define their genera were virtually the same. That was a controversial paper and was not accepted by most drosophilid authors, as Wheeler (1952), Wheeler \& Takada (1971), Ashburner (1981), Wheeler (1981), Vilela \& Bachli (1990), Grimaldi (1990) and Grimaldi \& Nguyen (1999).

After this, Wheeler \& Takada (1971) commented on the difficulty to define the boundaries between Cladochaeta-Clastopteromyia-Diathoneura complex, but identified a group of about 30 Neotropical species that should be placed in the same genus due to their very distinctive male genitalia. Among these flies are Cladochaeta nebulosa and Clastopteromyia inversa, the type-species of their respective genera, leading to the synonymy between both genera and the suppression of the name Clastopteromyia. The remaining species of this complex compose Diathoneura.

Vilela \& Bächli (1990), in a paper about Neotropical species previously described in Diathoneura and Cladochaeta, mentioned the problem of defining precisely each genus, but left it as an open question. Nevertheless, they outlined a more comprehensive diagnosis for Cladochaeta and included 13 species in the genus, redescribing and making new combinations of already known species but without describing any new ones. Grimaldi (1990), in his phylogenetic analysis of the Drosophilidae using morphological information, treated both genera as separated sister groups.

More recently, Grimaldi \& Nguyen (1999) revised the genus and described a great number of species, estimating that the real extent of the group could reach 800 species, leading Cladochaeta to the position of the second largest genus of Drosophilinae, just behind Drosophila. In that paper their transferred Diathoneura taeniatipennis Duda, 1925, the typespecies of Diathoneura, to Cladochaeta. This could have led to the suppression of the name Diathoneura, but in personal communication with Dr. David Grimaldi (August, 2014), it was 
said that an exception case would be asked to the International Commission on Zoological Nomenclature for the maintenance of both generic names.

The most recent paper dealing with the Cladochetini, although in a broader discussion of the phylogenetic classification of the family, was Yassin (2013), combining molecular and morphological data. Yassin (2013) proposed to transfer the tribe Cladochaetini to the family Ephydridae. Due to some flaws in Yassin's (2013) approach, especially regarding low molecular markers and taxonomic sampling (e.g., a single Diathoneura, not identified species included in the analysis), we decided to not follow his classification. For Diathoneura and some of the remaining terminal taxa, only the $28 \mathrm{~S}$ ribossomal DNA region was sequenced, leading to a large amount of missing data and, thus, to a quite uninformative matrix. Furthermore, Yassin (2013) used morphological data from the literature to insert taxa without molecular sampling into the molecular tree, as was the case of Cladochaeta. The transference of the Cladochaetini to the Ephydridae was justified on the absence of $\mathrm{A}_{1}+\mathrm{CuA}_{2}$ and cell cup. Grimaldi (2010) had previously discussed this character, considering it a clear convergence among various unrelated drosophilid taxa (e.g. Chymomyza Czerny, 1903; Hypselothyrea Meijere, 1906; Liodrosophila Duda, 1922; Microdrosophila Malloch, 1921; Sphaerogastrella Duda, 1922) and some other ephydroids (e.g. Camilla Haliday, 1838 and Ephydridae in general).

Members of Cladochaeta sensu Grimaldi \& Nguyen (1999) can be recognized by the flat face or a face with a shallow carina. The arista has a single ventral branch and the eyes are bare or with sparse, thin interfacetal setulae. The male terminalia presents a clavate surstylus with several setae, but without peg prensisatae-a feature present virtually in all Drosophilinae (Grimaldi, 1990). The aedeagus is reduced, sometimes to a U-shaped sclerite with an apical diaphanous membrane; the paraphyses are often well developed, with long hooked projections. The male terminalia may reach an extraordinary complexity, with very complicated aedeagus and/or paraphysis. The female terminalia is reduced, without oviscapt and the spermathecal capsule absent or vestigial.

The immatures of this group have a particularly interesting biology. Some species are known to be associated to spittlebug nymphs. Spittlebugs or froghoppers are the common name of Cercopoidea hemipterans, their nymphs being covered with masses of viscous bubbles spewed out by the insect's abdomen, composed by the host plant fluids (Cryan \& Svenson, 2010). Except for one host record to Cephisus Stål, 1866 (Tsacas \& Couturier, 1993 ) and another to Sphodroscarta Stål, 1869 (Grimaldi \& Nguyen, 1999) 
("Aphrophoridae"), all other host records are to the genus Clastoptera Germar, 1839 (Clastopteridae) (summarized by Grimaldi \& Nguyen, 1999).

Ainsilie (1906) was probably the first to describe this phenomenon, despite having misidentified the fly. This was found out later by Sturtevant (1921), when he noticed that the specimen was not a Drosophila sigmoides Loew, 1872, but a D. inversa (Walker, 1861), later erected as the type-species of Clastopteromyia Malloch, 1924 (as seen, a junior synonym of Cladochaeta). Subsequently other studies on the biology of the species of these drosophilids were conducted (Ashburner, 1981; Thompson \& Mohd-Saleh, 1995; Grimaldi \& Nguyen, 1999). They summarized information available on the literature and came into their own respective conclusions. Ashburner (1981) considered the larvae of Cladochaeta as commensals, while Thompson \& Mohd-Saleh (1995) was inconclusive on this issue. Grimaldi \& Nguyen (1999) considered them as parasites. Tsacas \& Couturier (1993), while describing Cladochaeta ptyelophila Tsacas, 1993 and its biology, were the first (and only) to record Cladochaeta larvae living in association with "Aphrophoridae" hemipterans, Cephisus erythrocephalus (Walker, 1851)

Despite most of the species of the genus sharing this biology, not all larvae of Cladochaeta species live in association with spittlebugs. There is one record of C. psychotria Grimaldi \& Nguyen, 1999 feeding on the flower of the Rubiaceae Psychotria L., 1759 in Costa Rica. For most species of the genus there is no biology information available.

Other interesting feature concerning the life history of the immature of these flies is viviparity. Grimaldi \& Nguyen (1999) observed females of five species of Cladochaeta ( $C$. antalba Grimaldi \& Nguyen, 1999; C. fasciata Grimaldi \& Nguyen, 1999; C. glapica Grimaldi \& Nguyen, 1999; C. telescopica Grimaldi \& Nguyen, 1999; and C.vivipara Grimaldi \& Nguyen, 1999 - all of which from Las Alturas, Costa Rica), harboring first-instar larvae in their abdomen. They discuss the known cases of viviparity within the Drosophilidae and consider that in Cladochaeta the phenomenon could be related to seasonality and scarcity of hosts, since all records are from them same locality. Even though females harboring eggs were observed as well, this should be further investigated to have a better understanding of the evolution of this feature in the tribe. Grimaldi \& Nguyen (1999) also described in detail the morphology of the immature stages of some Cladochaeta species, as well as the injuries caused in hosts (previously described in less detail by Baerg, 1920).

The Brazilian fauna of Cladochaeta is very poorly known. Up to now, only four species have been assigned to Brazil. This study corresponds to a first effort to properly 
approach the taxonomy of the genus in this part of the Neotropical region, describing 16 new species based on males in the genus. A key to the Brazilian fauna of the genus is provided, as well as a distributional map for the genus in Brazil. 


\section{Material and Methods}

The material analyzed in this study belongs to the Museu de Zoologia de São Paulo, Universidade de São Paulo, São Paulo, São Paulo, Brasil (MZUSP) and to the Coleção Camargo, Universidade de São Paulo, Ribeirão Preto, São Paulo, Brasil (RPSP).

The male terminalia were cleared with $10 \% \mathrm{KOH}$ at $30-40^{\circ} \mathrm{C}$ for a variable extension of time, according to the degree of sclerotization, and then dissected. The terminalia were transferred to provisory slide mountings with jelly glycerin to be observed, drawn and photographed under microscope. Permanent slide mountings of the wing and head (in some cases, just the antenna) of some species were prepared. The photographs of several views (habitus lateral, dorsal view of head, lateral view of head, face, lateral view of thorax, dorsal view of thorax, and dorsal view of the abdomen ) were taken with a Leica DC500 camera coupled to a Leica MZ16 stereoscope. Z-stacking of the photos was made using the AutoMontage Pro v5.02.0096 or Adobe Bridge CS6 and Adobe Photoshop CS6 softwares, also used to further edit final images. Different views of the male terminalia (e.g. terminal view, terminal oblique view and lateral view) were drawn under camera lucida coupled to a Leica DM2500 scope and later vetorized using Adobe Illustrator CS6. In some cases, the complex of aedeagus, paraphysis and phallapodeme were separated from the rest of the terminalia to be drawn in detail. The male terminalia, wing and antenna were photographed using a Leica DC500 camera coupled to a Leica DM2500 compound microscope. The male terminalia were stored in microvials, and wing and head or antenna in double-mounted slides pinned together with each specimen.

The morphologic terminology used here mostly follows Cumming \& Wood (2009), except for the enumeration of dorsal branches of the arista, the cross-vein dm-cu and the terminology of some sclerites of the male terminalia, which follows Grimaldi \& Nguyen (1999). The interpretation of surstylus and paraphyses follows Grimaldi \& Nguyen (1999).

The distributional maps were made using Google Earth 7.1.2.2041 and Quantum Gis 2.0.1-Dufour. Locality data were provided by the labels of examined material. 


\section{Results}

\subsection{Taxonomy}

\section{Cladochaeta Coquillett, 1900}

Cladochaeta Coquillett, 1900: 23. Type species: C. nebulosa Coquillett, 1900.

Clastopteromyia Malloch, 1924: 31. Type species: Drosophila inversa Walker, 1861; synonymy with Cladochaeta, Wheeler \& Takada (1971: 232).

Diagnosis (adapted from Grimaldi \& Nguyen, 1999): 1.0-2.0 mm long, general body color dark brown to pale yellow, never metallic but sometimes with light shining reflections. Face flat, sometimes with a shallow carina. Arista with a single ventral branch, except for the apical fork. Eyes bare or with thin interfacetal setulae. Wing membrane usually hyaline, sometimes entirely dusky or with diffuse clouds of infuscation on costal region, over dm-cu and at apex of $\mathrm{R}_{2+3} \cdot \mathrm{A}_{1}+\mathrm{CuA}_{2}$ and $\mathrm{A}_{2}$ absent or vestigial. Crossveins bm-br and bm-cu absent; cell br open basally. Male genitalia with ventral margins of cercus often extended ventrad; surstylus essentially clavate, but very variable, never with peg prensisetae; aedeagus typically reduced, sometimes a U-shaped sclerotized structure apically membranous; paraphyses mostly well developed into sclerotized hooked, complex structure with a broad dorsal bridge uniting them; hypandrium usually $\mathrm{Y}$-shaped with a ventral keel. Female genitalia reduced; oviscapt not developed; spermathecal capsule not present or vestigial; ventral receptacle developed but not sclerotized.

Comments. We did not have access to the Brazilian types of Cladochaeta (see item 4.4 of discussion ahead) and because of this, they are not redescribed here.

\section{Cladochaeta sp. 1, nov. sp.}

(Figs. 1 A-C; 2 A-C; 32 A; 35 A)

Diagnosis. General body color light brown, abdomen darker than thorax; Infuscated wing; legs pale brown; arista with 3 dorsal and 1 ventral branches; male terminalia with a pair of asymmetrical paraphyses united by a large dorsal bridge, aedeagus entirely membranous. 
Material examined. Holotype 1 đָ, BRAZIL, State of São Paulo, Serra do Japi, 18.iii.2010, Malaise III, N.W. Perioto e eq. cols. (MZUSP). Paratype: 1 ${ }^{\lambda}$, BRAZIL, State of São Paulo, São Luís do Paraitinga, P.E.S.M. Núcleo Sta. Virgínia 23¹9’16.9”S 4505’56.6”W, 21.i.2011, Malaise Point 5, N.W. Perioto \& team cols. (MZUSP).

Description. Head (Figs. 1 A-B). Higher than wide. Eyes bare, pale brown. Pedicel light ochre, first flagellomere whitish; arista with 3 dorsal and 1 ventral branches; d- 1 and d- 2 close to each other, closer to the base of arista than to d-3; three minute dorsal branches between d3 and apical fork; ventral branch midway between d-3 and apical fork; long apical fork. Frons brown, slightly darker on posterodorsal half; ocellar triangle dark brown. Fronto-orbital setae: anterior reclinate small, almost indistinguishable from fronto-orbital setulae, lateroposterior to proclinate fronto-orbital in position; posterior reclinate the same size as proclinate and midway between it and inner vertical. Face flat, pale brown. Gena brown, with a lighter area above eye, bearing six long setae not in a row, plus vibrissa. Proboscis and palpus pale brown; palpus with two apical setae. Thorax (Fig. 1 C). Entirely light brown. Anterior dorsocentral ca. $1 / 2$ the length of posterior dorsocentral. Posterior dorsocentral midway between scutoscutellar suture and anterior dorsocentral. Acrostichals in eigth uneven rows; only two median rows of achrosticals reach posterior portion of scutum. Basal scutellars curved, parallel; apical scutellars convergent. Three large postpronotal setae, mid one longer than other two. Legs uniformly pale brown; forefemur with two rows of long posterodorsal setae and three longer posteroventral setae. Wing (Fig. 35 A). Infuscated membrane, without clouds of infuscation. $\mathrm{R}_{2+3}$ very slightly turned towards anterior wing margin. $\mathrm{R}_{4+5}$ and $\mathrm{M}$ parallel, tips slightly convergent. Crossvein dm-cu sinuous, perpendicular to $\mathrm{CuA}_{1}$. Wing tip slightly acute. Halter greyish. Abdomen. Tergites brown. Male terminalia (Figs. 2 A-C). Epandrium inverted U-shaped, slightly higher than wide, with a row of 7-8 long setae on ventro-lateral halves; ventro-lateral halves with a broader extension near the cercus. Cercus without ventral lobes, ventro-lateral edges rounded. Aedeagus entirely membranous, between both paraphyses and phallapodeme. Paraphyses flattened laterally, heavily sclerotized, united by a broad bridge on dorsal half, slightly curved inwards. Left paraphyses longer than right paraphyses. Phallapodeme higher than wide, heavily sclerotized, with a long oblique projection backwards. Surstylus not heavily sclerotized, simple, clavate, with numerous 
relatively long setae of similar length. Hypandrium rounded, with a strongly sclerotized ventral keel.

Comments. Possibly related to the inversa species group Grimaldi \& Nguyen, 1999 based on the general morphology of male terminalia, e.g. aedeagus and paraphyses clearly separated, the aedeagus entirely membranous, lying between the sinuous hooked paraphyses (these characters are observable by the descriptions and ilustrations of Grimaldi \& Nguyen, 1999, but not mentioned on the diagnosis of the group). However, this species does not have the diffuse infuscation over the costal edge of wing, which is one of the characters described as diagnostic to the group. Furthermore, these characters of male terminalia are shared with the sororia species group Grimaldi \& Nguyen, 1999. The sororia species group, on the other hand, presents the crossvein dm-cu clouded and the hind femur usually with comb of stiff setae on apical half of ventral surface, which is not observed in $C$. sp. 1 , nov. sp. Despite the similar condition of male terminalia shared by the two mentioned groups, they differ from each other on external morphology as mentioned before. However, $C$. sp. 1, nov. sp. does not show the characters of external morphology that defines the groups, what turns difficult to assign it to any of them.

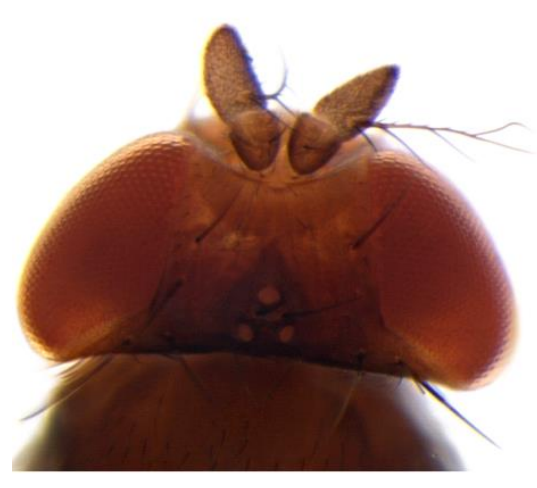

A
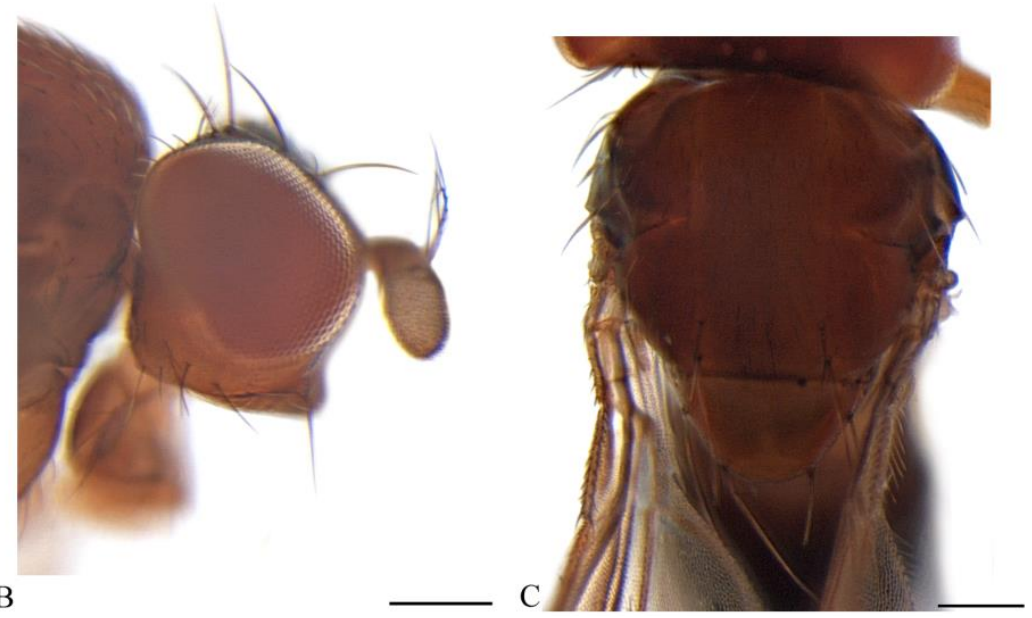

Figure 1. Cladochaeta sp. 1, nov. sp., holotype. A. Frons. B. Lateral view of head. C. Dorsal view of thorax. Scale bars: $0.1 \mathrm{~mm}$. 


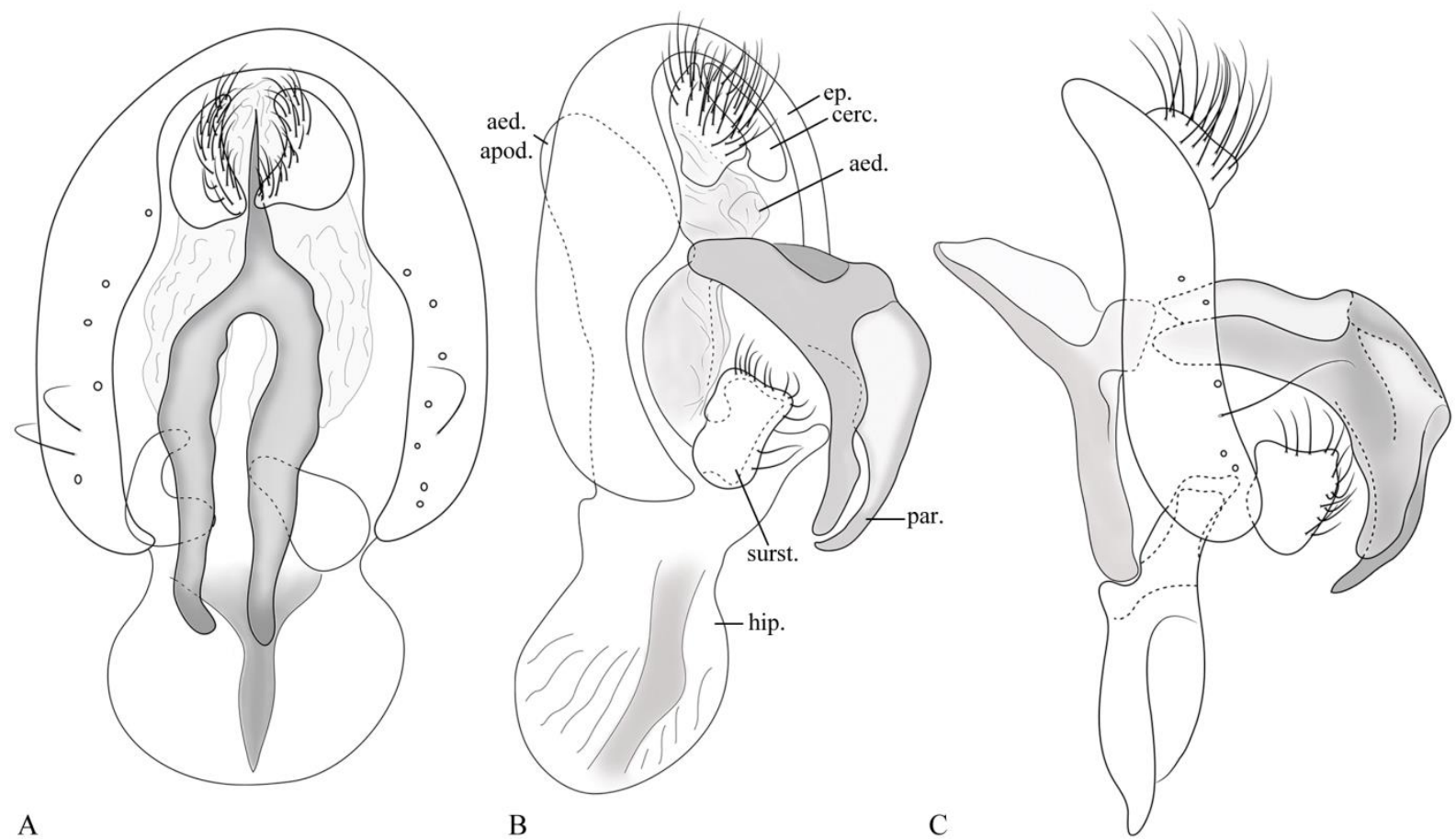

Figure 2. Illustrations of male terminalia of Cladochaeta sp. 1, nov. sp., holotype. A. Terminal view. B. Terminal oblique view. C. lateral view. Aed: aedeagus; aed. apod.: phallapodeme; cerc.: cercus; ep.: epandrium; hip.: hipandrium; par.: paraphyses; surst.: surstylus.

\section{Cladochaeta sp. 2, nov. sp.}

(Figs. 3 A-F; 4 A-D; 32 B; 35 B)

Diagnosis. General body color light brown. thorax brown, slightly darker pleuron, abdomen dark brown; infuscated wing; legs brown; arista with 4 dorsal and 1 ventral branches, plus apical fork; ventral branch between d-3 and d-4, closer to d-4 than to apical fork; at least 4 minute branches on dorsal surface of arista; distinguishable portion of aedeagus membranous, lying between the paraphyses and phallapodeme; both paraphyses present, heavily sclerotized, united by a sinuous dorsal bridge.

Material examined. Holotype $1 \delta^{\lambda}$ : BRAZIL, State of Ceará, Guaramiranga, 4 $4^{\circ} 16^{\prime} 13$ "S 3854’21”W, 880m, 10.v.2014, Malaise trap, Almeida, Lucena \& Tavares cols. (RPSP).

Description. Head (Figs. 3 A-C). As high as wide. Eyes bare, light brown. Pedicel light brown, first flagellomere grayish; arista with 4 dorsal and 1 ventral branches, plus apical fork; ventral branch between $\mathrm{d}-3$ and $\mathrm{d}-4$, closer to $\mathrm{d}-4$ than to apical fork; at least 4 minute branches on dorsal surface of arista. Frons ochre, ocellar triangle, fronto-orbital plate, and 
anterodorsal margin of frons light brown; fronto-orbital setae: anterior reclinate small, but easily distinguishable, postero-lateral in position to proclinate fronto-orbital; posterior reclinate as long as proclinate, midway between proclinate and inner vertical. Face flat, dorsal half ochre, ventral half light brown. Gena light brown; proboscis and palpus light brown. Thorax. (Figs. 3 D-E). Brown, darker pleuron. Anterior dorsocentral ca. $1 / 2$ of posterior dorsocentral length. Posterior dorsocentral midway between anterior dorsocentral and scutoscutellar suture. Acrostichals in 6 somewhat even rows. Basal scutellars slightly divergent; apical scutellars convergent but not crusciate at tip. Postpronotal lobe slightly darker, with 3 large postpronotal setae, median longer than others. Legs brown. Wing (Fig. 35 B). Membrane entirely infuscated. Tip of $R_{2+3}$ straight, not curved towards $C$. $R_{4+5}$ and $M$ parallel. Crossvein dm-cu straight, perpendicular to $\mathrm{CuA}_{1}$. Wing tip slightly acute. Halter light brown. Abdomen (Fig. 3 F). All tergites brown, posterior margins darker. Male terminalia (Figs. 4 A-D). Epandrium inverted U-shaped, with 5 long setae on ventro-lateral halves; ventral tip of ventro-lateral halves gradually tapering; terminal portion slightly curved inwards, broader extension near cercus. Cercus with rounded ventro-lateral margin. Aedeagus partly sclerotized, partly membranous, lying between both paraphyses and phallapodeme; both paraphyses present, heavily sclerotized, each with two inner longitudinal folds. Phallapodeme higher than wide, heavily sclerotized. Surstylus sinuous, with setae on entire dorsal and dorsolateral surface. Hypandrium Y-shaped, ventral keel present.

Comments. This species could be related to the inversa species group or to the sororia species group, based on the general morphology of paraphyses (see comments under the description of $C$. sp. 1, nov. sp. concerning the sharing of these characters by both groups). $C$. sp. 2, nov. sp., however, has a hyaline wing and head setuale of usual lengths, which is not consistent with the diagnosis given for none of the mentioned groups. 

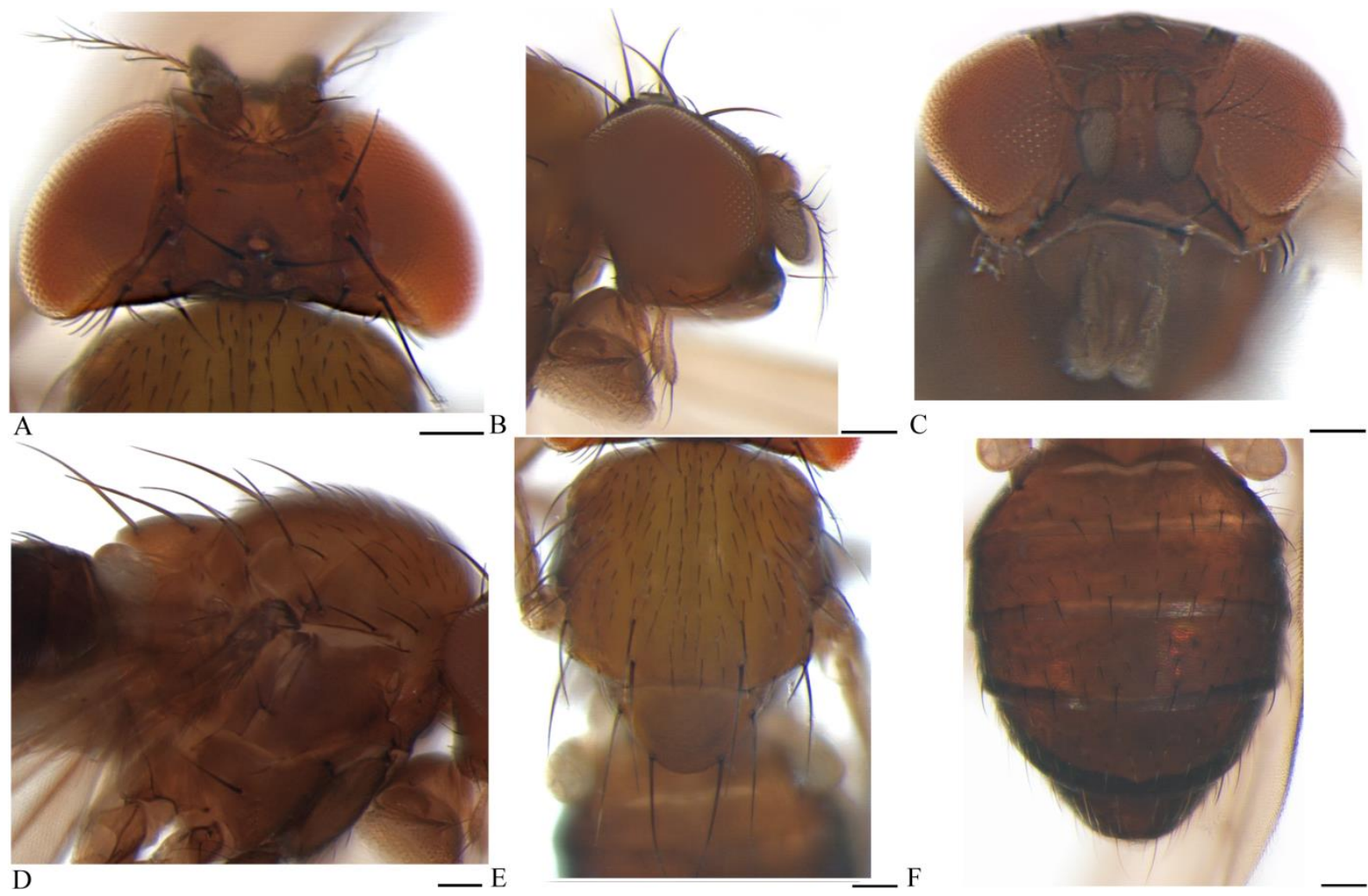

Figure 3. Cladochaeta sp. 2, nov. sp., holotype. A. Frons. B. Lateral view of head. C. Face. D. Lateral view of thorax. E. Dorsal view of thorax. F. Dorsal view of abdomen. Scale bars: $0.1 \mathrm{~mm}$. 

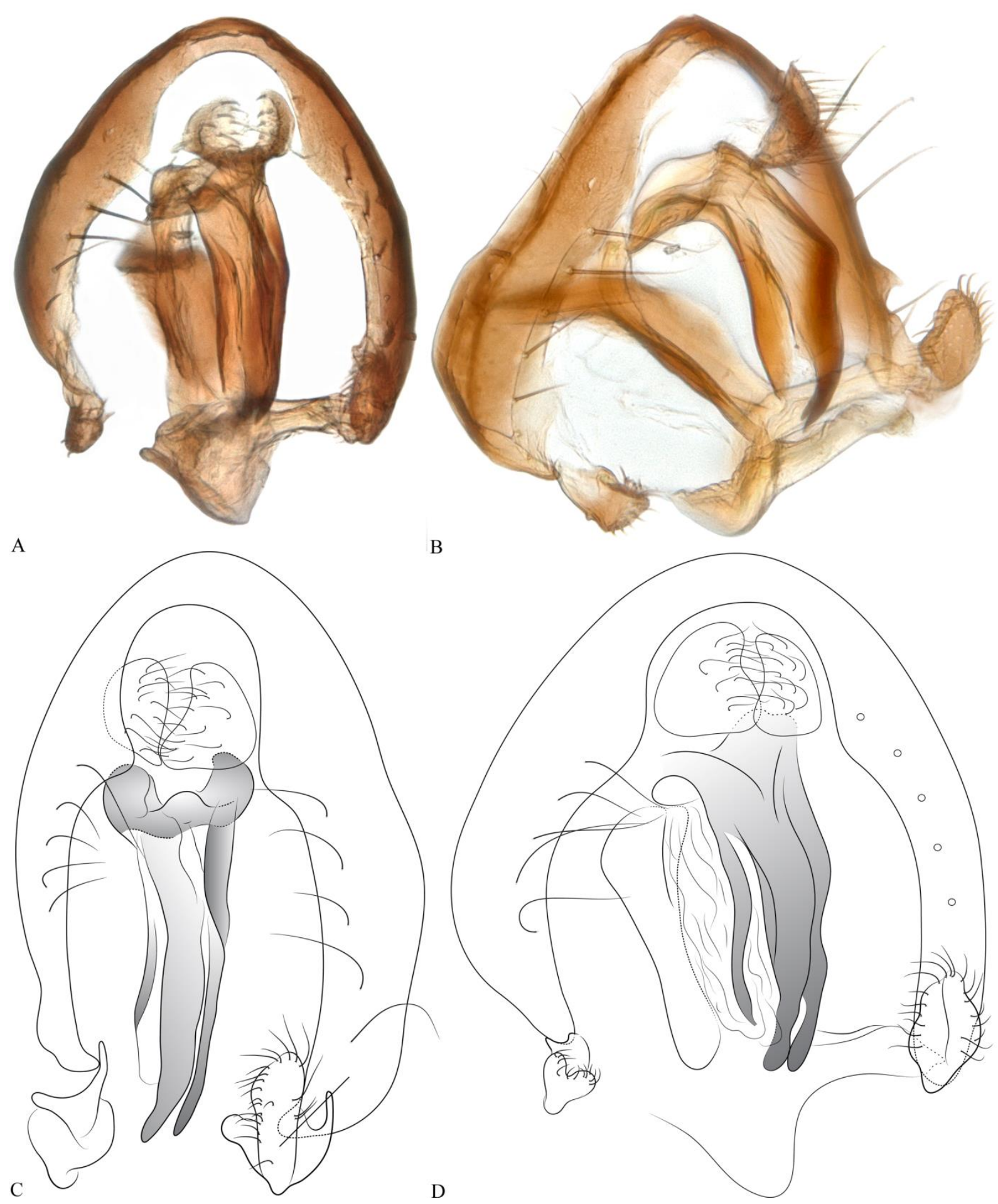

Figure 4. Male terminalia of Cladochaeta sp. 2, nov. sp., holotype. A. Photograph of terminal view. B. Photograph of terminal oblique view. C. Illustration of terminal view. D. Illustration of terminal oblique view. 


\section{Cladochaeta sp. 3, nov. sp.}

(Figs. 5 A-F; 6 A-C; 32 C; 35 C)

Diagnosis. General body color ochre, thorax ochre, pleuron slightly darker, abdomen slightly lighter than thorax; arista with 4 dorsal and 1 ventral branches, dorsal branch between d-3 and d-4; infuscated wing; distinguishable portion of aedeagus membranous; paraphyses very distinctive: heavily sclerotized, long, with seven ventral projections.

Material examined. Holotype $1 \delta$ : BRAZIL, State of São Paulo, São Luís do Paraitinga, P.E.S.M. Núcleo Sta. Virgínia, 23ำ19’24.8”S 4505'40.1”W, 21.i.2011, Malaise trap \#3, N.W. Perioto \& team cols. (MZSP).

Description. Head (Figs. 5 A-C). Higher than wide. Eyes bare; light ochre. Pedicel ochre, first flagellomere whitish; arista with 4 dorsal and 1 ventral branches, dorsal branch between d-3 and d-4. Frons light ochre, ocellar triangle slightly darker; fronto-orbital setae: anterior reclinate absent; posterior reclinate smaller than proclinate, closer to proclinate than to inner vertical. Face flat, ochre, ventral margin whitish. Gena thin, ochre; proboscis and palpus whitish. Thorax (Figs. 5 D-E). Ochre, pleuron slightly darker. Anterior dorsocentral ca. 1/2 of posterior dorsocentral length. Posterior dorsocentral slightly closer to anterior dorsocentral than to scutoscutellar suture. Acrostichals in 6 more or less even rows. Basal scutellars parallel, posterior convergent, cruciate at tip. Three large postpronotal setae, mid one larger than other two. Legs pale yellow. Wing (Fig. 35 C). Membrane entirely dusky brown. Tip of $\mathrm{R}_{2+3}$ slightly curved towards $\mathrm{C}$. $\mathrm{R}_{4+5}$ and $\mathrm{M}$ slightly divergent. Crossvein dm-cu slightly bent medially, perpendicular to $\mathrm{CuA}_{1}$. Wing tip round. Halter whitish. Abdomen. All tergites dark ochre, with slightly darker margins. Male terminalia. Epandrium inverted U-shaped, with 6 or more long setae on ventro-lateral halves; ventral tip of ventro-lateral halves gradually tapering, slightly curved inwards; broad squared extension of epandrium underneath cercus. Cercus with slightly acute ventro-lateral margin. Distinguishable portion of distinguishable portion of aedeagus membranous, ventral tip curved apically. Paraphyses dorsal bridge Mshaped, projected apically; paraphyses thin and sinuous, broader ventrally; 7 ventrally connected projections. Phallapodeme longer than wide, heavily sclerotized, with a posterodorsal projection. Surstylus rounded, not clavate, setae present on lateral surface. Hypandrium Y-shaped, ventral keel present. 
Comments. This species could be related to the inversa species group or sororia species group (see comments under $C$. sp. 1, nov. sp. and $C$. sp. 2, nov. sp. relative to the definition of these groups). This species however has an arrangement of the hooked projections of paraphyses which could lead to its assignment to the armata species group Grimaldi \& Nguyen, 1999 as well (see coments under $C$. sp. 6, nov. sp., $C$. sp. 10, nov. sp. and $C$. sp. 11, nov. sp. ahead).

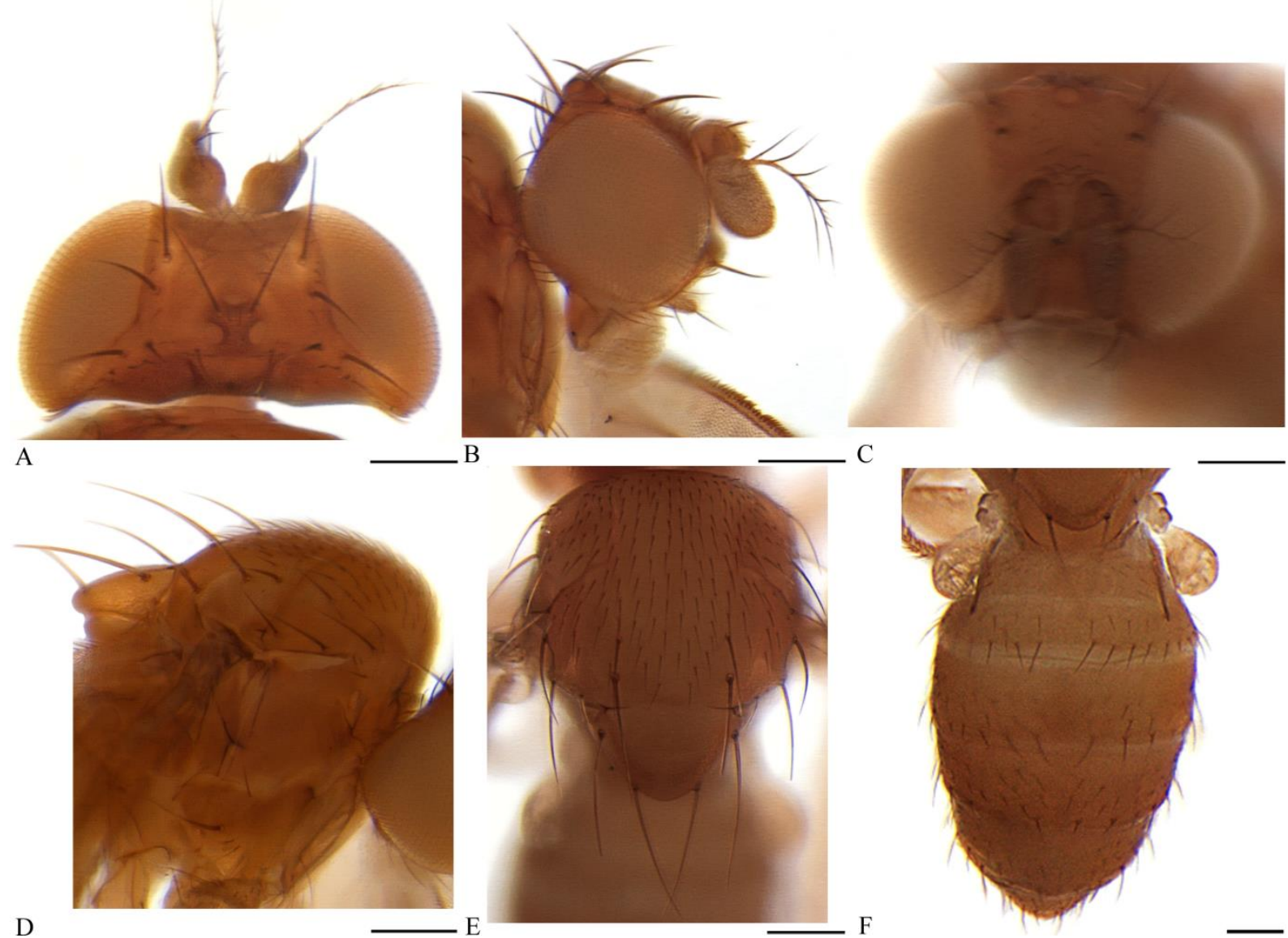

Figure 5. Cladochaeta sp. 3, nov. sp., holotype. A. Frons. B. Lateral view of head. C. Face. D. Lateral view of thorax. E. Dorsal view of thorax. F. Dorsal view of abdomen. Scale bars: $0.1 \mathrm{~mm}$.

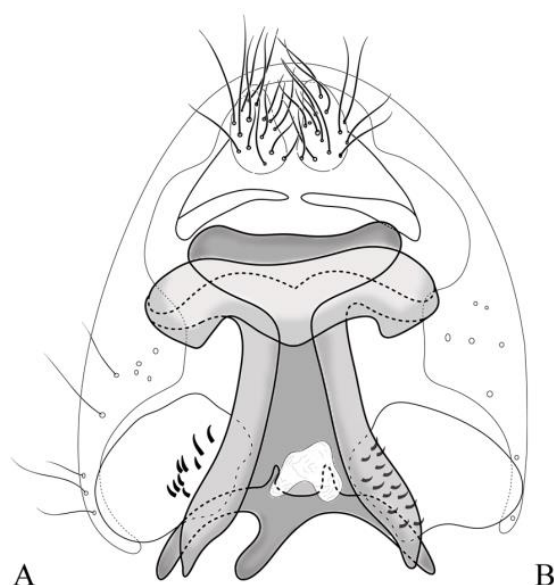

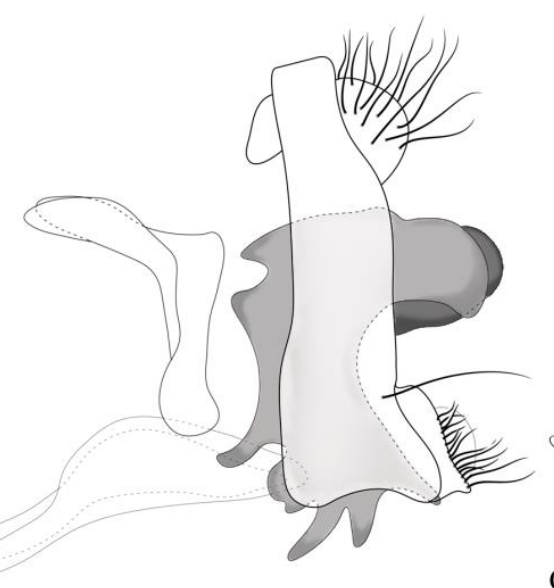

$\mathrm{C}$

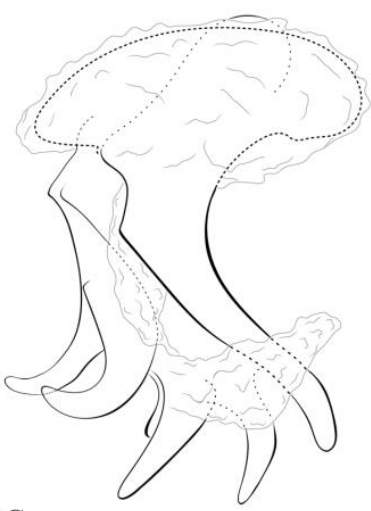

Figure 6. Illustrations of male terminalia of Cladochaeta sp. 3, nov. sp., holotype. A. Terminal view. B. Lateral view. C. Lateral view of the complex of aedeagus and paraphyses. 


\section{Cladochaeta sp. 4, nov. sp.}

(Figs. 7 A-B; 8 A-D; 32 D; 35 D)

Diagnosis. General body color dark brown, abdomen darker than thorax, with light bluish metallic reflections; Infuscated wing; legs pale brown; arista with 3 dorsal and 1 ventral branches; male terminalia with a heavily sclerotized, conic aedeagus; paraphyses absent.

Material examined. Holotype $1 \curvearrowright$ : BRAZIL, State of Minas Gerais, Cabo Verde, Fazenda da Cata, 593 m, $21^{\circ} 27^{\prime} 8,46^{\prime \prime} S 46^{\circ} 26$ 52.8”W, Malaise trap, 14.vii.2011, Amorim \& Oliveira cols. (MZUSP).

Description. Head (Figs. 7 A-B). Higher than wide. Eyes bare; dark red. Pedicel brown, first flagellomere whitish; arista with three dorsal and 1 ventral branches; ventral branch midway between d-3 and apical fork. Frons brown with a whitish band on anterodorsal half; ocellar triangle dark brown. Fronto-orbital setae: anterior reclinate small, almost indistinguishable from fronto-orbital setulae, right posterior to proclinate fronto-orbital; posterior reclinate as proclinate and closer to it than to inner vertical. Face flat, pale brown; oral margin dark brown. Gena brown, with a large whitish horizontal band, extending ventrally the entire area underneath eye; ventral margin of gena brown. Proboscis and palpus pale brown. Thorax. Entirely dark brown. Anterior dorsocentral ca. $1 / 2$ the length of posterior dorsocentral. Posterior dorsocentral midway between scutoscutellar suture and anterior dorsocentral. Acrostichals in six even rows. Scutellars broken. One postpronotal seta. Legs uniformly light brown; forefemur with two distinctively large posteroventral setae. Wing (Fig 35 D). Infuscated membrane, no clouds of infuscation. $\mathrm{R}_{2+3}$ very slightly curved towards anterior wing margin. $\mathrm{R}_{4+5}$ and $\mathrm{M}$ parallel, both slightly curved towards posterior margin. Crossvein dm-cu slightly bent medially, perpendicular to $\mathrm{CuA}_{1}$. Wing tip slightly acute. Halter whitish. Abdomen. All tergites dark brown, with light bluish metallic reflections. Male terminalia (Figs. 8 A-D): epandrium with inverted U-shape, longer than wide, with a row of 6 long setae on ventro-lateral halves; ventro-lateral halves, with a small projection near cercus, ventral portion of halves, thinner. Cercus without ventral lobes; ventro-lateral edges acute. Aedeagus heavily sclerotized, conic, dorsal portion with a neck, ventral portion slender, curved backwards. Paraphyses absent. Surstylus bilobed, gonopods present connected to hypandrium, 
with numerous relatively long setae. Hypandrium Y-shaped, with a strongly sclerotized ventral keel.

Comments. This species could be related to the diminuta species group Grimaldi \& Nguyen, 1999 based on the absence of the paraphyses, the conical shape of aedeagus and the general proportions of head. Closely resembles C. fasciata Grimaldi \& Nguyen, 1999 but the sinuosity of the aedeagus is somewhat different and $C$. sp. 4, nov. sp. doesn't have the thin silvery stripe across the anterior edge of frons. Also resembles C. dolichofrons Grimaldi \& Nguyen, 1999 but differ from it on the absence of the trifurcate setulae on surstylus. There are two controversial structures present on the male terminalia, a supposed bilobed surstylus and a supposed gonopods tightly connected to hypandrium (see the discussion section for considerations about the homology of these characters).
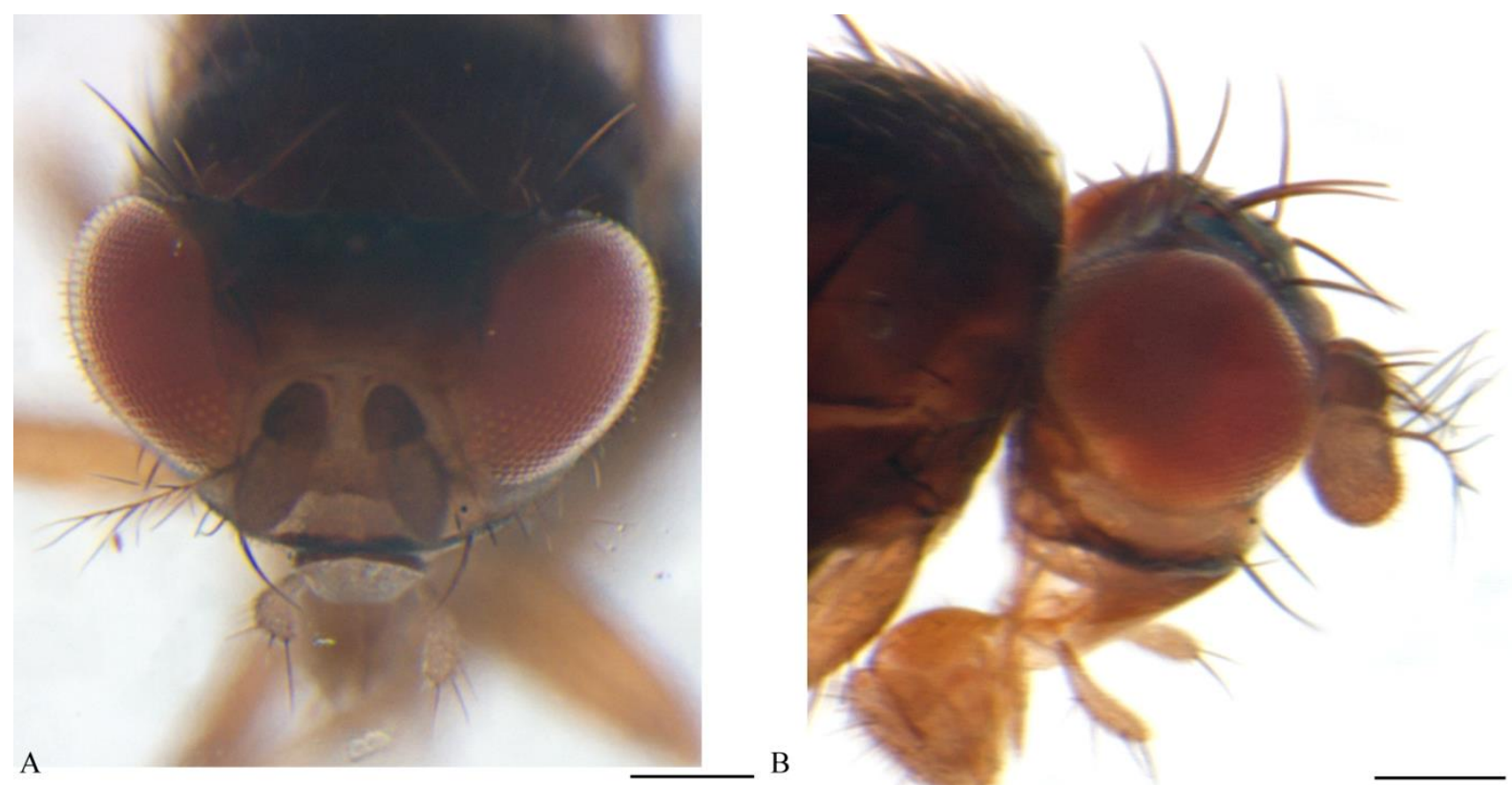

Figure 7. Cladochaeta sp. 4, nov. sp., holotype. A. Frons. B. Lateral view of head. Scale bars: $0.1 \mathrm{~mm}$. 


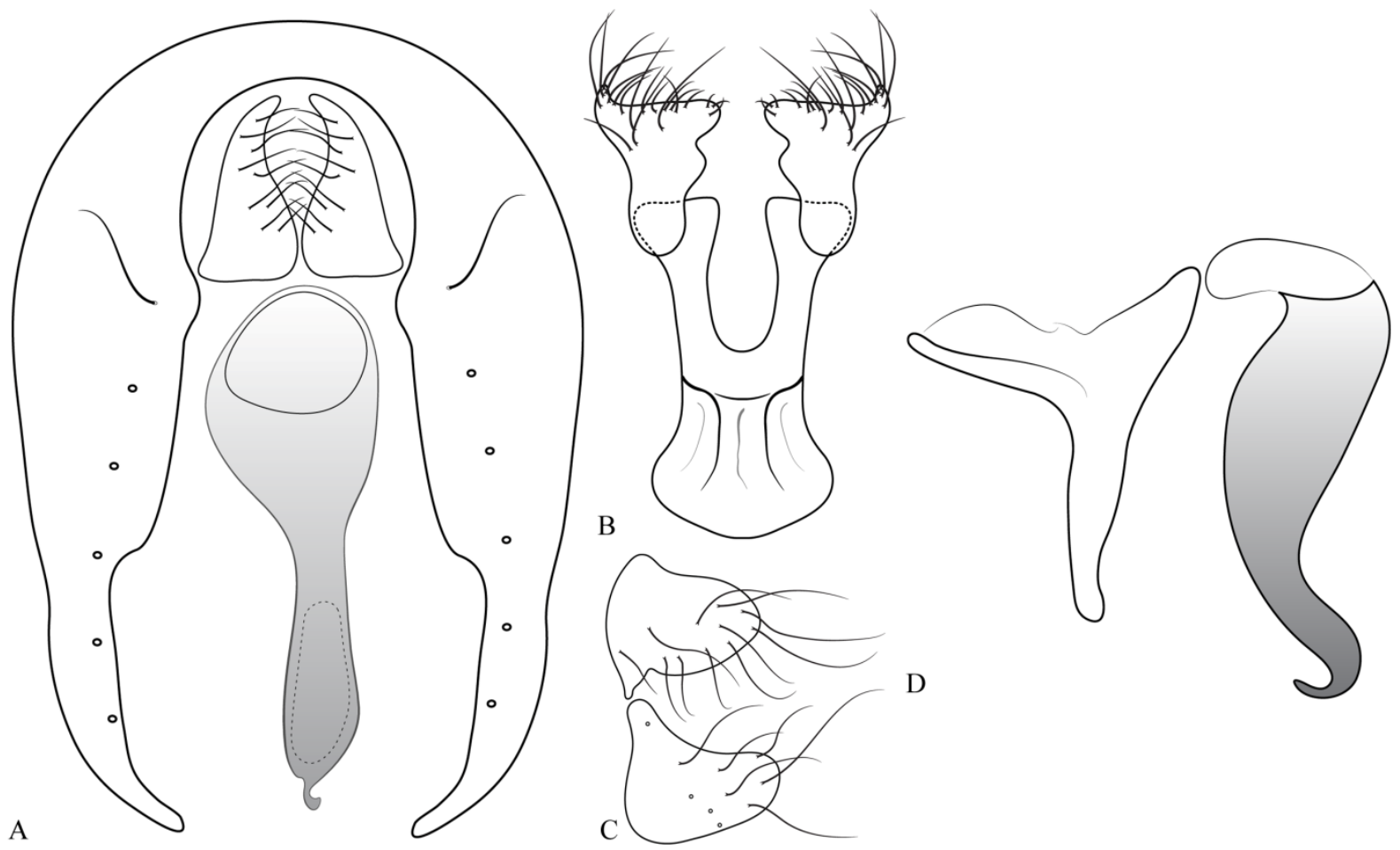

Figure 8. Illustrations of male terminalia of Cladochaeta sp. 4, nov. sp., holotype. A. Terminal view. B. Ventral view of hypandrium and gonopods. C. Surstylus. D. Lateral view of the aedeagus phallapodeme.

\section{Cladochaeta sp. 5, nov. sp.}

(Figs. 9 A-E; 10 A-F; 32 E; 35 E)

Diagnosis. General body color brown, abdomen slightly darker than thorax; Infuscated wing; legs light brown; arista with 3 dorsal and 1 ventral branches, ventral branch between d-3 and apical fork; epandrium much longer than wide, aedeagus weakly sclerotized; paraphyses absent.

Material examined. Holotype $1 \sigma^{\Uparrow}$ : BRAZIL, State of São Paulo, Campos do Jordão, Horto Florestal Estadual, 22.xi.2010, Malaise trap \#2, Airton and Marcos cols. (MZUSP).

Description. Head (Figs. 9 A-C). As high as wide. Eyes bare, light brown. Pedicel brown, first flagellomere light ochre; arista straight, not curved downwards, with 3 dorsal and 1 ventral branches; ventral branch between d-3 and apical fork. Frons brown, lighter band on anterior margin; ocellar triangle brown. Fronto-orbital setae: anterior reclinate absent; posterior reclinate slightly longer than proclinate and closer to it than to inner vertical. Face flat, light brown. Gena brown with a large whitish horizontal band, extending ventrally along 
the entire area underneath the eye. Proboscis and palpus pale light brown. Thorax (Figs. 9 DE). Dark brown. Anterior dorsocentral ca. 1/3 the length of posterior dorsocentral. Posterior dorsocentral slightly closer to scutoscutellar suture than to anterior dorsocentral. Acrostichals in 6 even rows. Scutellum brown with darker margin; basal scutellars slightly divergent; apical scutellars broken. Three postpronotal setae, median one larger than the two others. Legs uniformly light brown, 3 large posteroventral setae on forefemur. Wing (35 E) Infuscated membrane, without clouds of infuscation. Tip of vein $\mathrm{R}_{2+3}$ curved towards anterior margin. $\mathrm{R}_{4+5}$ and $\mathrm{M}$ parallel. Crossvein dm-cu almost straight, perpendicular to $\mathrm{CuA}_{1}$. Wing tip slightly acute. Halter whitish. Abdomen. All tergites dark brown, margins darker. Male terminalia (Figs. $10 \mathrm{~A}-\mathrm{F}$ ). Epandrium inverted U-shaped, much longer than wide, with a row of 10 long setae on ventro-lateral halves; ventro-lateral halves with a median broader extension; ventral tip of ventral halves thin and turned inwards. Cercus with ventro-lateral edges acute, slightly projected. Aedeagus conic and sinuous, weakly sclerotized, with two small dorsal folds,. Paraphyses absent. Phallapodeme higher than wide, poorly sclerotized, with a long, oblique backward projection. Surstylus poorly sclerotized, clavate, with numerous relatively long setae of similar size. Hypandrium Y-shaped; ventral keel present.

Comments. This species could be related to the diminuta species group, based on the morphology of the conical aedeagus and absence of paraphyses.However, C. sp. 11, nov. sp. has two small dorsal folds on aedeagus, that were not described to this group. These folds are almost connected in the middle region, which resembles the morphology of dorsal bridge of paraphyses, present in lots of Cladochaeta species which has paraphyses. Thus, this structure could maybe be interpreted as a signal of fusion of paraphyses with aedeagus. 


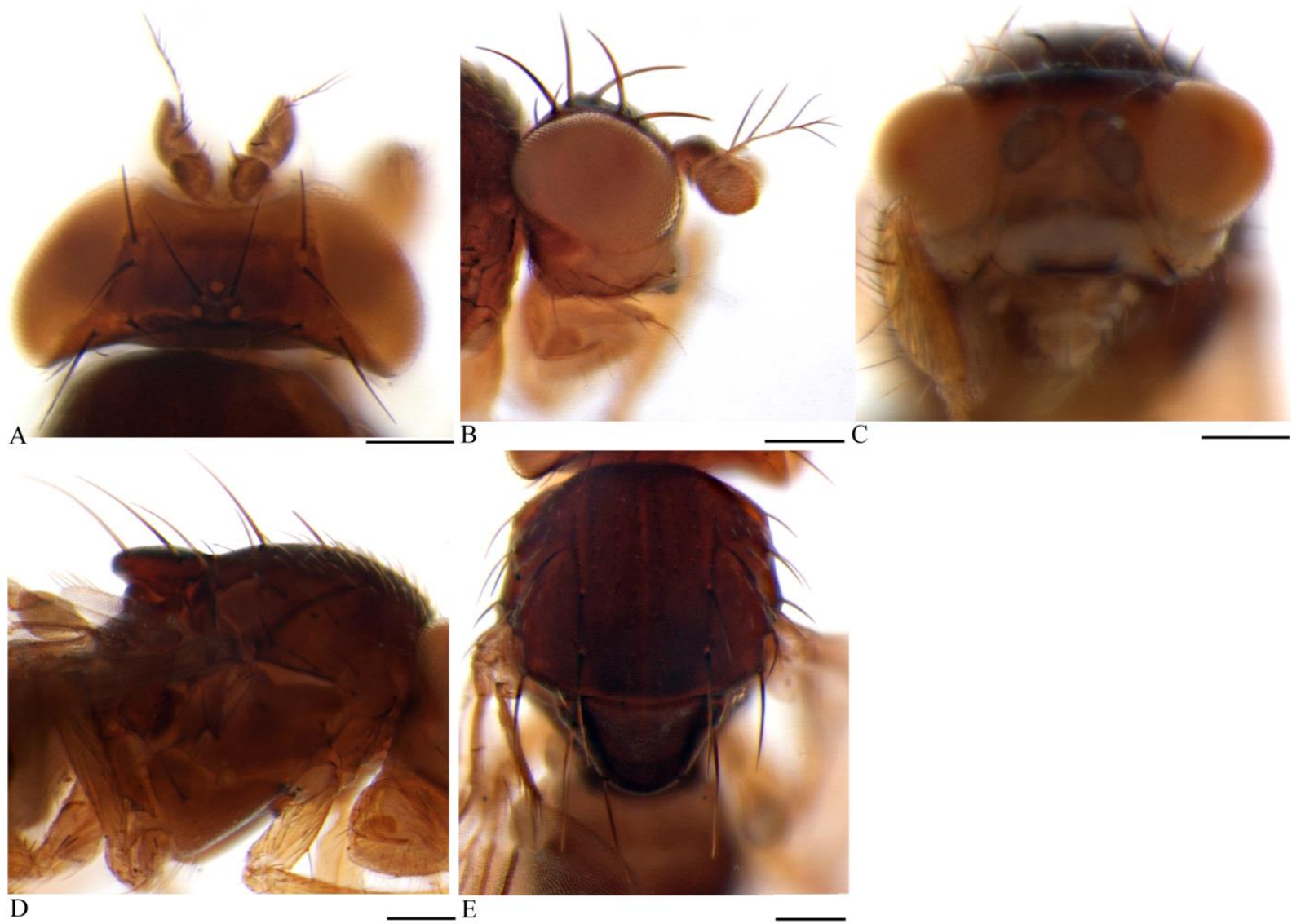

Figure 9. Cladochaeta sp. 5, nov. sp., holotype. A. Frons. B. Lateral view of head. C. Face. D. Lateral view of thorax. E. Dorsal view of thorax. Scale bars: $0.1 \mathrm{~mm}$. 


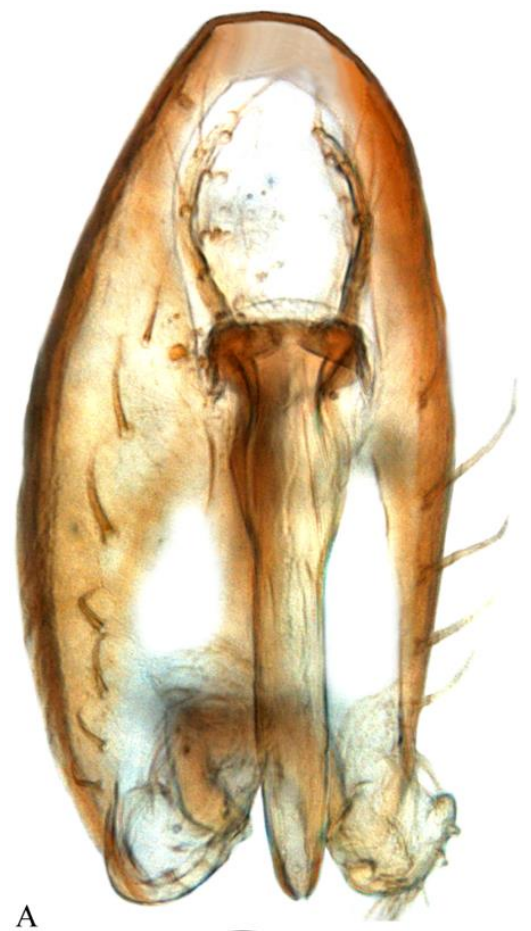

A
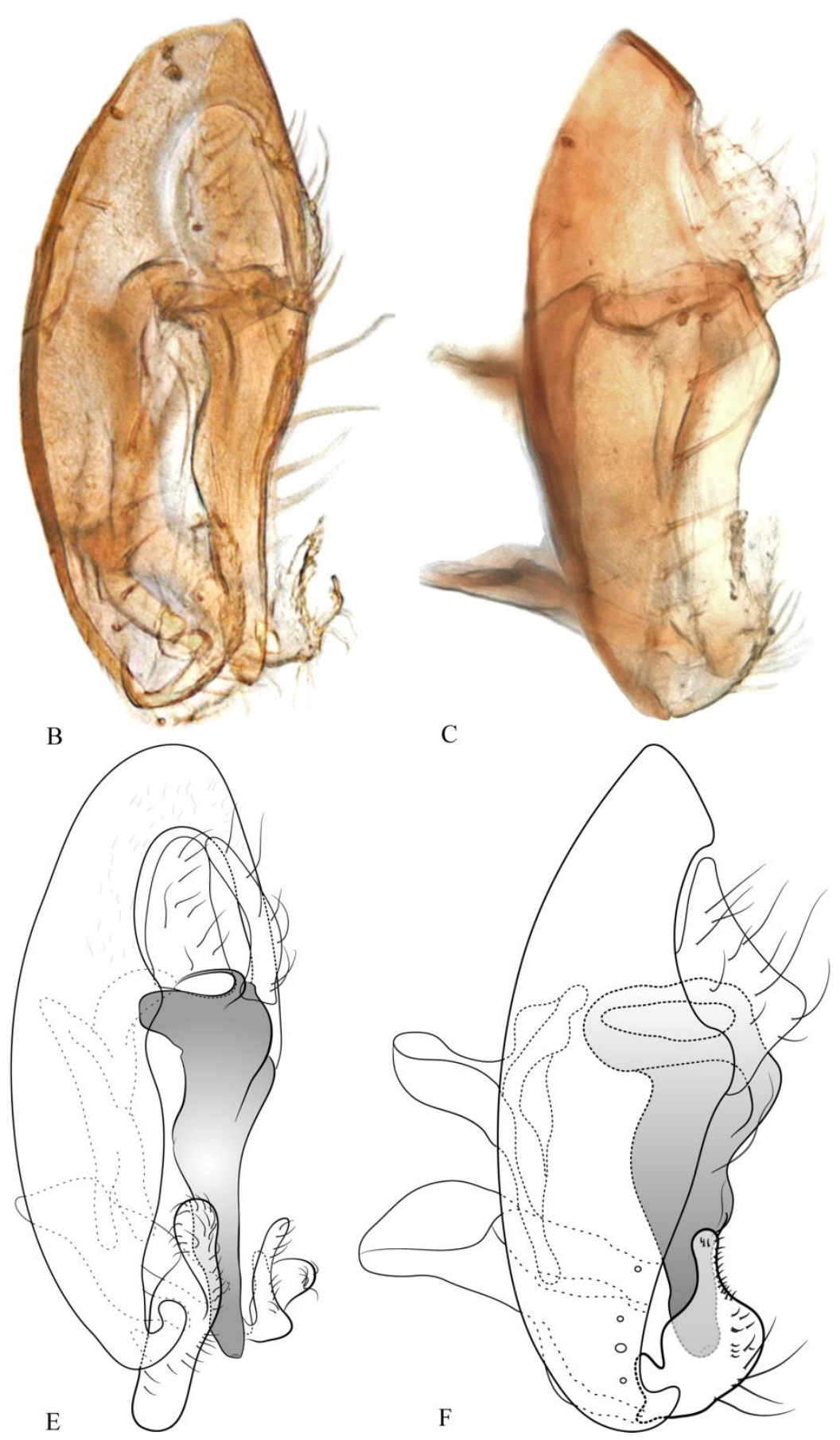

Figure 10. Male terminalia of Cladochaeta sp. 5, nov. sp., holotype. A. Photograph of terminal view. B. Photograph of terminal oblique view. C. Photograph of lateral view. D. Illustration of terminal view. E. Illustration of terminal oblique view. F. Illustrartion of lateral view.

\section{Cladochaeta sp. 6, nov. sp.}

(Figs. 11 A-E; 12 A-D; 32 F; 35 F) 
Diagnosis. General body color light brown, abdomen slightly darker than thorax, with light bluish metallic reflections; infuscated wing; legs light brown; arista with 3 dorsal and 1 ventral branches, plus apical fork; ventral branch between d-3 and apical fork. Aedeagus conical and sinuous, weakly sclerotized; paraphyses absent.

Material examined: Holotype 1 $\widehat{\jmath}$ : BRAZIL, State of São Paulo, Ribeirão Grande, P.E. Intervales, 24¹6’27.7 S 48²5’19.3”W, 22.ix.2010, Malaise trap \#3, N.W. Perioto \& team cols. (MZUSP).

Description. Head (Figs. 11 A-C). higher than wide. Eyes bare, light red. Pedicel light brown, first flagellomere ochre; arista with 3 dorsal and 1 ventral branches, plus apical fork; ventral branch between d-3 and apical fork; minute hair-like ventral branches along entire ventral surface of arista. Frons light brown; fronto-orbital setae: anterior reclinate absent; posterior reclinate as long as proclinate, closer to proclinate than to inner vertical. Face flat, ochre, oral margin with a broad whitish band. Gena ochre; proboscis and palpus light ochre, slightly lighter than gena. Thorax (Figs. 11 D-E). Entirelly brown. Anterior dorsocentral ca. $1 / 3$ the length of posterior dorsocentral. Posterior dorsocentral slightly closer to scutoscutellar suture than to anterior dorsocentral. Acrostichals in 6 even rows. Basal and apical scutellars convergent, with almost the same size. Three postpronotal setae, median one larger than other two. Legs uniformly pale light brown. Wing (Fig. 35 F). Membrane entirely infuscated. Tip of $\mathrm{R}_{2+3}$ gradually meeting $\mathrm{C}$. $\mathrm{R}_{4+5}$ and $\mathrm{M}$ parallel. Crossvein $\mathrm{dm}-\mathrm{cu}$ straight, perpendicular to $\mathrm{CuA}_{1}$. Wing tip slightly acute. Halter whitish. Abdomen. All tergites brown, with very light bluish metallic reflections, posterior margins darker. Male terminalia (Figs. 12 A-D). Epandrium inverted U-shaped, with 6 long setae on each ventro-lateral half; ventral tip of ventro-lateral halves gradually tapering; terminal portion curved inwards. Cercus with ventrolateral edges slightly acute, somewhat extended. Aedeagus conical and sinuous, weakly sclerotized; paraphyses absent. Phallapodeme higher than wide, heavily sclerotized, with a long oblique backwards projection. Clavate surstylus, setae present on entire dorsal and dorsolateral surfaces. Hypandrium Y-shaped, ventral keel present.

Comments. This species is possibly related to the diminuta species group according to the morphology of the conical aedeagus and absence of paraphyses. Closely resembles $C$. sp. 11, nov. sp. by the presence of two small dorsal folds on aedeagus, which was not described to 
diminuta species group (see comments under $C$. sp. 5, nov. sp.). However, the proportions of these folds are different between the two species, being almost the same length and joining in the midway in $C$. sp. 5, nov. sp. and asymmetrical in $C$. sp. 6, nov. sp. Furthermore, $C$. sp. 6, nov. sp. has a light bluish metallic reflection on abdomen, not seen in $C$. sp. 5, nov. sp.

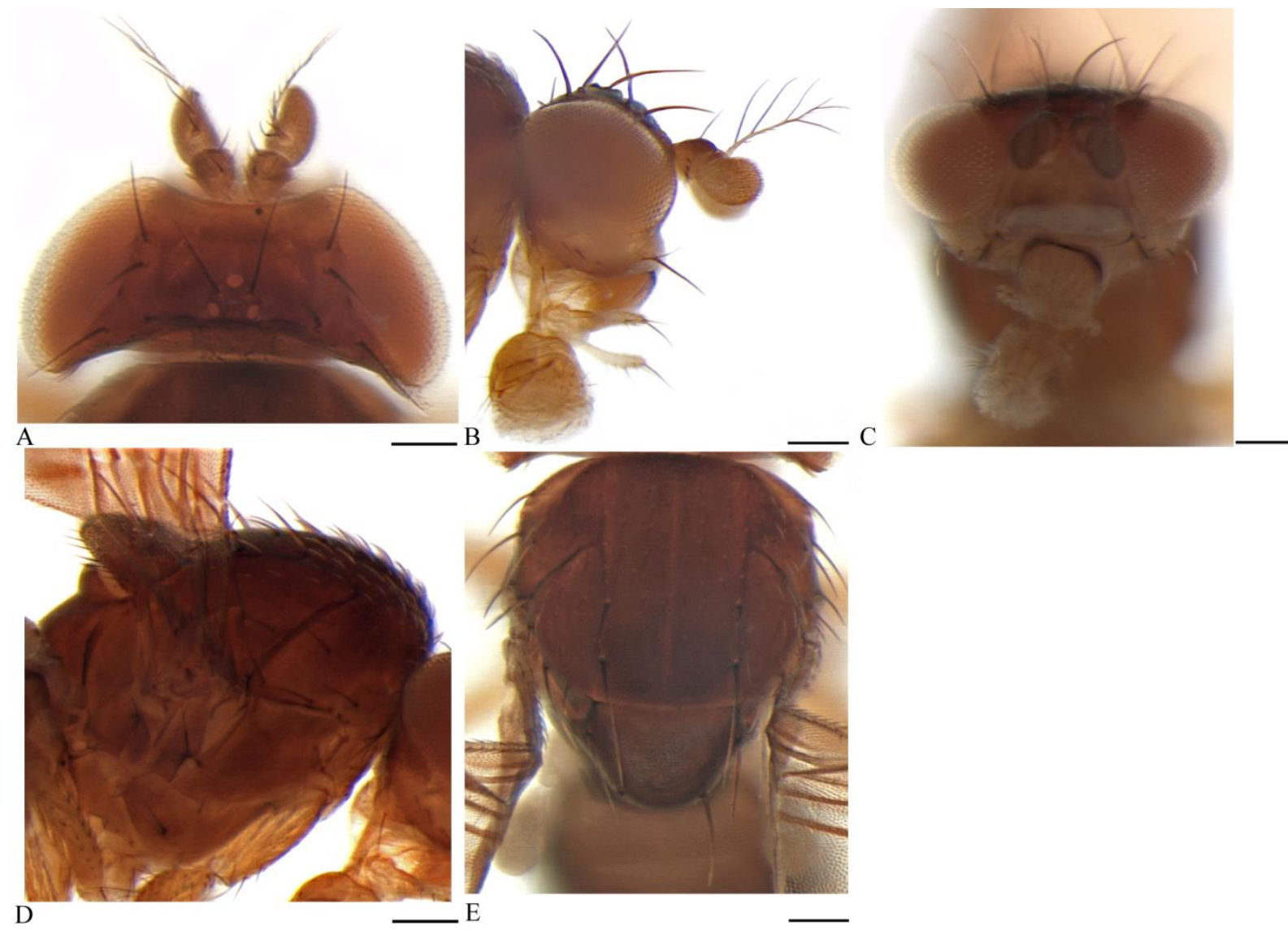

Figure 11. Cladochaeta sp. 6, nov. sp., holotype. A. Frons. B. Lateral view of head. C. Face. D. Lateral view of thorax. E. Dorsal view of thorax. Scale bars: $0.1 \mathrm{~mm}$. 

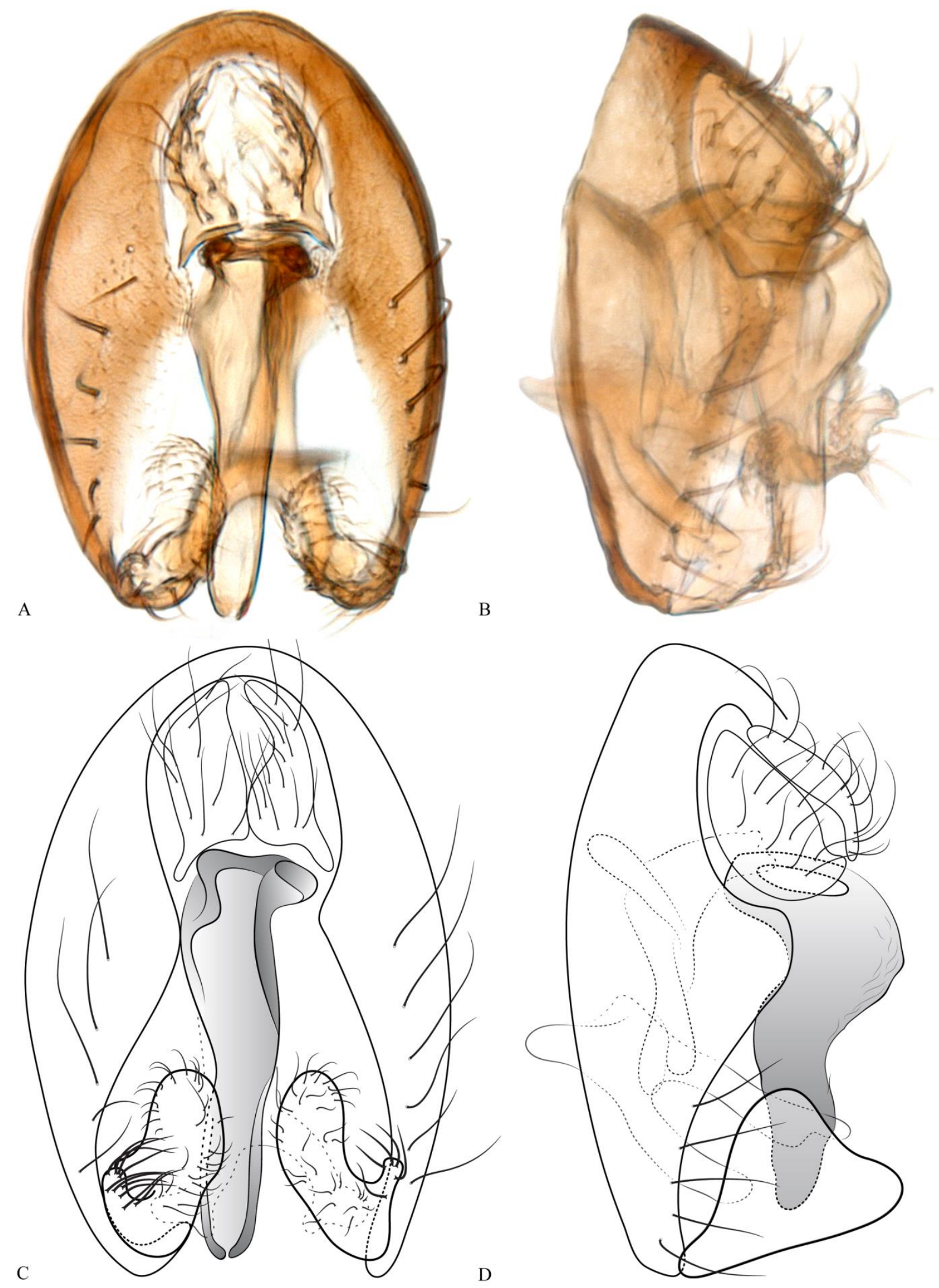

Figure 12. Male terminalia of Cladochaeta sp. 6, nov. sp., holotype. A. Photograph of terminal view. B. Photograph of lateral view. C. Illustration of terminal view. D. Illustration of lateral view. 


\section{Cladochaeta sp. 7, nov. sp.}

(Figs. 13 A-F; 14 A-F; 26 A; 33 A; 35 G)

Diagnosis. General body color light yellow; lighly infuscated wing, almost hyaline. Legs pale yellow to white; arista with 4 dorsal and 1 ventral branches; ventral branch between d-3 and d-4; Aedeagus weakly sclerotized; paraphyses absent.

Material examined. Holotype 1 $\delta^{\top}$ : BRAZIL, State of São Paulo, Gália, EE Caetetus, $22^{\circ} 17^{\prime} 29^{\prime \prime}$ S 49³3'10”W 21.ix.2009, Sweeping, N.W. Perioto \& team cols. (MZUSP).

Description. Head (Figs. 13 A-C). Higher than wide. Eyes bare, pale brown. Pedicel yellow, first flagellomere whitish; arista with 4 dorsal and 1 ventral branches; ventral branch between d-3 and d-4 (26 A). Frons pale yellow, somewhat darker on posterodorsal half; ocellar triangle slightly darker than frons. Fronto-orbital setae: anterior reclinate very short, barely distinguishable from other fronto-orbitals; posterior reclinate the same size as proclinate and closer to it than to inner vertical. Face flat, light yellow. Slender gena, pale yellow. Proboscis and palpus whitish. Thorax (Figs 13 D-E). Pale yellow. Anterior dorsocentral ca. $1 / 2$ the length of posterior dorsocentral. Posterior dorsocentral midway between anterior dorsocentral and scutoscutellar suture. Acrostichals in 6 even rows, only median two reaching posterior portion of scutum. Basal scutellars divergent; apical scutellars broken. Three postpronotal setae, median one longer than other two. Legs uniformly pale yellow. Wing (Fig. 35 G). Membrane very lightly infuscated, almost hyaline. Tip of $\mathrm{R}_{2+3}$ very slightly curved towards wing margin. $\mathrm{R}_{4+5}$ and $\mathrm{M}$ parallel, tips slightly divergent. Crossvein dm-cu slightly sinuous, perpendicular to $\mathrm{CuA}_{1}$. Wing tip slightly acute. Halter whitish. Abdomen (Fig. 13 F). All tergites pale yellow. Male terminalia (Figs. 14 A-F). Epandrium inverted U-shaped, with about 5 long setae on ventro-lateral half and densely spread microtrichia; ventro-lateral halves of epandrium with a mid broader extension; ventral tip of ventral halves gradually tapering and terminally curved inwards. Cercus with rounded ventro-lateral edges, not extended. Aedeagus conic, broader dorsally, gradually tapering ventrally, curved medially, dorsal and ventral portions towards phallapodeme; poorly sclerotized. Paraphyses absent. Phallapodeme very thin, sinuous, poorly sclerotized. Surstylus bilobed and clavate, with an antero-dorsal finger-shape upward projection on distal lobe, bearing a set of setae at tip; setae present on 
entire dorsal and dorsolateral surfaces of surstylus. Hypandrium Y-shaped, ventral keel present.

Comments. This species is very similar to those belonging to the diminuta species group, due to the absence of the paraphyses, the conical shape of aedeagus and the general proportions of head. C. sp. 7, nov. sp. present a very distinctive surstylus in comparison with the Brazilian species. The bilobed surtylus can be seen in several already described Cladochaeta species from different groups of species and also in $C$. sp. 8, nov. sp. (see the description and comments ahead). However, the combination of the bilobed surstylus and the finger shaped projection on the distal lobe seems to be a unique condition among Cladochaeta. On the other hand, the mentioned projection on surstylus can be seen in several species of the dikra species group Grimaldi \& Nguyen, 1999, although these species does not have the bilobed surstylus (except from C. erecta Grimaldi \& Nguyen, 1999 which has a small ventral lobe on it). Being that, it seems controversial to assign $C$. sp. 7, nov. sp. to any of these groups.

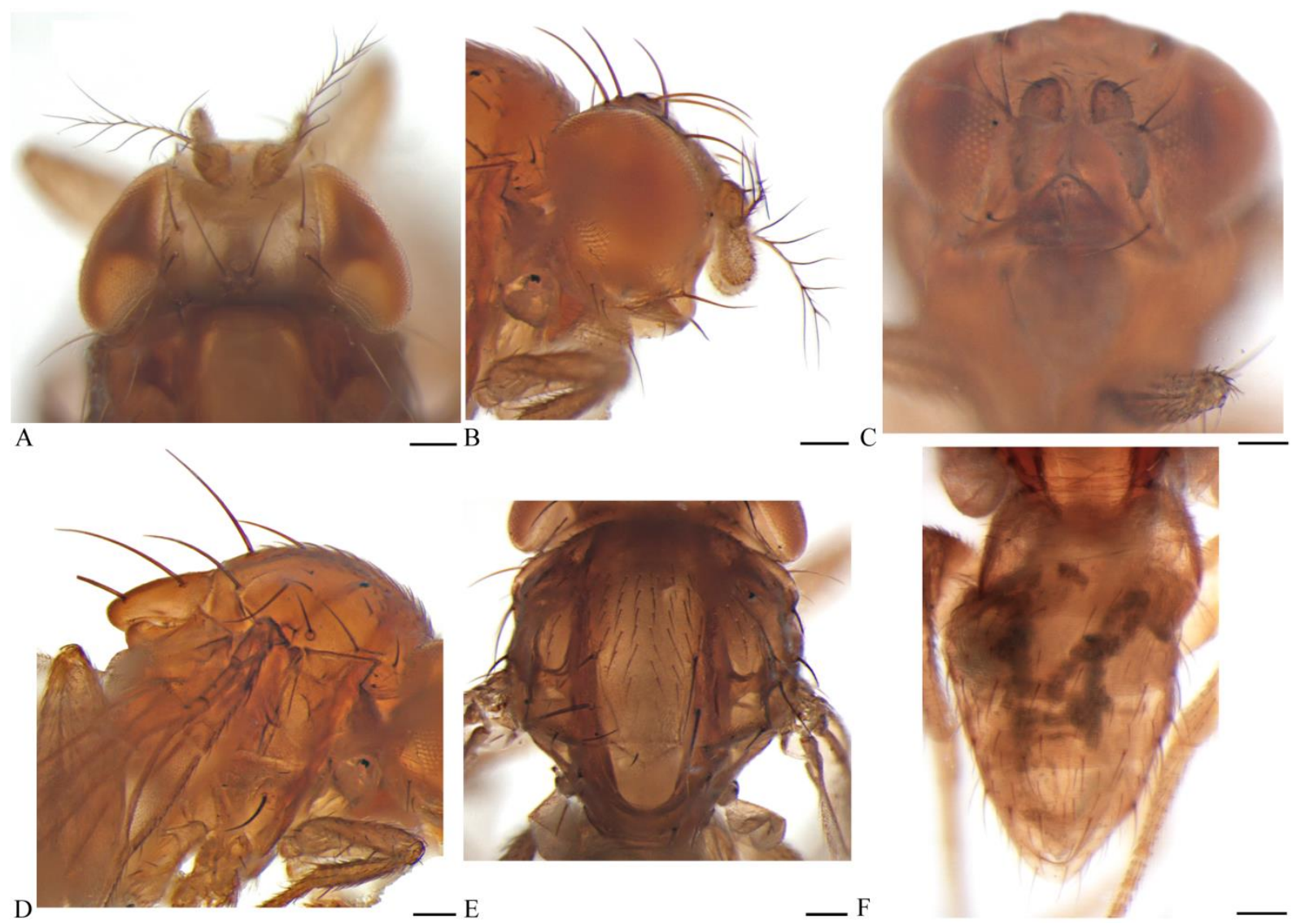

Figure 13. Cladochaeta sp. 7, nov. sp., holotype. A. Frons. B. Lateral view of head. C. Face. D. Lateral view of thorax. E. Dorsal view of thorax. F. Dorsal view of Abdomen. Scale bars: $0.1 \mathrm{~mm}$. 

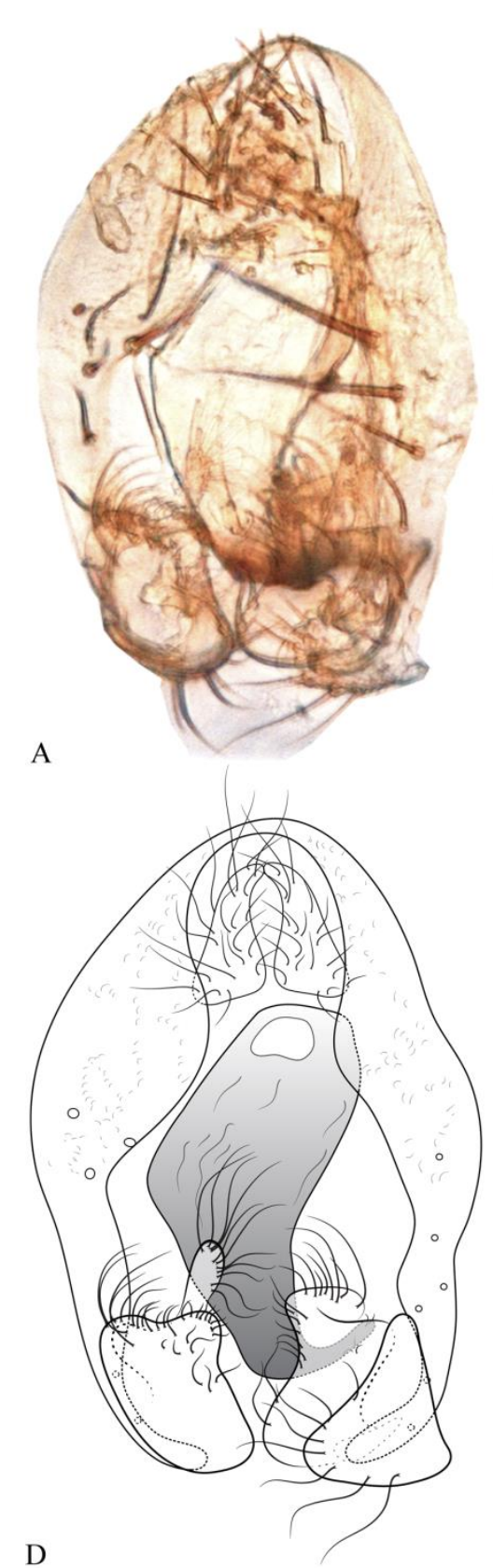
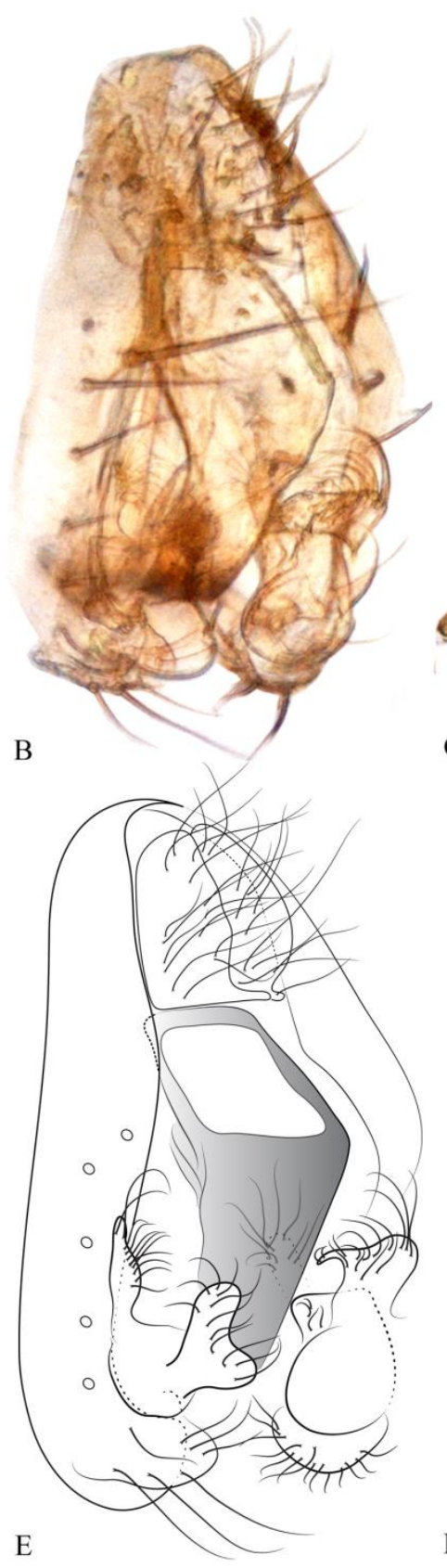
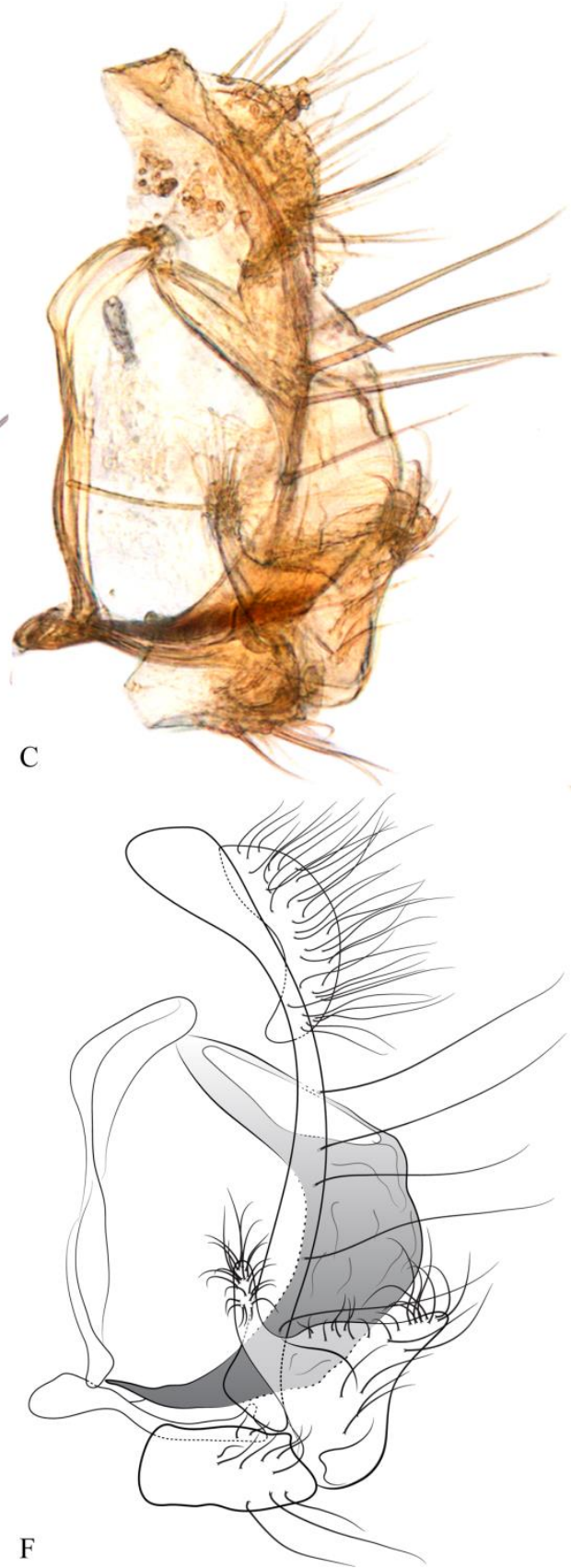

Figure 14. Male terminalia of Cladochaeta sp. 7, nov. sp., holotype. A. Photograph of terminal view. B. Photograph of terminal oblique view. C. Photograph of lateral view. D. Illustration of terminal view. E. Illustration of terminal oblique view. F. Illustrartion of lateral view.

\section{Cladochaeta sp. 8, nov. sp.}

(Figs. 15 A-F; 16 A-E; 33 B; 35 H)

Diagnosis. General body color light brown. thorax brown, pleuron lighter, abdomen brown, last tergite ochre; infuscated wing; legs ochre; arista with 3 dorsal and 1 ventral branches, plus 
apical fork; ventral branch between d-3 and apical fork; surstylus very distincitive, bilobed, with numerous three-branched setae on distal lobe; aedeagus sclerotized, somewhat conical, sinuous; paraphyses absent.

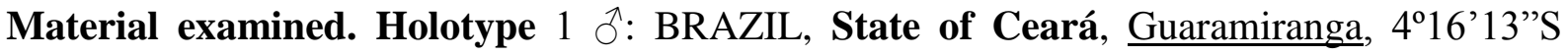
3854’21”W 880m, 10.v.2014, Malaise; Almeida, Lucena \& Tavares cols. (RPSP).

Description. Head (Figs. 15 A-C). Almost as high as wide. Eyes bare, light red. Pedicel ochre, first flagellomere whitish; arista with 3 dorsal and 1 ventral branches, plus apical fork; ventral branch between d-3 and apical fork. Frons dark brown on posterodorsal half, ochre on anterodorsal half; ocellar triangle dark brown; fronto-orbital setae: anterior reclinate small, lateral in position to proclinate fronto-orbital; posterior reclinate almost as long as proclinate, closer to proclinate than to inner vertical. Face flat, ochre. Gena ochre; proboscis and palpus pale ochre to whitish. Thorax (Figs 15 D-E). Brown, pleuron lighter; lighter area begins at mid of anepimeron, extending dorso-ventrally until ventral margin of katepisternum; postpronotal lobe ochre. Anterior dorsocentral ca. $1 / 2$ the length of posterior dorsocentral. Posterior dorsocentral midway between anterior dorsocentral and scutoscutellar suture. Acrostichals in 6 even rows. Basal scutellars slightly divergent; apical scutellars convergent, but not crusciate at tip. Two postpronotal setae, ventral one smaller than dorsal one. Legs uniformly pale light brown. Wing (Fig. $35 \mathrm{H}$ ). Membrane entirely infuscated. Tip of $\mathrm{R}_{2+3}$ straight, not curved towards $\mathrm{C}$. $\mathrm{R}_{4+5}$ and $\mathrm{M}$ parallel. Crossvein dm-cu straight, perpendicular to $\mathrm{CuA}_{1}$. Wing tip slightly acute. Halter whitish. Abdomen (Fig. 15 F). All tergites brown except last; tergite 6 ochre. Male terminalia (Figs. 16 A-E). Epandrium inverted U-shaped, with 7 long setae on ventro-lateral halves; ventral tip of ventro-lateral halves gradually tapering, curved inwards distally. Cercus with ventro-lateral edges slightly acute, somewhat extended. Aedeagus sclerotized, somewhat conical and sinuous with two medial longitudinal folds; paraphyses absent. Phallapodeme higher than wide, heavily sclerotized, with a long oblique backwards projection. Surstylus very distincitive, bilobed, with numerous threebranched setae on distal lobe; regular setae on entire dorsal and dorsolateral surfaces of proximal lobe. Hypandrium Y-shaped, ventral keel present.

Comments. This species os possibly related to the diminuta species group.The male terminalia of this species closely resembles that one from $C$. arthrostyla Grimaldi \& Nguyen, 
1999, from Costa Rica. C. arthrostyla has a similar bilobed surstylus, with three-branched setae at the distal lobe. It also resembles in a smaller extension $C$. dolichofrons Grimaldi \& Nguyen, 1999, from Trinidad, in which the surstylus setation is similar, though not bilobed. C. sp. 8, nov. sp. differs from C. arthrostyla in the coloration of the frons, described as velvety blue black for this species but dark brown in $C$. sp. 8, nov. sp. Also, the aedeagus of C. sp. 8, nov. sp. present two medial longitudinal folds not mentioned nor illustrated for $C$. arthrostyla.
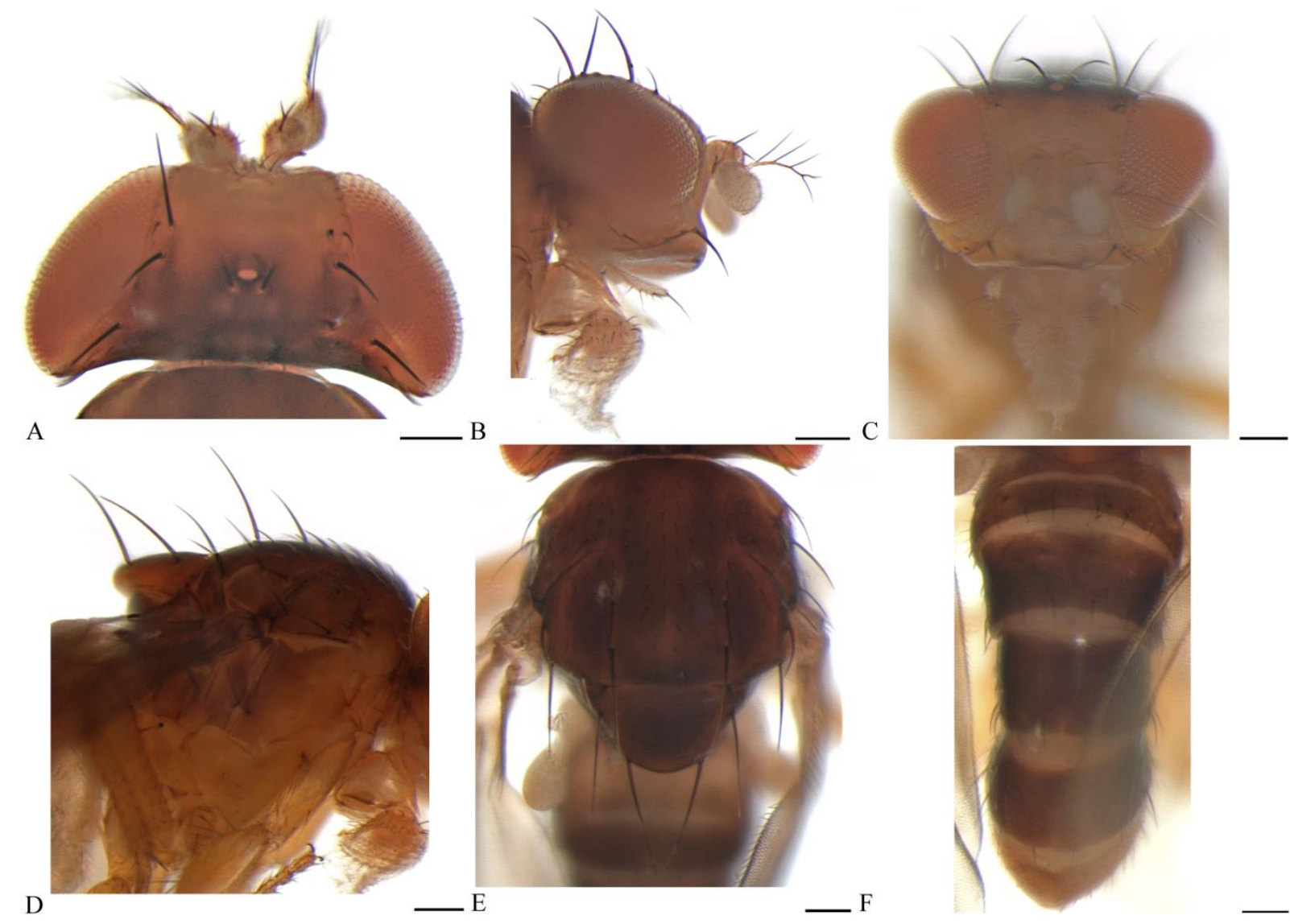

Figure 15. Cladochaeta sp. 8, nov. sp., holotype. A. Frons. B. Lateral view of head. C. Face. D. Lateral view of thorax. E. Dorsal view of thorax. F. Dorsal view of Abdomen. Scale bars: $0.1 \mathrm{~mm}$. 

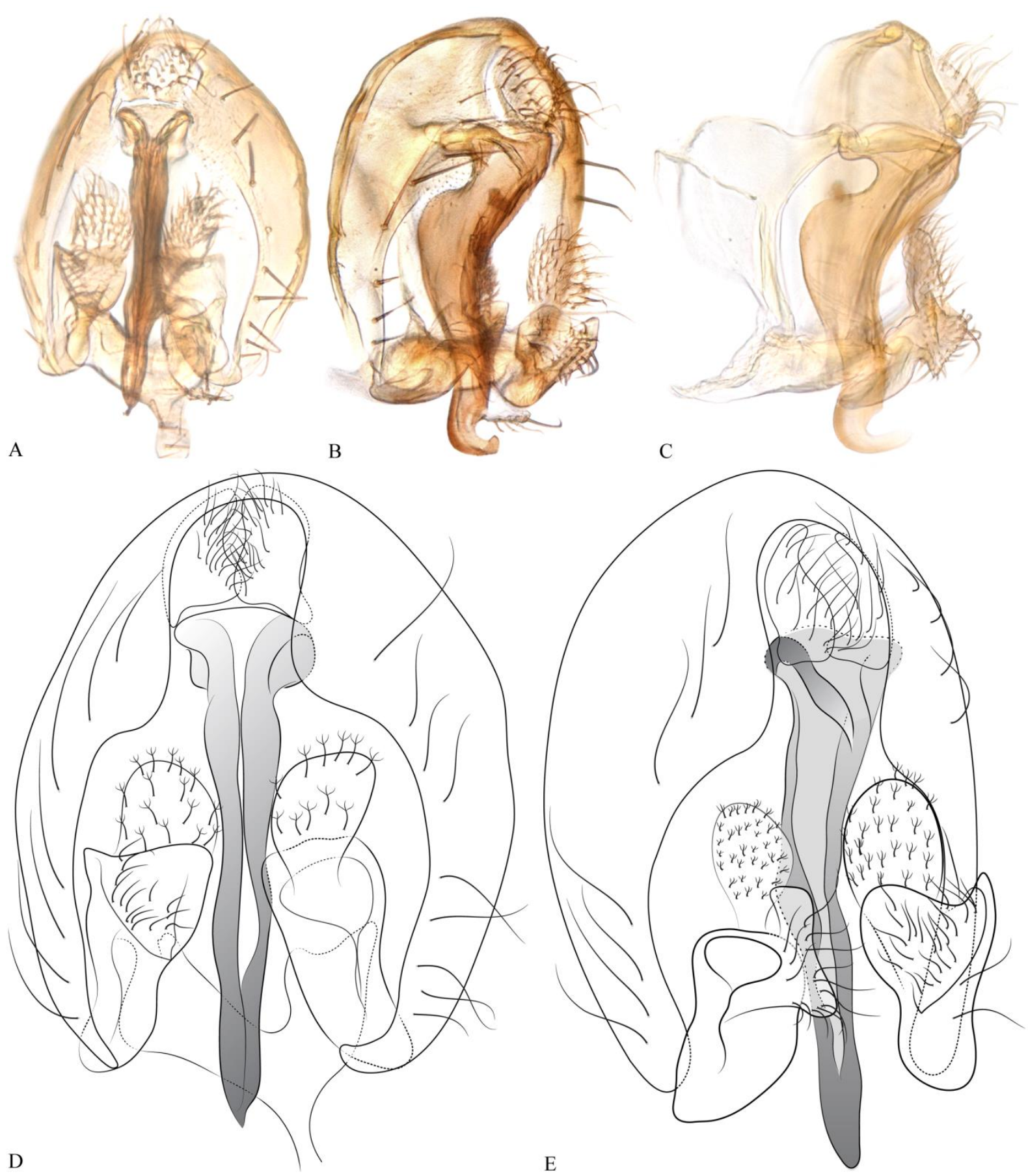

Figure 16. Male terminalia of Cladochaeta sp. 8, nov. sp., holotype. A. Photograph of terminal view. B. Photograph of terminal oblique view. C. Photograph of lateral view. D. Illustration of terminal view. E. Illustration of terminal oblique view.

\section{Cladochaeta sp. 9, nov. sp.}

(Figs. 17 A-E; 18 A-D; 33 C) 
Diagnosis. General body color ochre, abdomen slightly darker than thorax; wing Infuscated membrane; legs pale yellow; arista with 3 dorsal and 1 ventral branches; male terminalia with heavily sclerotized long and sinuous paraphyses, apically forked; aedeagus mostly membranous.

Material examined. Types: Holotype 1 $\widehat{~}$ : BRAZIL, State of São Paulo, São Luís do Paraitinga, P.E.S.M. Núcleo Sta. Virgínia, 23¹9’16.9”S 4505’56.6”W, 21.i.2011, Malaise trap, Ponto 5, N.W. Perioto \& team cols. (MZUSP).

Description. Head (Figs 17 A-C). Higher than wide. Eyes bare, pale brown. Pedicel ochre, first flagellomere whitish; arista with 3 dorsal and 1 ventral branches; ventral branch opposite to d-3. Frons pale ochre, fronto-orbital plates slightly lighter; ocellar triangle of same color as frons. Fronto-orbital setae: anterior reclinate absent; posterior reclinate the same size as anterior reclinate and in the middle between it and inner vertical. Face flat, pale ochre. Gena ochre. Proboscis and palpus whitish. Thorax (Figs. 17 D-E). Ochre, ventral half of katepisternum, lighter. Anterior dorsocentral ca. $1 / 4$ the length of posterior dorsocentral. Posterior dorsocentral midway between scutoscutellar suture and anterior dorsocentral. Acrostichals in six even rows, only two median rows reach the posterior portion of scutum. Basal scutellars divergent; apical scutellars convergent, but not crusciate at tip. Three postpronotal setae, median one longer than two. Legs pale yellow, forefemur with three spaced posteroventral long setae. Wing. Infuscated membrane, without clouds of infuscation. $\mathrm{R}_{2+3}$ curved very slightly towards anterior wing margin. $\mathrm{R}_{4+5}$ and $\mathrm{M}$ parallel. Crossvein dm-cu slightly bent medially, perpendicular to $\mathrm{CuA}_{1}$. Wing tip rounded. Halter pale ochre. Abdomen. All tergites pale brown, margins slightly darker. Male terminalia (Figs 18 A-D). Epandrium inverted U-shaped, slightly longer than wide, with a row of 7 long setae on ventro-lateral halves; ventro-lateral halves with a broader extension near cercus; ventral portion thin, turned inwards. Cercus without ventral lobes, ventro-lateral edges rounded. Aedeagus only partially sclerotized, dorsal portion membranous, recovering top of paraphyses, more ventral portion sclerotized, with a single posterior projection, ventrally curved at the medio-ventral portion, and a paired arrow-shaped projections, one of which directed forward. Paraphyses heavily sclerotized and with a very complex, though symmetrical shape. Both paraphyses present, united by a broad dorsal bridge; each paraphysis long, sinuous, forked apically. Phallapodeme higher than wide, poorly sclerotized, with a 
long, oblique projection backwards. Surstylus not heavily sclerotized, clavate, with numerous relatively long setae of similar length. Hypandrium Y-shaped, with a sclerotized ventral keel.

Comments. This species could be related to the armata species group Grimaldi \& Nguyen, 1999 according to the morphology of paraphyses and aedeagus, being strongly sclerotized and with several hook-shaped sinuous projections.
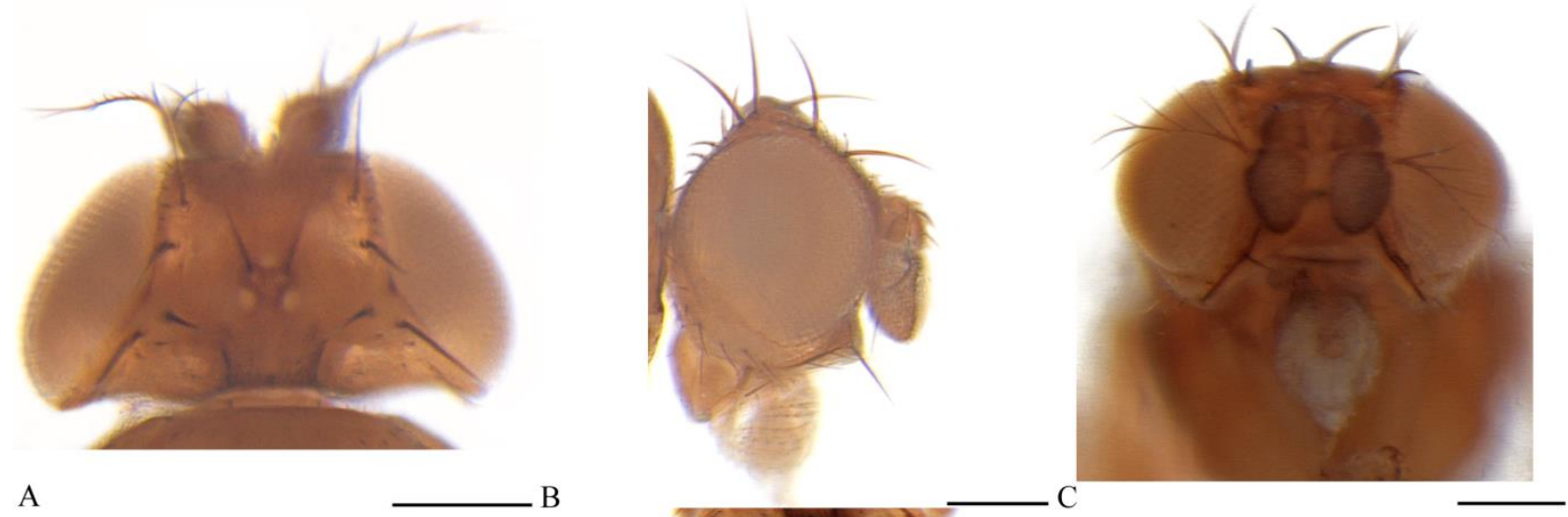

A B
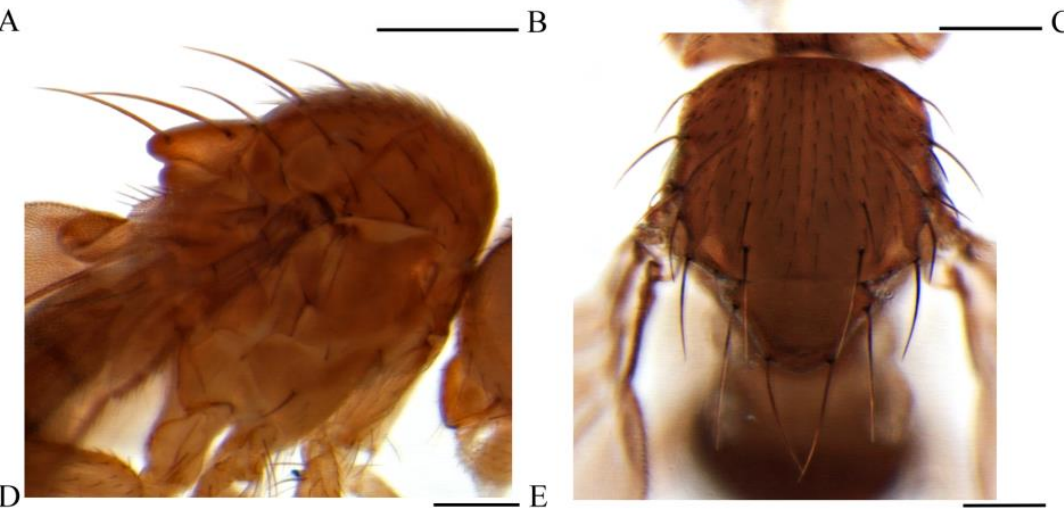

Figure 17. Cladochaeta sp. 9, nov. sp., holotype. A. Frons. B. Lateral view of head. C. Face. D. Lateral view of thorax. E. Dorsal view of thorax. Scale bars: $0.1 \mathrm{~mm}$. 

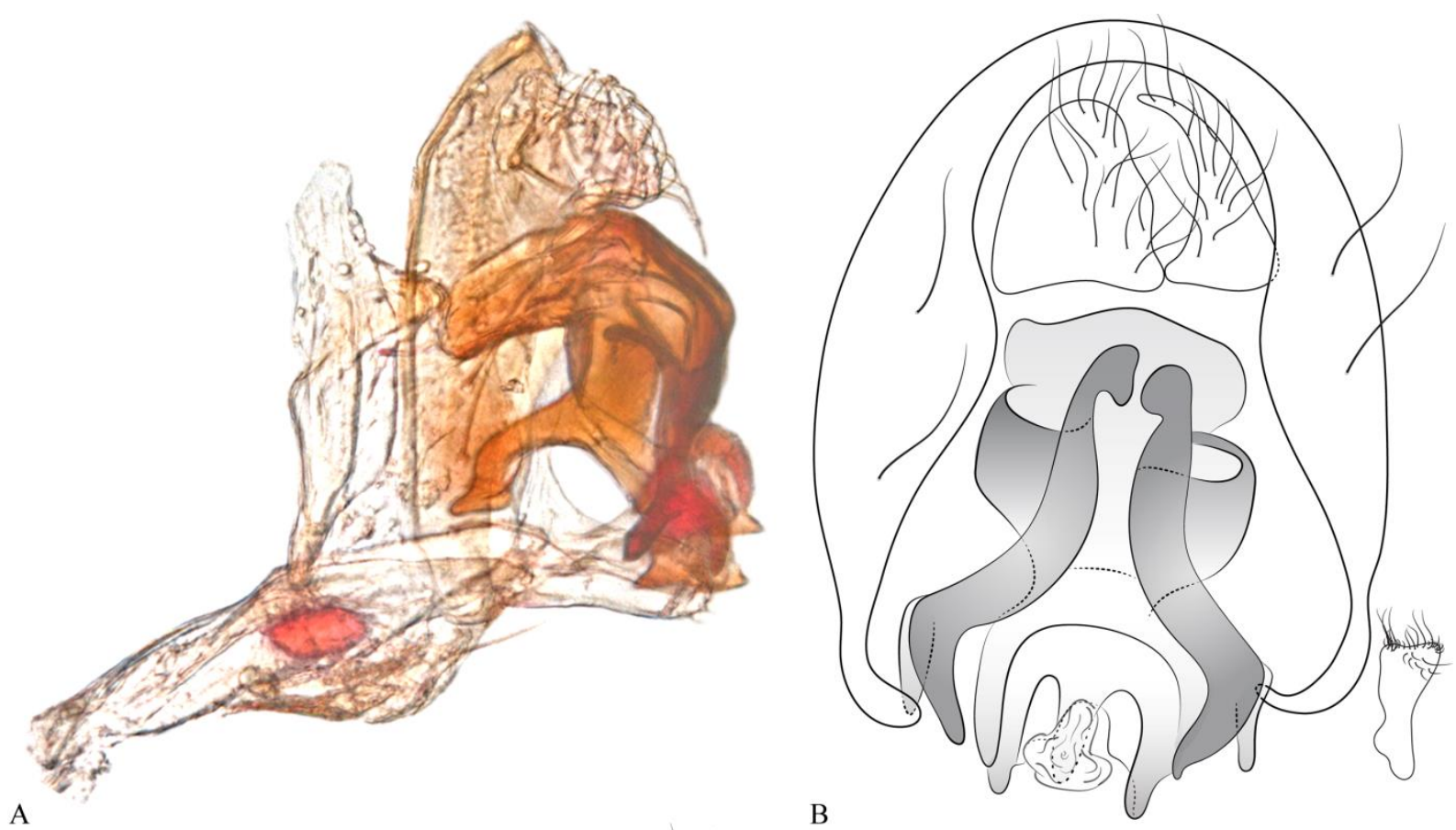

A
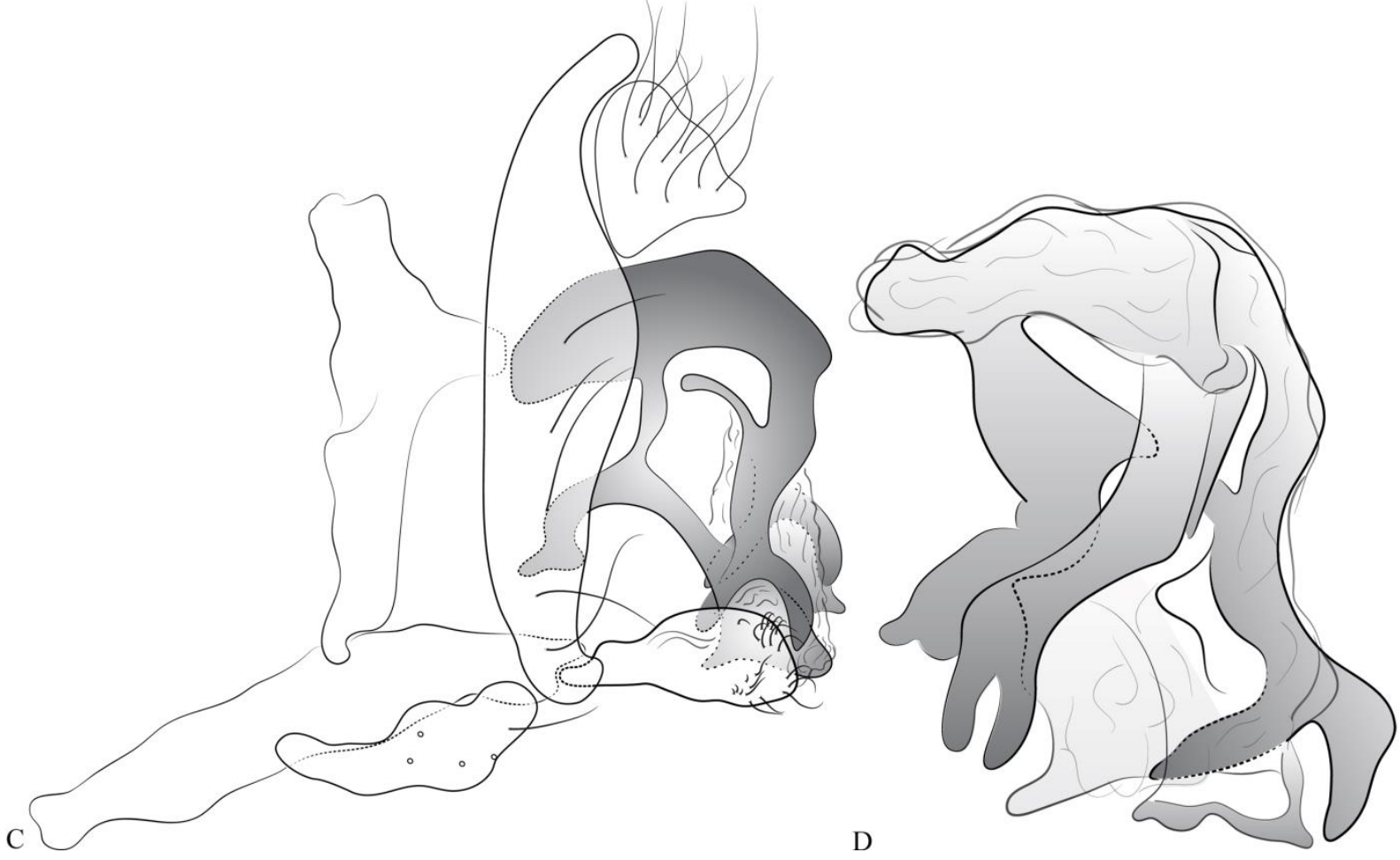

Figure 18. Male terminalia of Cladochaeta sp. 9, nov. sp., holotype. A. Photograph of lateral view. B. Illustration of terminal view. C. Illustration of lateral view. D. Illustration of lateral view of paraphyses and aedeagus.

\section{Cladochaeta sp. 10, nov. sp.}

(Figs. 19 A-F; 20 A-F; 33 D) 
Diagnosis. General body color light ochre. thorax ochre, two diffuse darker bands on pleuron, abdomen slightly lighter than thorax; arista with 3 dorsal and 1 ventral branches, ventral branch midway between apical fork and d-3; infuscated wing; aedeagus partially sclerotized, partially membranous, sclerotized part placed posteriorly, arrow-shaped, membranous part sac-form; both paraphyses present, heavily sclerotized, long, and sinuous.

Material examined. Holotype $1 \delta$ : BRAZIL, State of São Paulo, Ribeirão Grande, P.E.

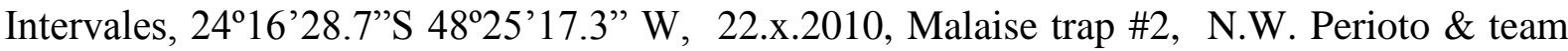
cols. (MZSP).

Description. Head (Figs. 19 A-C). Higher than wide. Eyes bare, light brown. Pedicel light ochre, first flagellomere light grayish brown; arista with 3 dorsal and 1 ventral branches, ventral branch midway between apical fork and $d-3$, minute branches present along ventral side of arista. Frons ochre, anterior margin darker; ocellar triangle slightly darker than frons; fronto-orbital setae: anterior reclinate absent; posterior reclinate slightly smaller than proclinate, closer to proclinate than to inner vertical. Face flat, ochre. Gena ochre; proboscis and palpus slightly lighter than gena. Thorax (Figs. 19 D-E). Ochre, two diffuse darker bands on pleuron, ventral band extending to mid of katepisternum. Anterior dorsocentral ca. 2/3 the length of posterior dorsocentral. Posterior dorsocentral midway between scutoscutellar suture and anterior dorsocentral. Acrostichals in 6 even rows. Basal scutellars divergent, apical scutellars convergent, but not cruciate. Three postpronotal setae, median one longer than other two. Legs light ochre. Wing. Membrane entirely dusky brown. Tip of $\mathrm{R}_{2+3}$ slightly curved towards C. $\mathrm{R}_{4+5}$ and $\mathrm{M}$ slightly divergent, both very slightly curved posteriorly. Crossvein dmcu very slightly bent medially, perpendicular to $\mathrm{CuA}_{1}$. Wing tip round. Halter whitish. Abdomen. All tergites light ochre, with slender darker bands on posterior margin. Male terminalia (Figs. 20 A-F). Epandrium inverted U-shaped, with 6 long setae on ventro-lateral halves; dense microtrichia covering entire epandrium; ventral tip of ventro-lateral halves gradually tapering, curved inwards; broad extension of epandrium near cercus. Cercus with acute ventro-lateral margin. Aedeagus partially sclerotized, partially membranous, placed between paraphyses and phallapodeme, sclerotized part placed posteriorly, arrow-shaped, membranous part sac-form, placed between both paraphyses; paraphyses present, heavily sclerotized, some more sclerotized folds dorsally, long and sinuous. Phallapodeme longer than 
wide, heavily sclerotized, with a posterodorsal projection. Surstylus clavate, setae present on dorsal and dorsolateral surfaces. Hypandrium Y-shaped, ventral keel present.

Comments. This species is possibly related to the armata species group. The male terminalia of $C$. sp. 10, nov. sp. is similar to Cladochaeta armata Frota-Pessoa, 1947 and to C. sp. 11, nov. sp. C. sp. 10, nov. sp., however, lacks the distinctive setation on mid and hind legs described to $C$. armata and has the distal portion of paraphyses simple, which is forked in $C$. armata. It also resembles $C$. sp. 11, nov. sp. on the shape of paraphyses, but the distal portion of paraphyses of $C$. sp. 11, nov. sp. are forked like in $C$. armata (see comments under $C$. sp. 11, nov. sp. about the delimitation between it and C. armata).
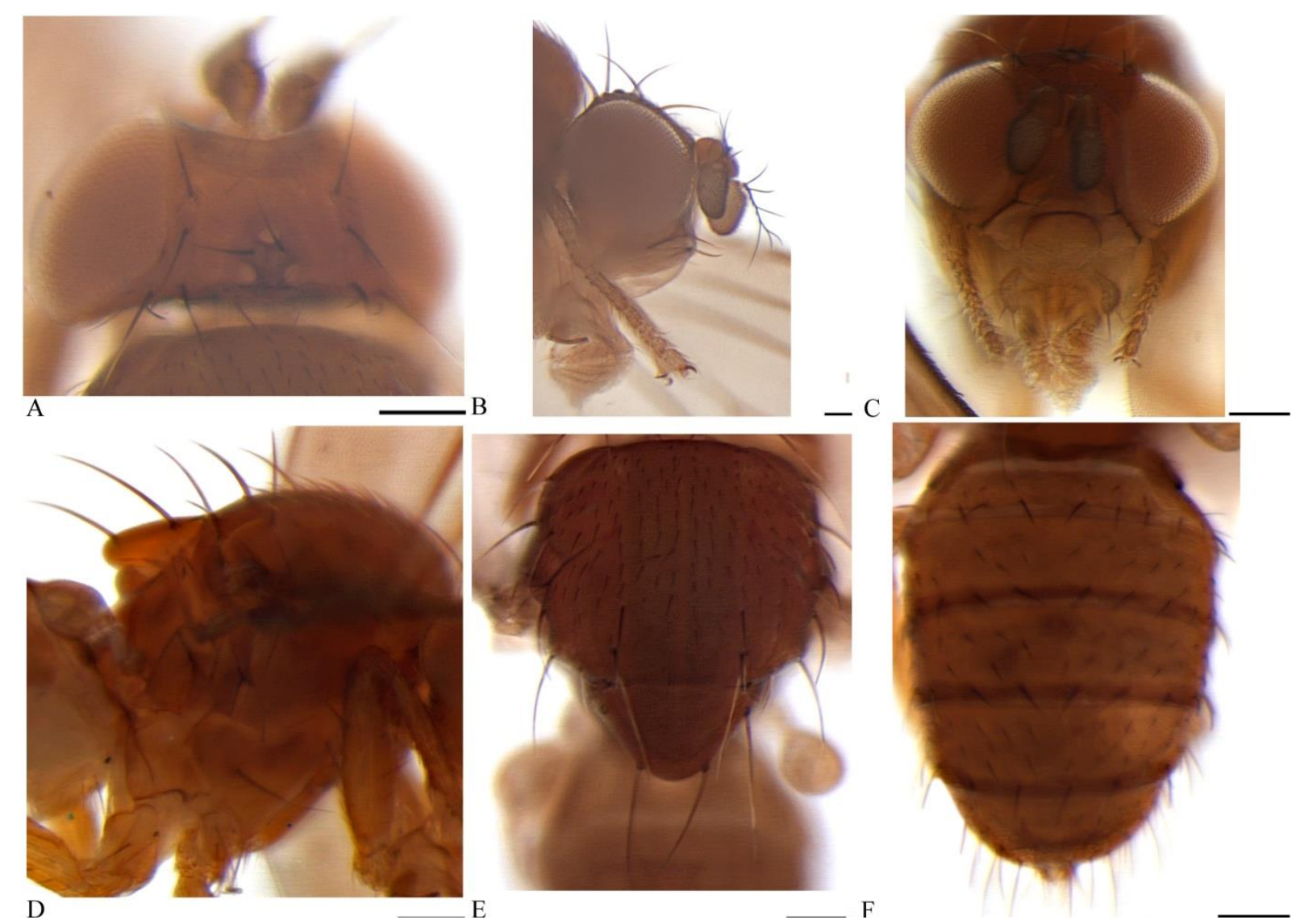

Figure 19. Cladochaeta sp. 10, nov. sp., holotype. A. Frons. B. Lateral view of head. C. Face. D. Lateral view of thorax. E. Dorsal view of thorax. F. Dorsal view of abdomen. Scale bars: $0.1 \mathrm{~mm}$. 

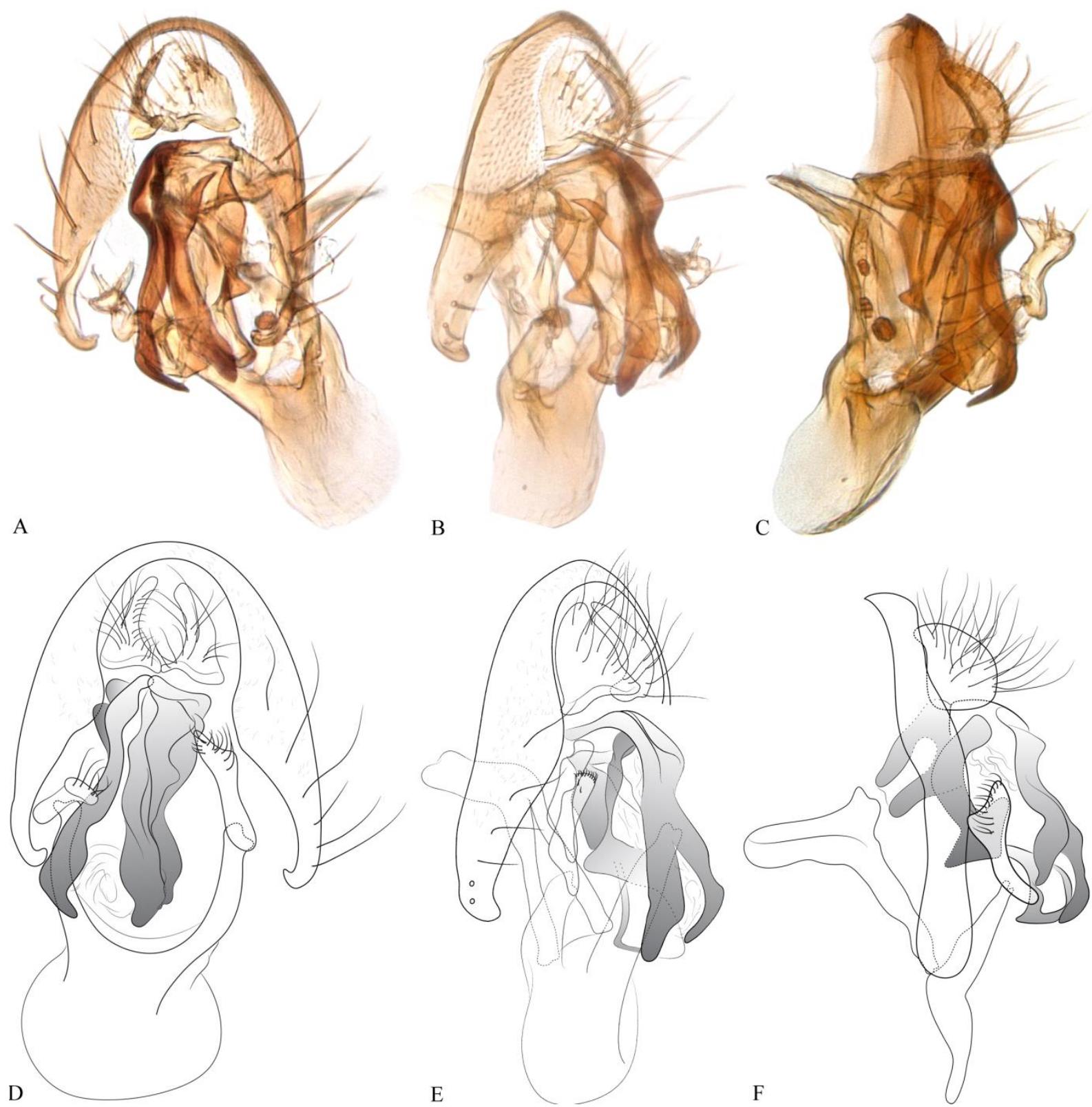

B

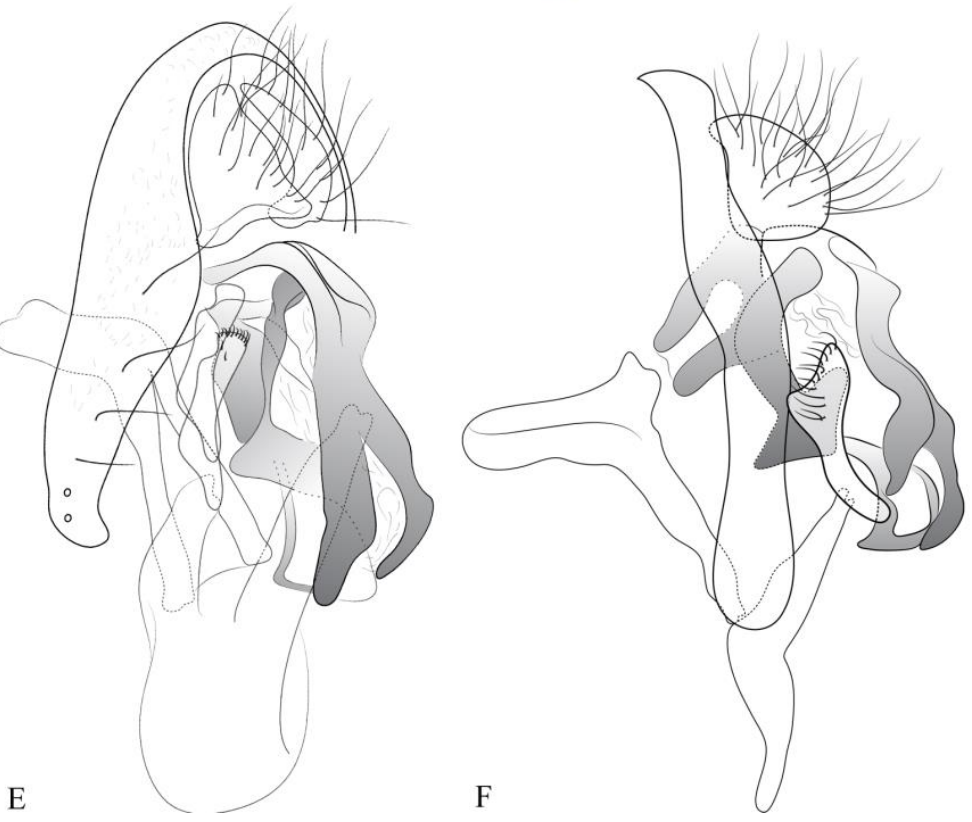

Figure 20. Male terminalia of Cladochaeta sp. 10, nov. sp., holotype. A. Photograph of terminal view. B. Photograph of terminal oblique view. C. Photograph of lateral view. D. Illustration of terminal view. E. Illustration of terminal oblique view. F. Illustrartion of lateral view.

\section{Cladochaeta sp. 11, nov. sp.}

(Figs. 21 A-F; 22 A-F; 33 E; 35 G)

Diagnosis. General body color light ochre. Thorax ochre, pleuron slightly darker, abdomen slightly lighter than thorax; arista with 3 dorsal and 1 dorsal branches, dorsal branch closer to d-3 than to apical fork. Infuscated wing; aedeagus partially sclerotized, partially membranous, 
sclerotized part placed posteriorly, arrow-shaped, membranous part sac-form; both paraphyses present, heavily sclerotized, long, sinuous.

Material examined. Holotype $1 \hat{\jmath}$, BRAZIL, State of São Paulo, Ribeirão Grande, P.E. Intervales, $24^{\circ} 16^{\prime} 28.7^{\prime \prime} \mathrm{S} 48^{\circ} 25^{\prime} 17.3^{\prime \prime} \mathrm{W}, 22 . x .2010$, Malaise \#2, N. W. Perioto \& team, cols. (MZSP).

Description. Head (Figs. 21 A-C). Higher than wide. Eyes with minute sparse setulae between the ommatidia; light red. Pedicel light ochre, first flagellomere light grayish brown; arista with 3 dorsal and 1 ventral branches, ventral branch closer to d-3 than to apical fork. Frons light ochre, anterior margin darker; ocellar triangle slightly darker than frons; frontoorbital setae: anterior reclinate small, lateral to proclinate in position; posterior reclinate the same size as proclinate, closer to proclinate than to inner vertical. Face flat, ochre, ventral margin whitish. Gena thin, ochre; proboscis and palpus the same color as gena. Thorax (Figs 21 D-E). Ochre, slightly darker pleuron: darker area extending until the middle of katepisternum. Anterior dorsocentral ca. $1 / 2$ the length of posterior dorsocentral. Posterior dorsocentral midway between scutoscutellar suture and anterior dorsocentral. Acrostichals in 6 even rows. Basal scutellars divergent, posterior convergent but not crusciate. Two postpronotal setae, ventral seta longer than dorsal. Legs light ochre. Wing. Membrane entirely dusky brown. Tip of $\mathrm{R}_{2+3}$ slightly curved towards $\mathrm{C} . \mathrm{R}_{4+5}$ and $\mathrm{M}$ slightly convergent. Crossvein dm-cu slightly bent in the middle, perpendicular to $\mathrm{CuA}_{1}$. Wing tip slightly acute. Halter light brown. Abdomen. All tergites pale ochre with slightly darker margins. Male terminalia (Figs. 22 A-F). epandrium inverted U-shaped, with 7 long setae on ventro-lateral halves; dense microtrichia covering all the Epandrium; ventral tip of ventro-lateral halves gradually tapering and curved inwards; broad extension of epandrium near the cercus. Cercus with slightly acute ventro-lateral margin. Aedeagus partially sclerotized, partially membranous, positioned between the paraphyeses and phallapodeme: the sclerotized part positioned posteriorly, arrow-shaped, with a posterior oblique triangular projection; membranous part sacform, positioned between the two paraphyses; both paraphyses present, heavily sclerotized, with some more sclerotized folds on dorsal portion; long and sinuous, ventral tips forked. Phallapodeme higher than wide, heavily sclerotized, with a posterodorsal projection. Surstylus clavate, setae present on dorsal and dorsolateral surface. Hypandrium Yshaped, ventral keel present. 
Comments. This species is possibly related to the armata species group. The male terminalia of $C$. sp. 10 , nov. sp., $C$. sp. 11, nov. sp. and $C$. armata closely resemble each other, being possible that they form a complex of species (see comments under $C$. sp. 10, nov. sp.). This species differs from $C$. armata because it lacks the distinctive setation on mid and hind legs described to C. armata.

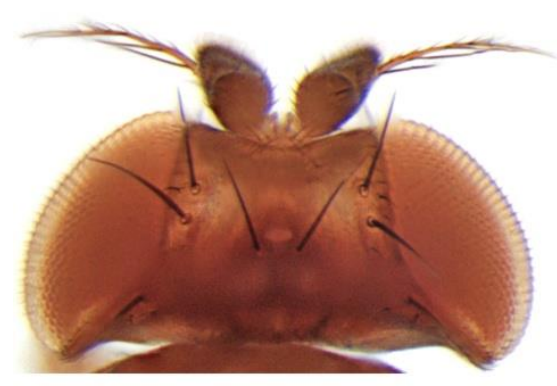

A

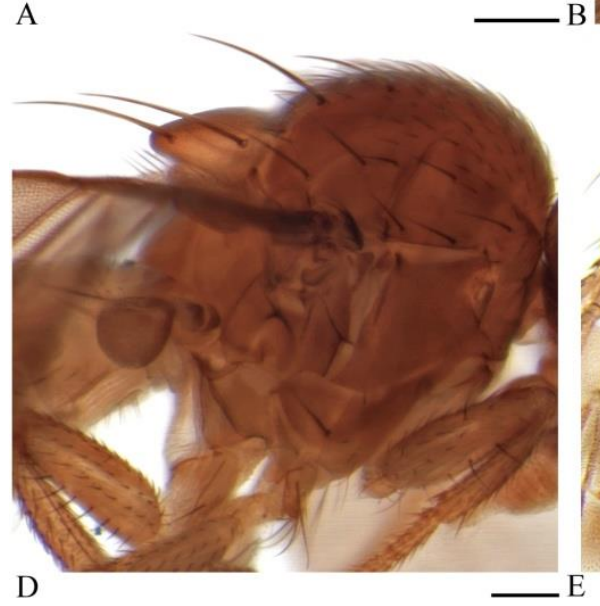

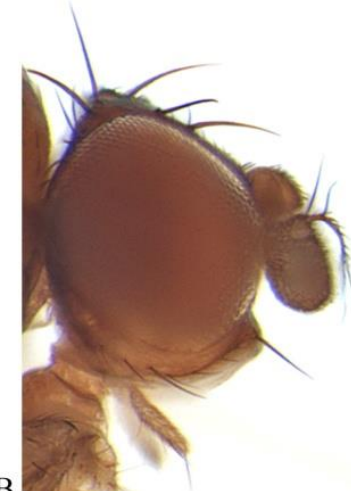

$\mathrm{B}$

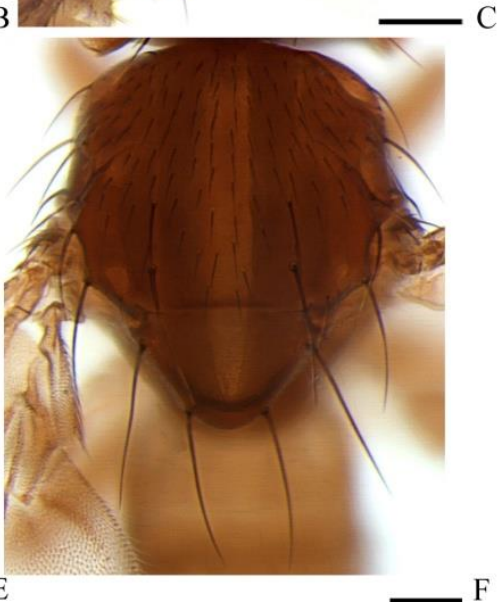

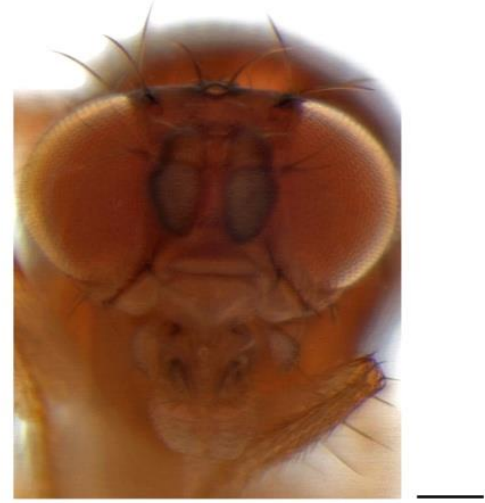

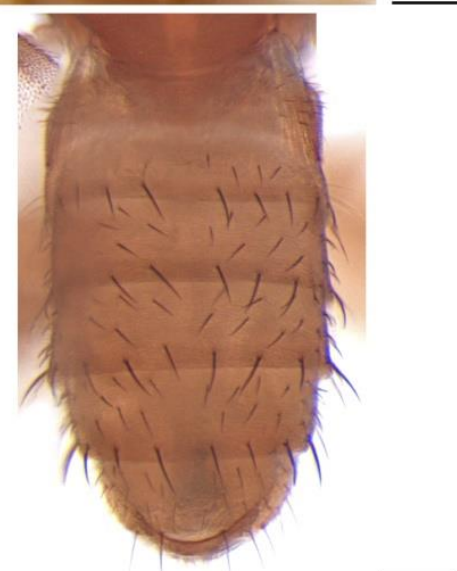

Figure 21. Cladochaeta sp. 11, nov. sp., holotype. A. Frons. B. Lateral view of head. C. Face. D. Lateral view of thorax. E. Dorsal view of thorax. F. Dorsal view of abdomen. Scale bars: $0.1 \mathrm{~mm}$. 


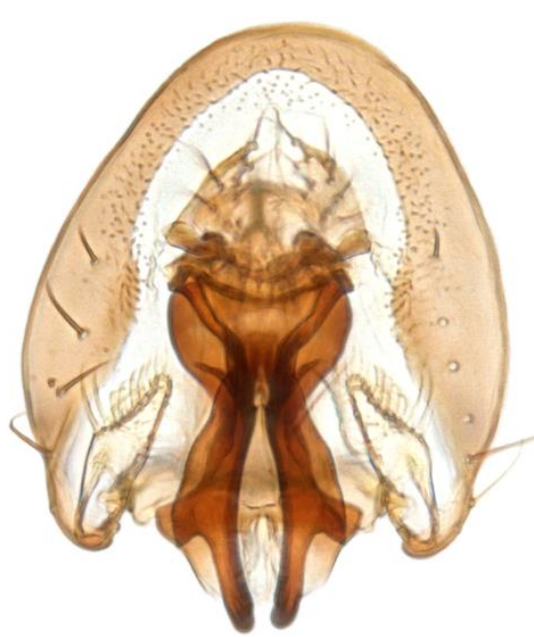

A

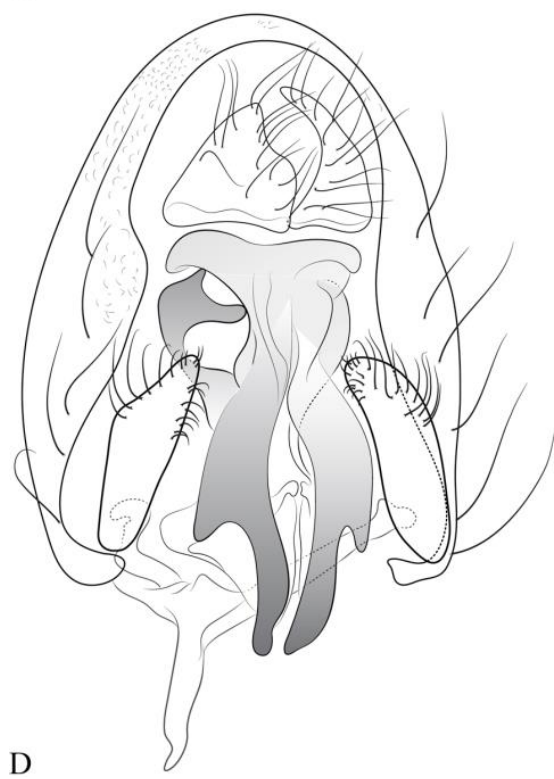

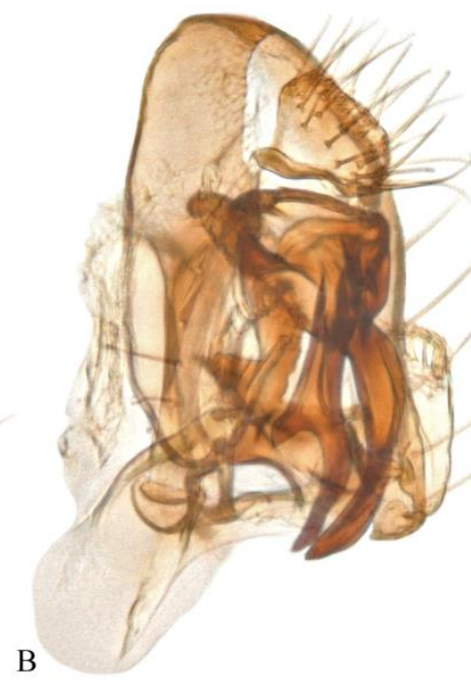

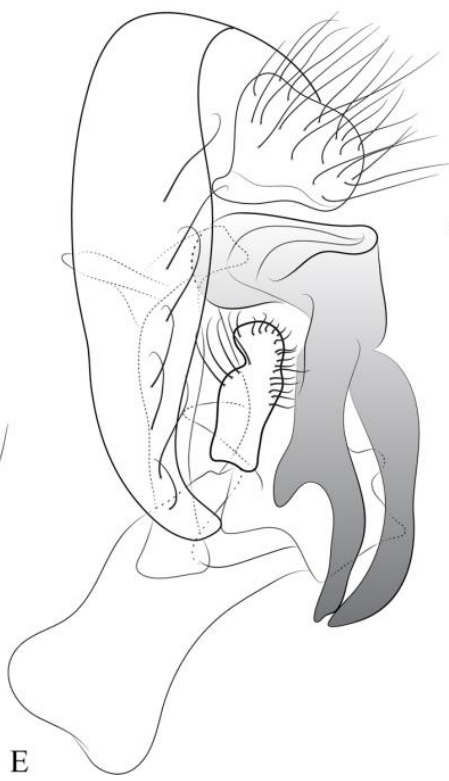

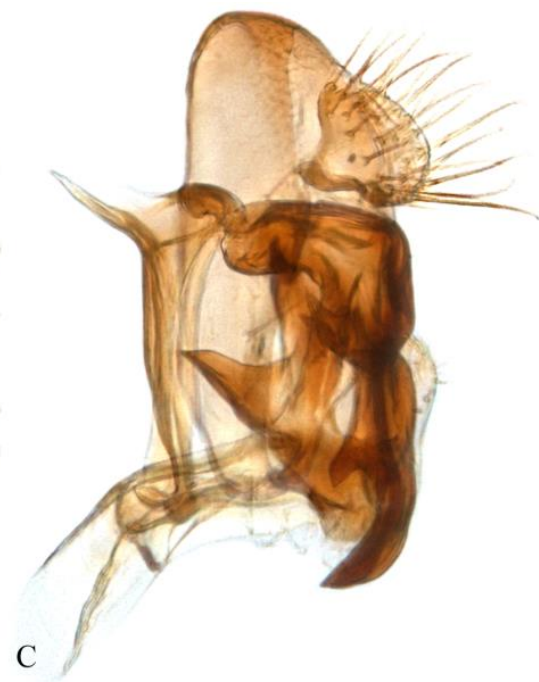

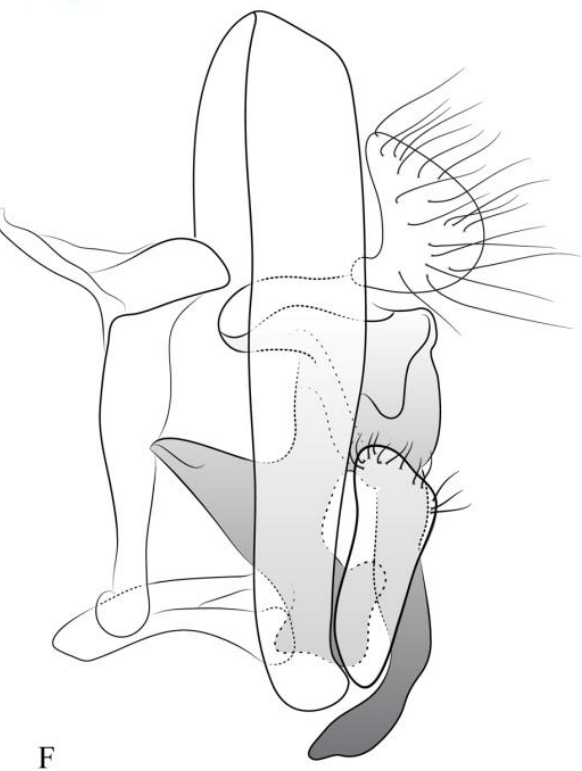

Figure 22. Male terminalia of Cladochaeta sp. 6, nov. sp., holotype. A. Photograph of terminal view. B. Photograph of terminal oblique view. C. Photograph of lateral view. D. Illustration of terminal view. E. Illustration of terminal oblique view. F. Illustrartion of lateral view.

\section{Cladochaeta sp. 12, nov. sp.}

(Figs. 23 A-F; 24 A-F; 33 F; 35 I)

Diagnosis. General body color uniformly dark brown; Infuscated wing, $\mathrm{R}_{2+3}$ short; legs light brown; fore tibia and tarsi dark bown, mid and hind ultimate tarsomere dark brown; arista with 8 dorsal branches, ventral branch and apical fork absent; male terminalia very distinctive, surstylus with long heavly sclerotized ventral projections, aedeagus membranous sac shaped; paraphyses heavly sclerotized, short and sinuous. 
Material examined. Holotype 1 $\delta^{\Uparrow}$ : BRAZIL, State of São Paulo, Gália, EE Caetetus, 22¹7’29”'S 49³3'10”'W 12.iii.2010, Varredura, Bertoni col. (MZUSP).

Description. Head (Figs. 23 A-C). Higher than wide. Eyes bare, light red. Pedicel dark brown, first flagellomere light brown; arista straight, slightly curved downwards; 8 dorsal branches, no ventral branches, neither at apical fork. Frons dark brown, ocellar triangle concolor. Fronto-orbital setae (damaged on holotype): anterior reclinate apparently absent, posterior reclinate broken, very close to proclinate. Face flat, dark brown. Gena thin, dark brown. Proboscis and palpus dark brown, only slightly lighter than rest of the head. Thorax (Figs 23 D-E). Dark brown. Posterior dorsocentral broken. Acrostichals in 6 even rows. Basal scutellars convergent, apical scutellars broken. Postpronotal setae broken. Legs ochre, except for fore tibia and tarsi, dark brown. Wing (Fig 35 I). Membrane entirely infuscated, no cloudy area over crossveins. Subcostal break weak. $\mathrm{R}_{2+3}$ short, tip of $\mathrm{R}_{2+3}$ curved in an oblique angle towards anterior margin. $\mathrm{R}_{4+5}$ and $\mathrm{M}$ parallel, tips slightly convergent. Crossvein $\mathrm{dm}-\mathrm{cu}$ straight, perpendicular to $\mathrm{CuA}_{1}$. Wing tip rounded. Halter whitish. Abdomen (Fig. 23 F). All tergites brown. Male terminalia (Figs. 24 A-F). Epandrium inverted U-shaped, wider than high, approximately 14 long setae along its extension (not restricted to ventro-lateral halves); ventro-lateral halves with a broader ventral extension; ventral tip of ventral halves short, clavate. Cercus with ventro-lateral edges acute, slightly projected. Distinguishable portion of aedeagus membranous, sac-shaped. Paraphyses sclerotized (though not strongly sclerotized), short, sinuous. Phallapodeme higher than wide, sclerotized. Surstylus very distinctive, heavily sclerotized, with a very long acute projection. Hypandrium Y-shaped.

Comments. The male terminalia morphology of this species is similar tothat of the simplex species group Grimaldi \& Nguyen, 1999 e.g., the U-shaped hypandrium and the long triangular surstily. However, the group is defined by three dorsal branches on arista, a condition not seen in $C$. sp. 12 , nov. sp., which has a very distinctive antenna, with 8 dorsal and none ventral branches. 

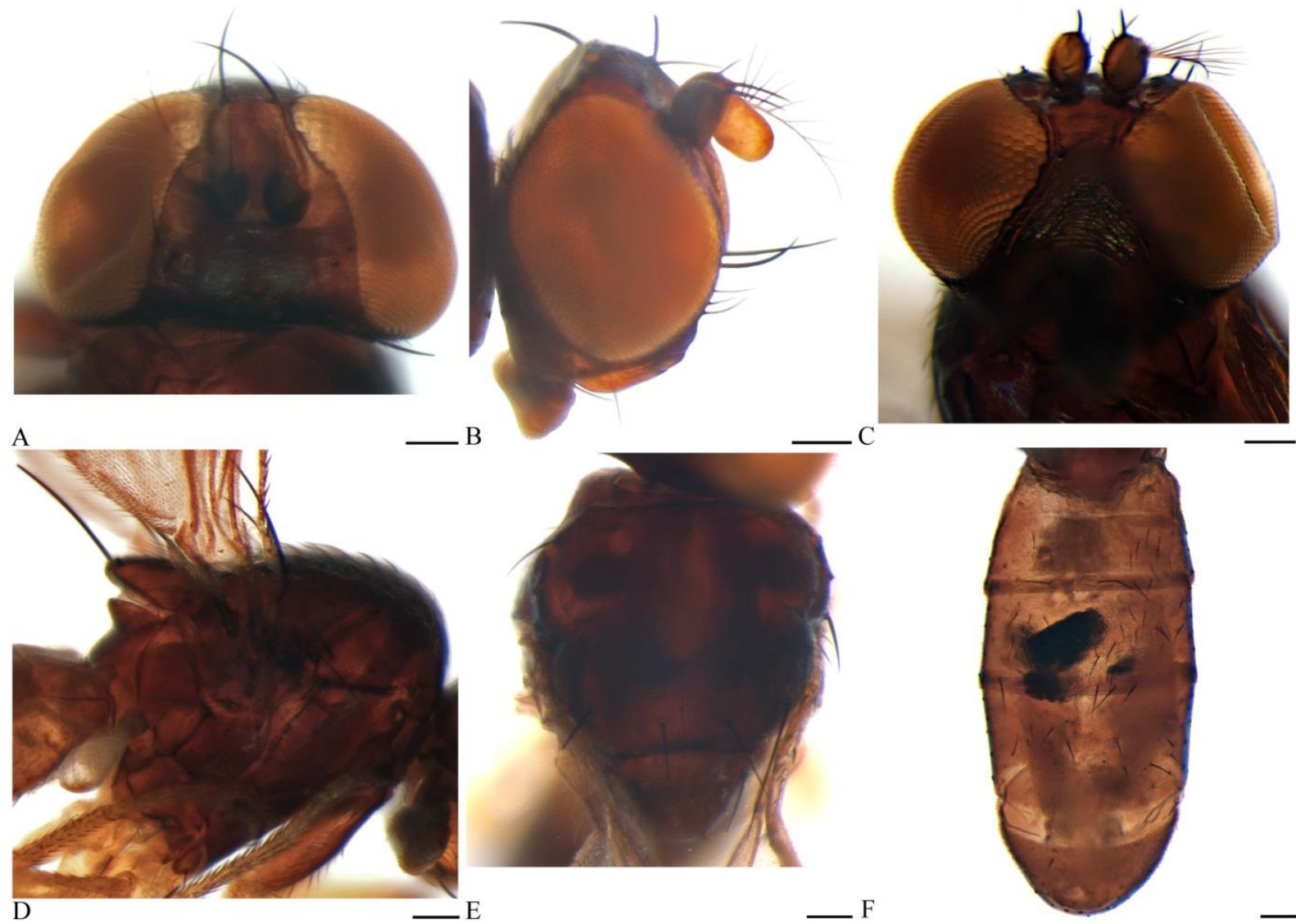

Figure 23. Cladochaeta sp. 12, nov. sp., holotype. A. Frons. B. Lateral view of head. C. Face. D. Lateral view of thorax. E. Dorsal view of thorax. F. Dorsal view of abdomen. Scale bars: $0.1 \mathrm{~mm}$. 


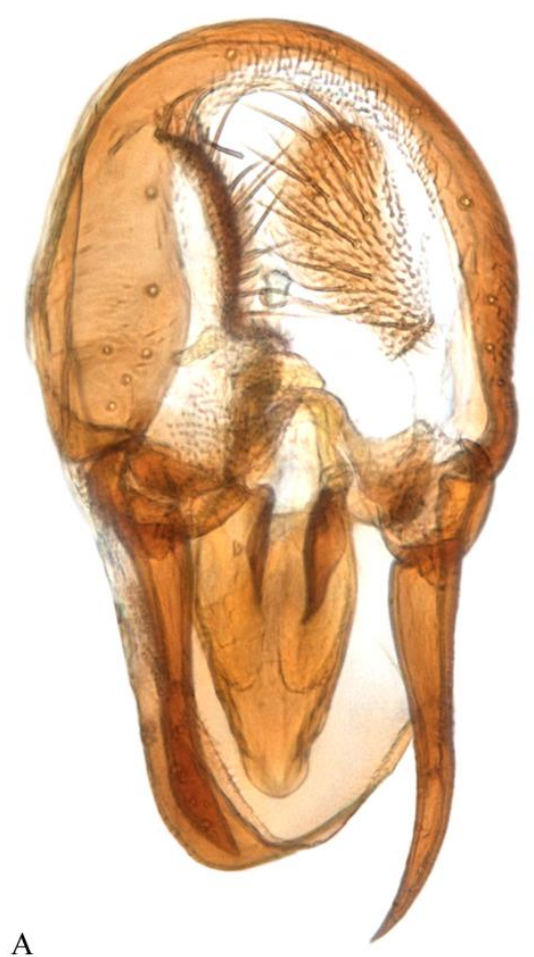

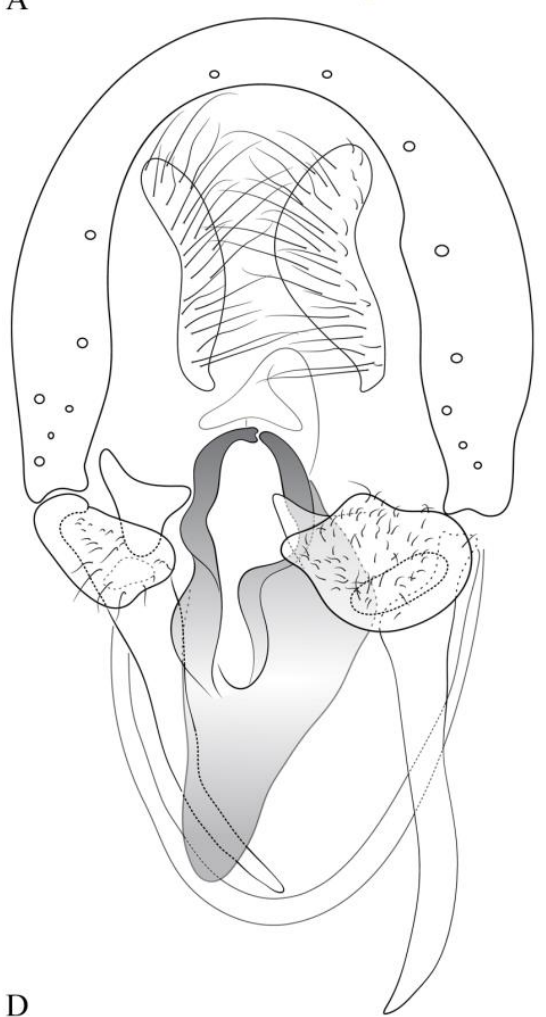

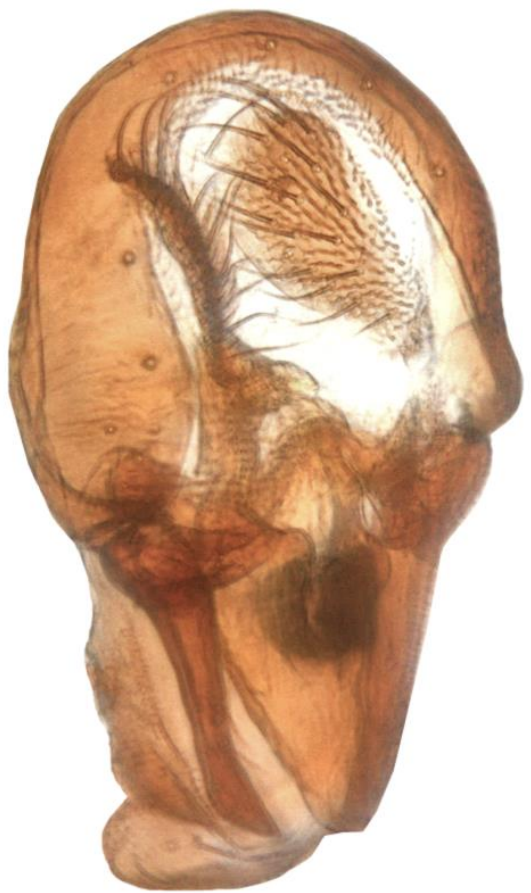

B

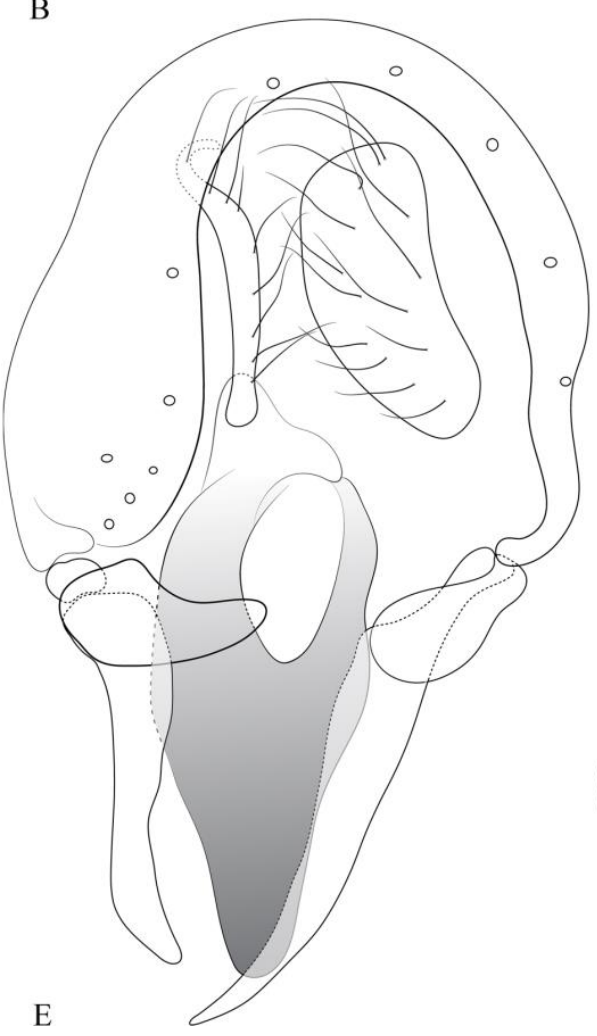

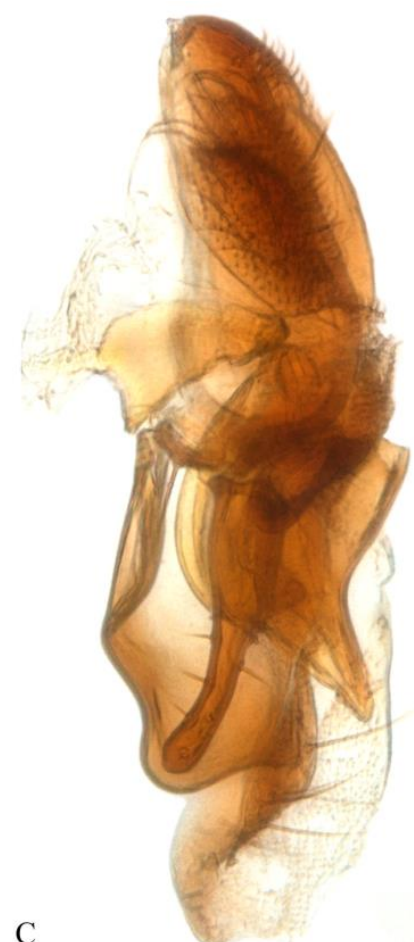

$\mathrm{C}$

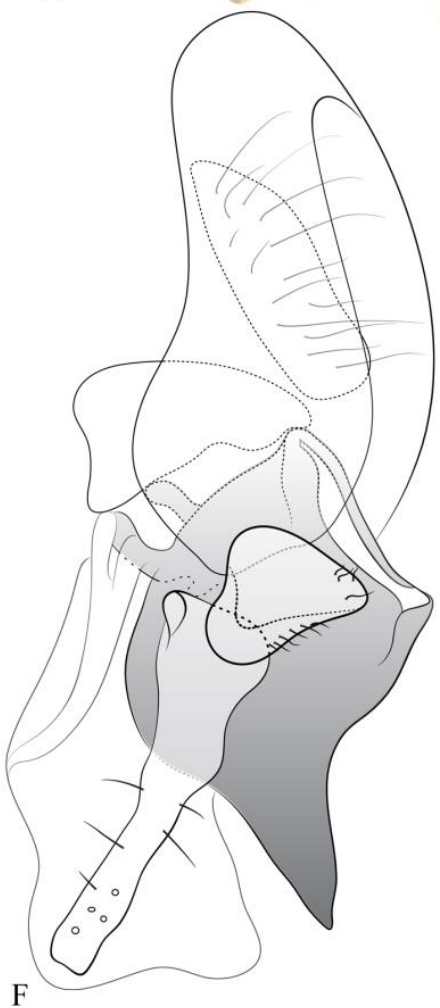

Figure 24. Male terminalia of Cladochaeta sp. 12, nov. sp., holotype. A. Photograph of terminal view. B. Photograph of terminal oblique view. C. Photograph of lateral view. D. Illustration of terminal view. E. Illustration of terminal oblique view. F. Illustrartion of lateral view. 


\section{Cladochaeta sp. 13, nov. sp.}

(Figs. 25 A-F; 26 B; 27 A-F; 34 A; 35 J)

Diagnosis. Thorax light yellow, abdomen ochre; wing with infuscation over costal region and over crossvein dm-cu; legs pale yellow to white; arista with just the dorsal basal branch; Distinguishable portion of aedeagus membranous; paraphyses thin, sinuous, asymmetrical; right paraphyse long; left paraphyse, very short.

Material examined. Holotype 1 T : BRAZIL, State of São Paulo, Gália, E.E. Caetetus, 22 ${ }^{\circ} 17^{\prime 2} 29^{\prime \prime S} 49^{\circ} 33^{\prime} 10^{\prime \prime} \mathrm{W}, 12.1 i i .2010$, Sweeping, Bertoni col. (MZUSP).

Description. Head (Figs. 25 A-C). Higher than wide. Eyes bare, light red. Pedicel ochre, first flagellomere light ochre; arista curved downwards, with just the dorsal basal branch (Fig. 26 B). Frons pale yellow, ocellar triangle of same color. Fronto-orbital setae: anterior reclinate short, barely distinguishable from other fronto-orbitals, posterior reclinate slightly smaller than proclinate, closer to inner vertical than to proclinate; anterior reclinate slightly closer to proclinate than to posterior reclinate. Face flat, light ochre. Gena light ochre. Proboscis and palpus concolor with gena. Thorax (Figs. 25 D-E). light yellow. Anterior dorsocentral ca. 1/2 the length of posterior dorsocentral. Posterior dorsocentral closer to scutoscutellar suture than to anterior dorsocentral. Acrostichals in 6 even rows. Basal and apical scutellars convergent. Three postpronotal setae, median one longer than other two. Legs uniformly pale yellow. Wing (Fig. $35 \mathrm{~J}$ ). infuscated, with darker area extending of $\mathbf{R}_{2+3}$ cell until the middle of $\mathbf{R}_{4+5}$ cell, gradually fading; small, rounded, very light and diffuse cloud over r-m and a small darker cloud over dm-cu barely extending to $\mathrm{CuA}_{1}$. Tip of $\mathrm{r}_{2+3}$ curved up towards wing margin. $\mathrm{R}_{4+5}$ and $\mathrm{M}$ parallel, tips slightly divergent. Crossvein $\mathrm{dm}-\mathrm{cu}$ slightly sinuous, perpendicular to $\mathrm{CuA}_{1}$. Wing tip slightly acute. Halter whitish. Abdomen (Fig. 25 F). All tergites ochre, posterior margins darker. Male terminalia (Figs. 27 A-F). Epandrium inverted U-shaped, almost as high as wide, with 7 long setae on ventro-lateral halves; ventral tip of ventro-lateral halves gradually tapering, curved inwards terminally. Cercus with ventro-lateral edges rounded, not extended. Aedeagus large, bulbous and membranous, no sclerotization. Paraphyses heavily sclerotized, thin, sinuous, asymmetric; right paraphyse long, left paraphyse very short, both connected by a thin dorsal bridge. Phallapodeme very thin, 
sinuous, heavily sclerotized. Surstylus simple, clavate; setae present on entire dorsal and dorsolateral surfaces of surstylus. Hypandrium Y-shaped, ventral keel present.

Comment. This species is probably related to the nebulosa species group Grimaldi \& Nguyen, 1999 based on the following combination of characters: arista with only the dorsal basal branch, clouded wing, membranous laterally flattened aedeagus and assymetrical long and thin paraphyses. It closely resembles C. genuinus Grimaldi \& Nguyen, 1999 on the morphology of paraphyses, pattern of clouds of infuscation on wings and sinuosity of crossvein dm-cu, that is described as straight but seems slight sinuous on the photography published, the same condition seen in $C$. sp. 13, nov. sp. However, C. genuinus has a long ventral lobe on surstylus, not present in $C$. sp. 13, nov. sp. and the proportional length of the left paraphyses is different between both species as well.

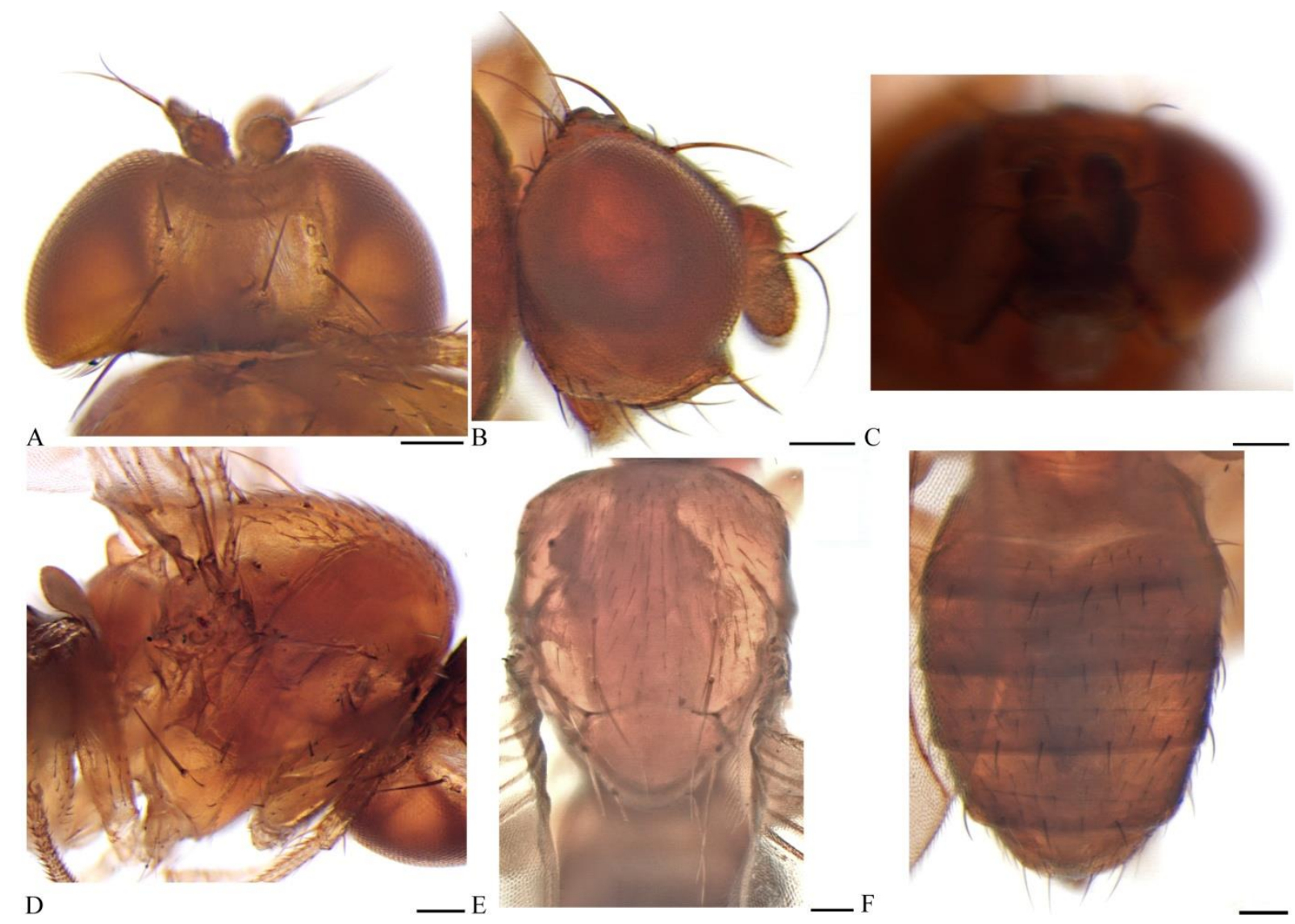

Figure 25. Cladochaeta sp. 13, nov. sp., holotype. A. Frons. B. Lateral view of head. C. Face. D. Lateral view of thorax. E. Dorsal view of thorax. F. Dorsal view of abdomen. Scale bars: $0.1 \mathrm{~mm}$. 


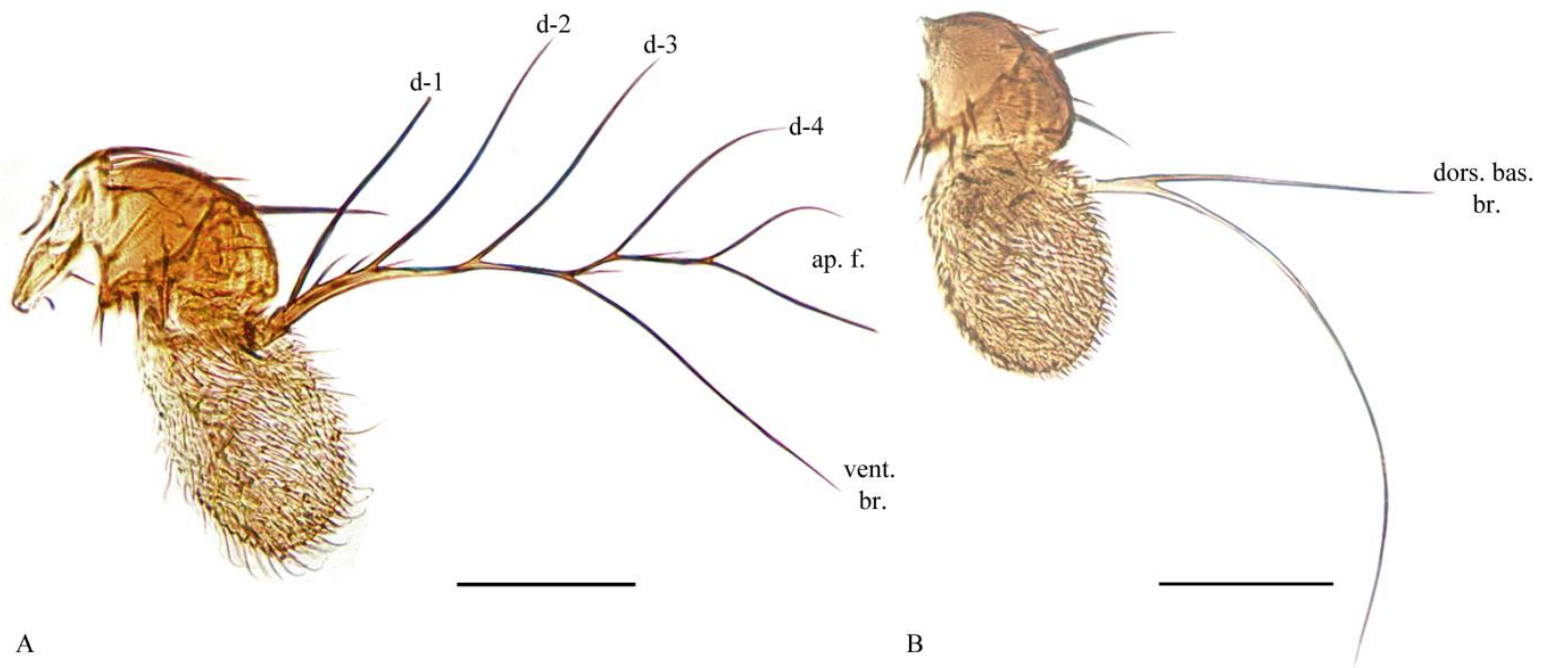

Figure 26. Two conditions of Cladochaeta aristae. A. Antennae of $C$. sp. 7, nov. sp., holotype. B. Antennae of C. sp. 13, nov. sp., holotype. Scale bars: 0.1mm. Ap. f.: apical fork; d-1: first dorsal branch; d-2: second dorsal branch; d-3: third dorsal branch; d-4: forth dorsal branch; dors. bas. br.: dorsal basal branch; vent. br.: ventral branch.

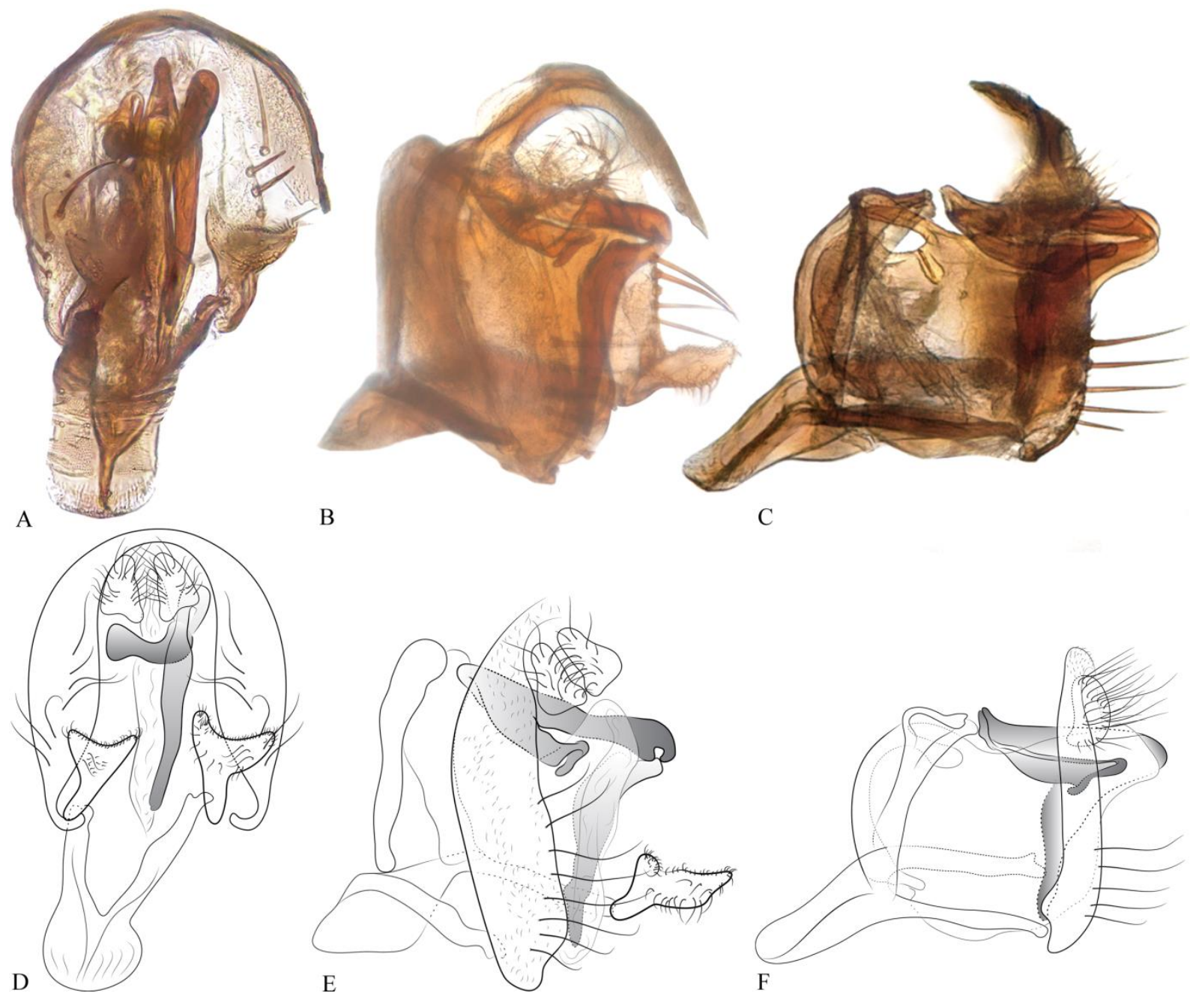

Figure 27. Male terminalia of Cladochaeta sp. 13, nov. sp., holotype. A. Photograph of terminal view. B. Photograph of terminal oblique view. C. Photograph of lateral view. D. Illustration of terminal view. E. Illustration of terminal oblique view. F. Illustrartion of lateral view. 


\section{Cladochaeta sp. 14, nov. sp.}

(Figs. 28 A-F; 29 A-F; 34 B; 35 K)

Diagnosis. Thorax dark ochre, pleuron and abdomen brown; wing Infuscated membrane; legs light ochre; arista with 4 dorsal and 1 ventral branches; aedeagus membranous, marginal folds turned posteriad; paraphyses absent.

Material examined. Holotype $1 \hat{\sigma}$, BRAZIL, State of São Paulo, São Luís do Paraitinga, P.E.S.M. Núcleo Sta. Virgínia, 2319'16.9”'S 4505'46.6”W, 21.xi.2011, Malaise trap 5, N.W. Perioto \& team, cols. (MZUSP).

Description. Head (Figs. 28 A-C). Higher than wide. Eyes bare, light red. Pedicel light ochre, first flagellomere greyish; arista with 4 dorsal and 1 ventral branch; ventral branch between d-3 and d-4; d-4 small, curved downwards; 3 minute dorsal branches: one before d-4 and two between d-4 and apical fork; apical fork small. Frons brown, anterodorsal half ochre; ocellar triangle concolor with posterodorsal half of frons. Fronto-orbital setae: anterior reclinate short but easily distinguishable from other fronto-orbital setulae and lateroposterior to proclinate in position; proclinate broken in holotype; posterior reclinate closer to proclinate than to inner vertical. Face flat, brown, with an inverted whitish triangular stain medially. Gena brown; proboscis pale ochre; palpus brown. Thorax (Figs. 28 D-E). Dark ochre, brown pleuron. Anterior dorsocentral ca. $1 / 3$ the length of posterior dorsocentral. Posterior dorsocentral slightly closer to scutoscutellar suture than to anterior dorsocentral. Acrostichals in 6 uneven rows. Basal scutellars parallel, apical scutellars convergent. Two postpronotal setae, ventral one slightly longer than dorsal one. Legs uniformly pale ochre, with three large postero-ventral setae. Wing (Fig. $35 \mathrm{~K}$ ). Infuscated membrane; tip of $\mathrm{R}_{2+3}$ slightly curved up towards wing margin. $\mathrm{R}_{4+5}$ and $\mathrm{M}$ parallel; crossvein dm-cu sinuous, perpendicular to $\mathrm{CuA}_{1}$. Wing tip slightly acute. Halter pale ochre. Abdomen (Fig. 28 F). All tergites dark brown, posterior margins darker. Male terminalia (Figs. 29 A-F). Epandrium inverted U-shaped, with 9 long setae on ventro-lateral halves and dense microtricha covering entire epandrium ; ventral tip of ventro-lateral halves gradually tapering, slightly curved inwards terminally. Cercus with ventro-lateral edges acute, not extended. Aedeagus sclerotized with two marginal folds turned anteriad, broader dorsally, somewhat sinuous; ventral tip forked. Paraphyses absent. Phallapodeme higher than wide in lateral view, with a long oblique projection 
backwards, heavily sclerotized. Surstylus simple, clavate; setae present on entire dorsal and dorsolateral surface of surstylus. Hypandrium Y-shaped, ventral keel present.

Comments. This species is possibly related to the dikra species group Grimaldi \& Nguyen, 1999 based on the morphology of aedeagus (or fused paraphyses) that is somewhat conical with the ventral portion forked (considered as a bifid distiphallus by Grimaldi \& Nguyen, 1999). However, the unca species group Grimaldi \& Nguyen, 1999 also has a similar condition of aedeagus (or fused paraphyses). It closely resembles $C$. carinata Grimaldi \& Nguyen, 1999 and C. janzeni Grimaldi \& Nguyen, 1999 from dikra species group. Differs from $C$. carinata on the facial carina that is low in $C$. carinata, but absent in $C$. sp. 14, nov. sp. and by the presence of apical sternite on male terminalia of $C$. carinata, that is absent in $C$. sp. 14, nov. sp. It also resembles $C$. janzeni Grimaldi \& Nguyen, 1999, but differs from it on aristal branching, while $C$. janzeni presents 3 dorsal and no ventral branches, $C$. sp. 14, nov. sp. presents 4 dorsal and one ventral branches. Furthermore, C. janzeni has the achrosticals that are immediately anterior to the anterior dorsocentral enlarged, a condition not seen in $C$. sp. 14, nov. sp.

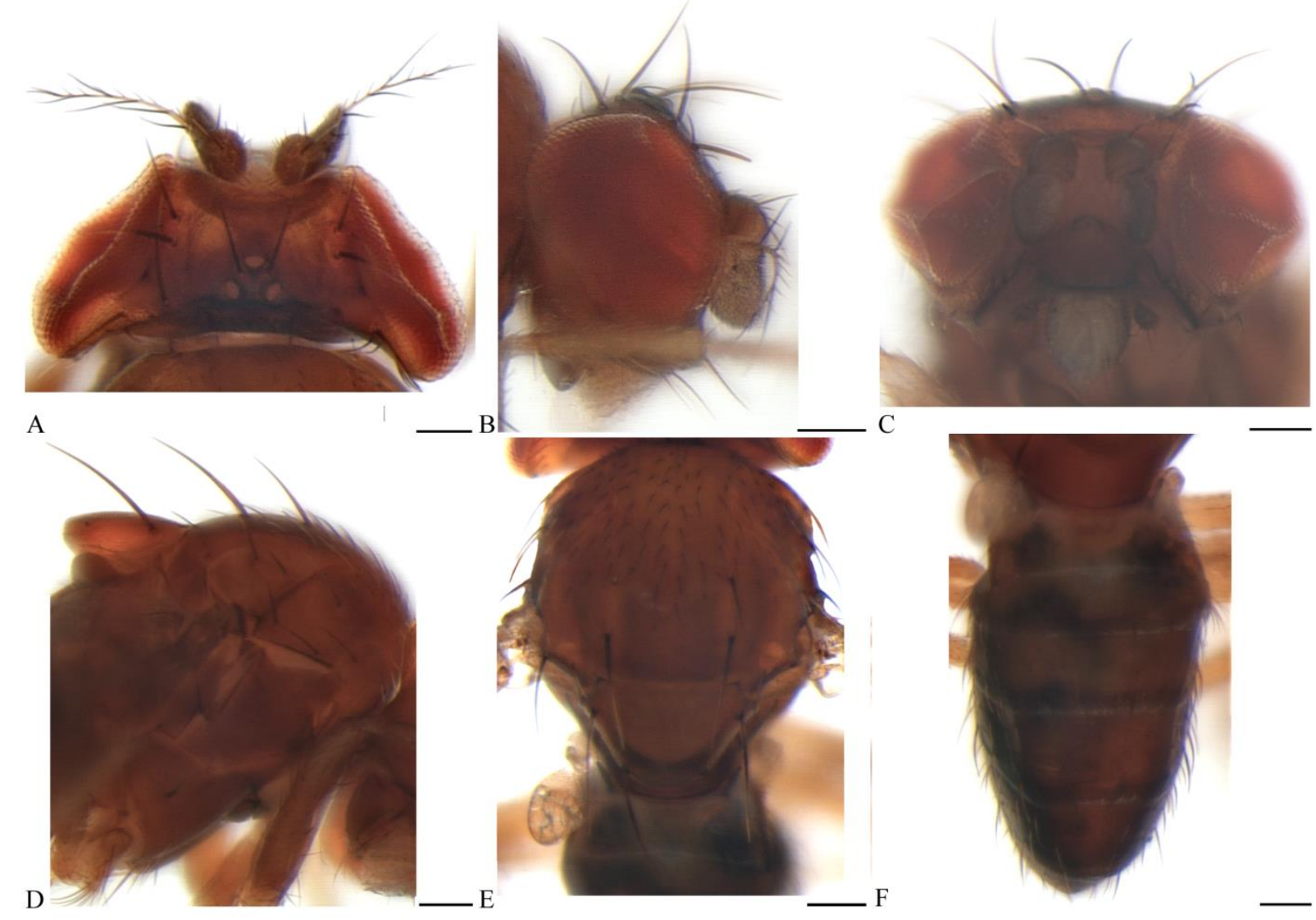

Figure 28. Cladochaeta sp. 14, nov. sp., holotype. A. Frons. B. Lateral view of head. C. Face. D. Lateral view of thorax. E. Dorsal view of thorax. F. Dorsal view of abdomen. Scale bars: $0.1 \mathrm{~mm}$. 


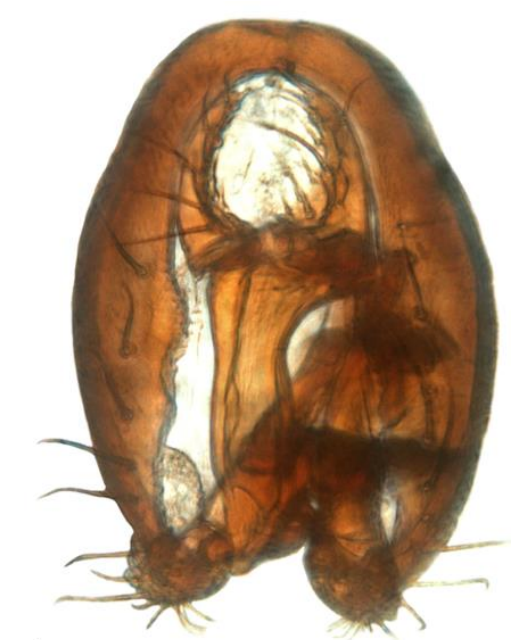

A

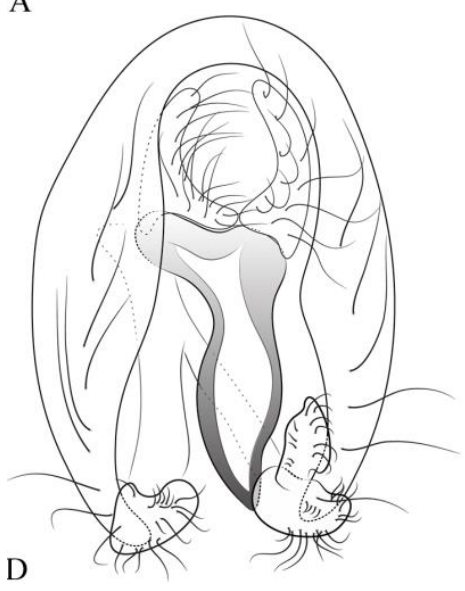

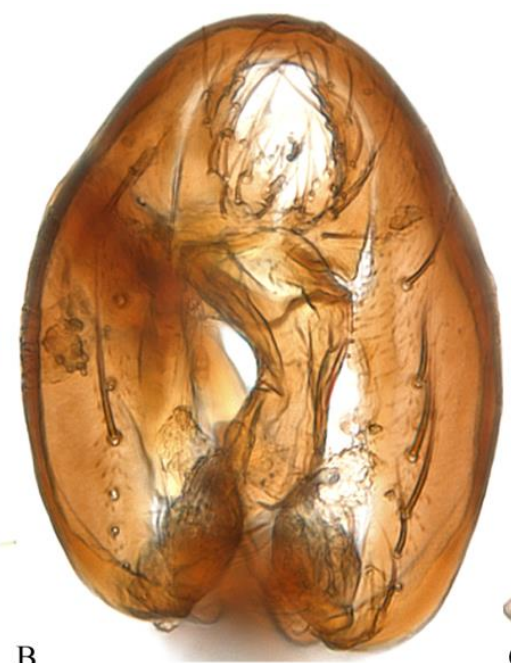

B

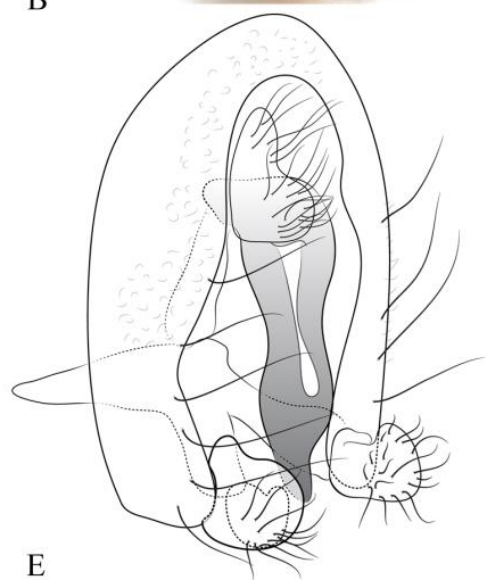

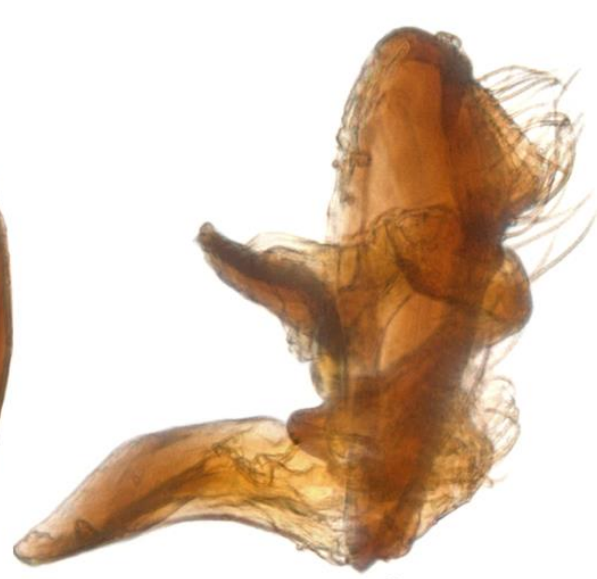

c

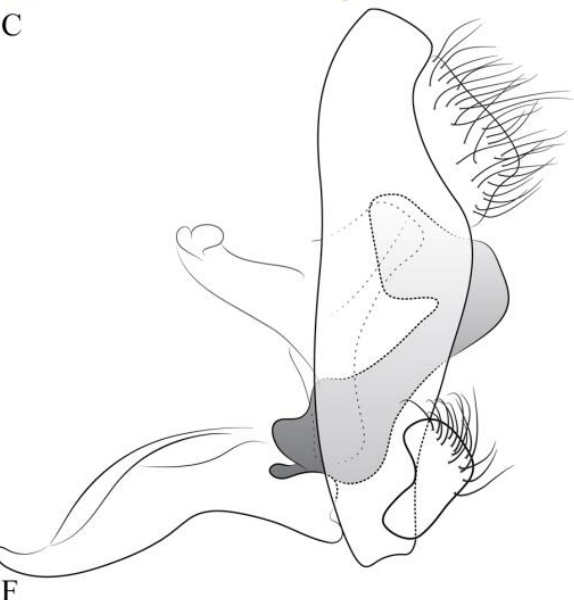

Figure 29. Male terminalia of Cladochaeta sp. 14, nov. sp., holotype. A. Photograph of terminal view. B. Photograph of terminal oblique view. C. Photograph of lateral view. D. Illustration of terminal view. E. Illustration of terminal oblique view. F. Illustrartion of lateral view.

\section{Cladochaeta sp. 15, nov. sp.}

(Figs. 30 A-F; 31 A-D; 34 C; 35 L)

Diagnosis. General body color ochre. thorax ochre, two darker bands on pleuron, abdomen light ochre, with brown bands on tergites; wing membrane uniformly infuscated; legs light brown; arista with just a basal dorsal branch and a single minute branch medially, no apical fork; aedeagus sharply bent into a $90^{\circ}$ angle medially; poorly sclerotized, margins slightly more sclerotized; paraphyses absent; surstylus clavate, with a dorsolateral finger-shaped projection with modified setae.

Material examined: Holotype 1 ภ : BRAZIL, State of Ceará, Guaramiranga, 4 $4^{\circ} 16^{\prime} 13$ 'S 3854'21’W, 880m, 10.v.2014, Malaise trap; Almeida, Lucena \& Tavares cols. (RPSP). 
Description. Head (Figs. 30 A-C). As high as wide. Eyes bare, light red. Pedicel light brown, first flagellomere grayish; arista with one basal dorsal branch and a single minute branch medially, no apical fork. Frons ochre, ocellar triangle brown, anterodorsal margin of frons dark ochre; fronto-orbital setae: anterior reclinate absent; posterior reclinate almost as long as proclinate, midway between proclinate and inner vertical. Face flat, ochre, ventral margin brown. Gena light ochre; proboscis almost whitish; palpus light ochre, margins brown. Thorax (Figs. 30 D-E). Ochre, two diffuse darker bands on pleuron, a diffuse darker median longitudinal band on notum ending on a triangular projection at base of scutoscutellar suture. Anterior dorsocentral ca. 2/3 of posterior dorsocentral length. Posterior dorsocentral slightly closer to scutoscutellar suture than to dorsocentral. Acrostichals in 6 even rows. Basal scutellarsconvergent; apical scutellars convergent but not cruciate at tip. Two postpronotal setae of equal length. Legs pale brown. Wing (Fig. 35 L). Membrane entirely infuscated. Tip of $\mathrm{R}_{2+3}$ slightly curved towards $\mathrm{C}$. $\mathrm{R}_{4+5}$ and $\mathrm{M}$ slightly convergent. Crossvein dm-cu slightly sinuous, perpendicular to $\mathrm{CuA}_{1}$. Wing tip slightly acute. Halter whitish. Abdomen (Fig. 30 F). Tergites light ochre, with brown broad bands covering posterior margin, with an acute projection medially. Male terminalia (Figs. 31 A-D). Epandrium inverted U-shaped, with 8 long setae on ventro-lateral halves; ventral tip of ventro-lateral halves gradually tapering, terminal portion slightly curved inwards, broader extension near cercus. Cercus with rounded ventro-lateral margin. Aedeagus sharply bent into a $90^{\circ}$ angle medially, poorly sclerotized, margins slightly more sclertized; paraphyses absent. Phallapodeme higher than wide, heavily sclerotized, with a long oblique backwards projection. Surstylus clavate, with a dorsolateral finger-shaped projection bearing 3 extremely modified setae. Hypandrium Y-shaped, ventral keel present.

Comments. This species is possibly related to the dikra species group or unca species group (see comments under $C$. sp. 14, nov. sp. for considerations about the delimitation of both groups). The male terminalia of this species closely resembles $C$. sp. 14 , nov. sp. on the shape of the aedeagus, but the surstylus is clearly different. $C$. sp. 15 , nov. sp. also resembles $C$. dominitica Grimaldi \& Nguyen, but they differ on the aristal branching, that is described as having two dorsal branches and 6-8 minute medial ones in $C$. dominitica, while $C$. sp. 11, nov. sp. has one basal dorsal branch and a single minute branch medially. Also, on the wing, C. dominitica has the crossvein dm-cu straight, while in $C$. sp. 11, nov. sp. it is sinuous. This 
species has a male terminalia very similar to an undescribed dikra species of Grimaldi \& Nguyen (1999).
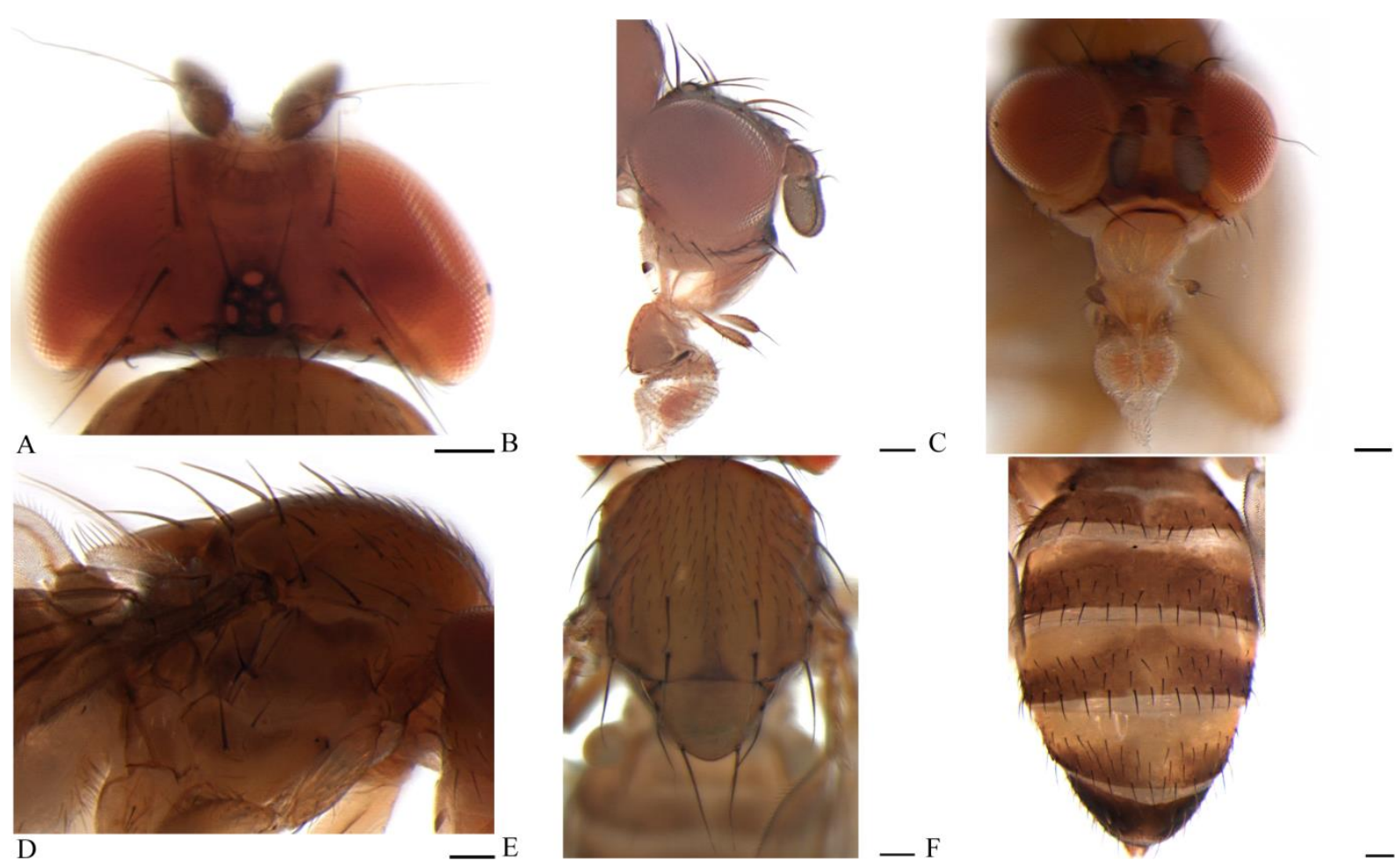

Figure 30. Cladochaeta sp. 15, nov. sp., holotype. A. Frons. B. Lateral view of head. C. Face. D. Lateral view of thorax. E. Dorsal view of thorax. F. Dorsal view of abdomen. Scale bars: $0.1 \mathrm{~mm}$. 

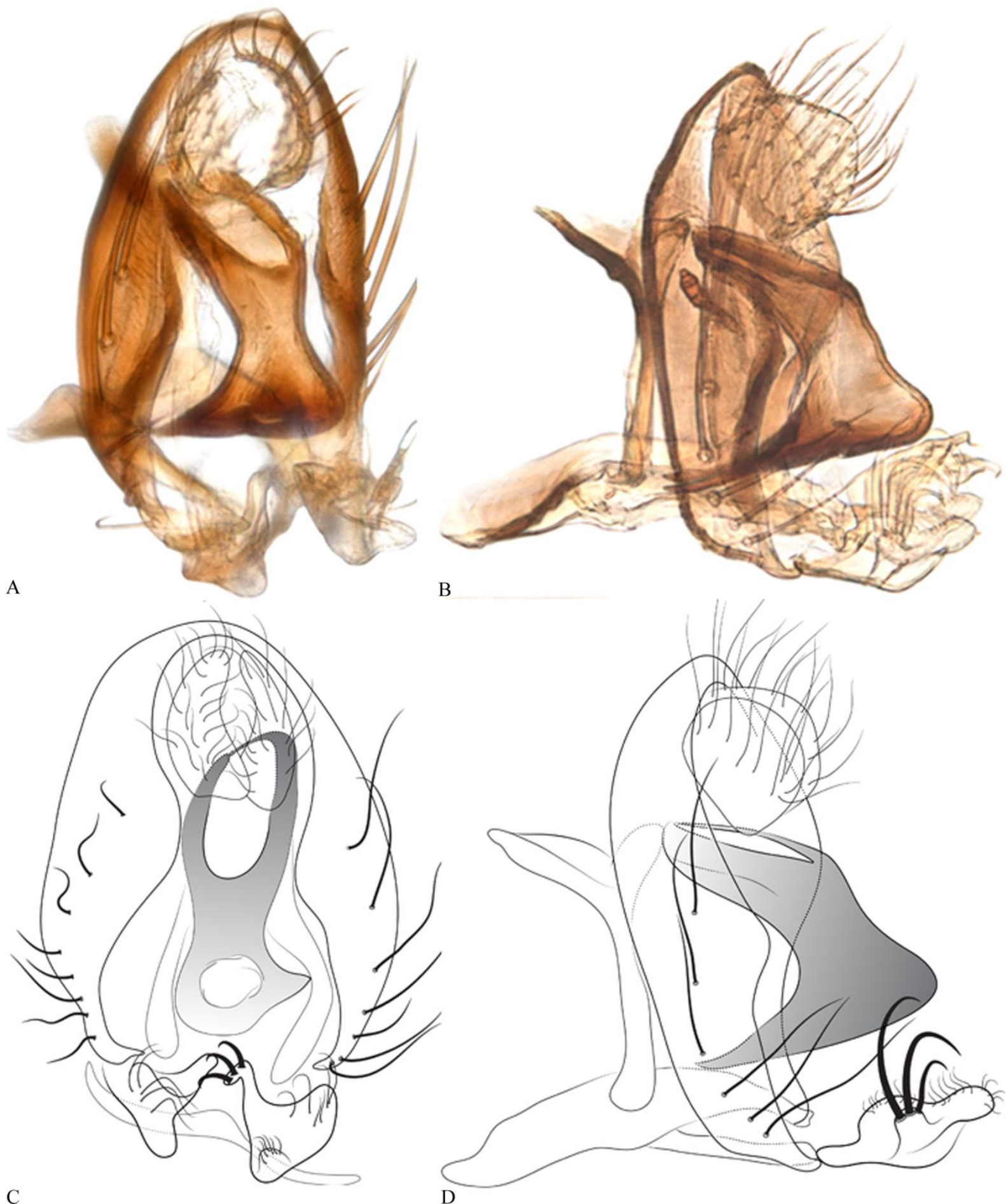

Figure 31. Male terminalia of Cladochaeta sp. 15, nov. sp., holotype. A. Photograph of terminal oblique view. B. Photograph of lateral view. C. Illustration of terminal view. D. Illustration of lateral view. 


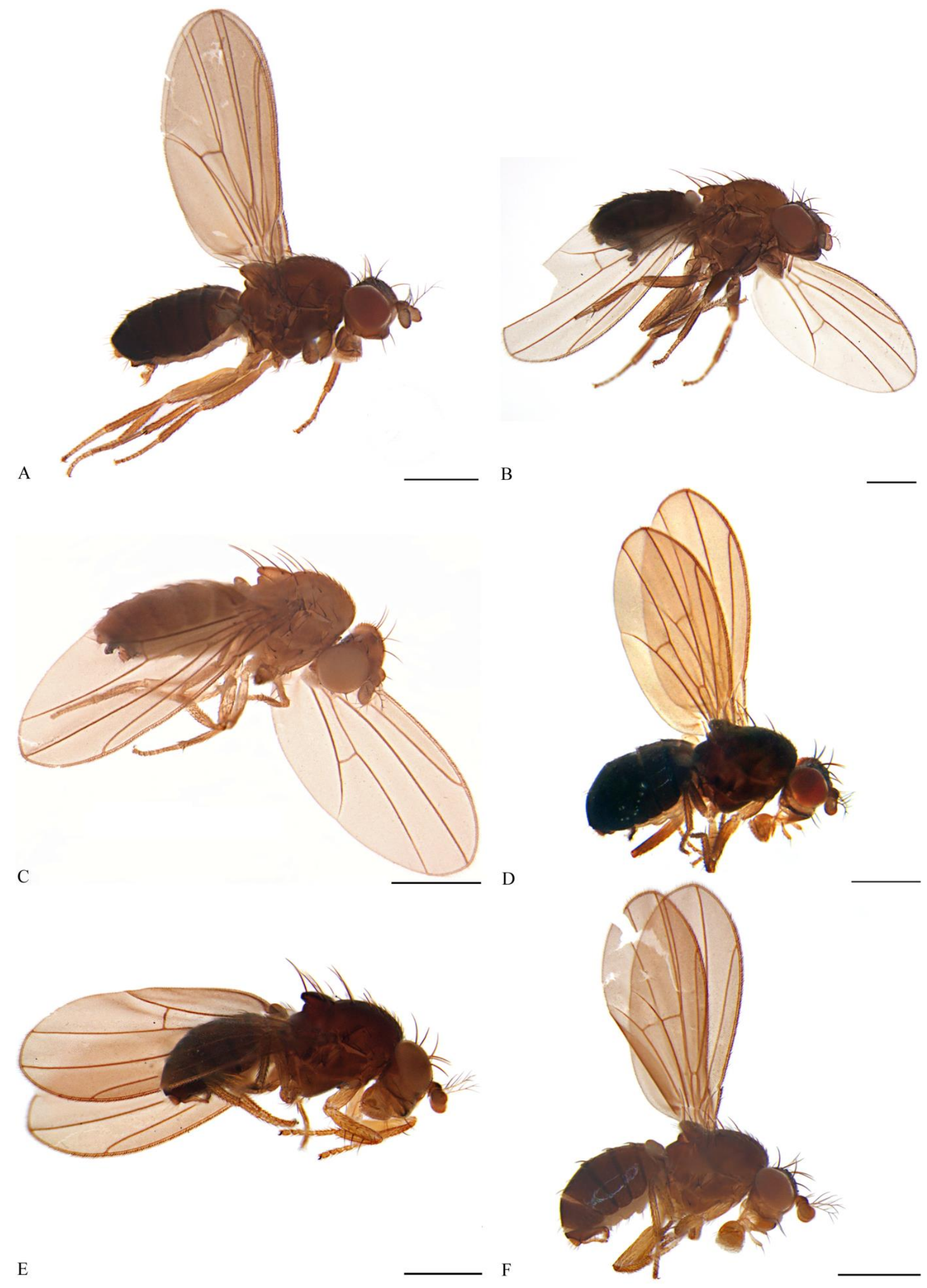

Figure 32. New Brazilian species of Cladochaeta holotypes in lateral habitus. A. C. sp. 1, nov. sp. B. C. sp. 2, nov. sp. C. $C$. sp. 3 , nov. sp. D. C. sp. 4 , nov. sp. E. $C$. sp. 5 , nov. sp. F. C. sp. 6, nov. sp. Scale bars: $0.5 \mathrm{~mm}$. 

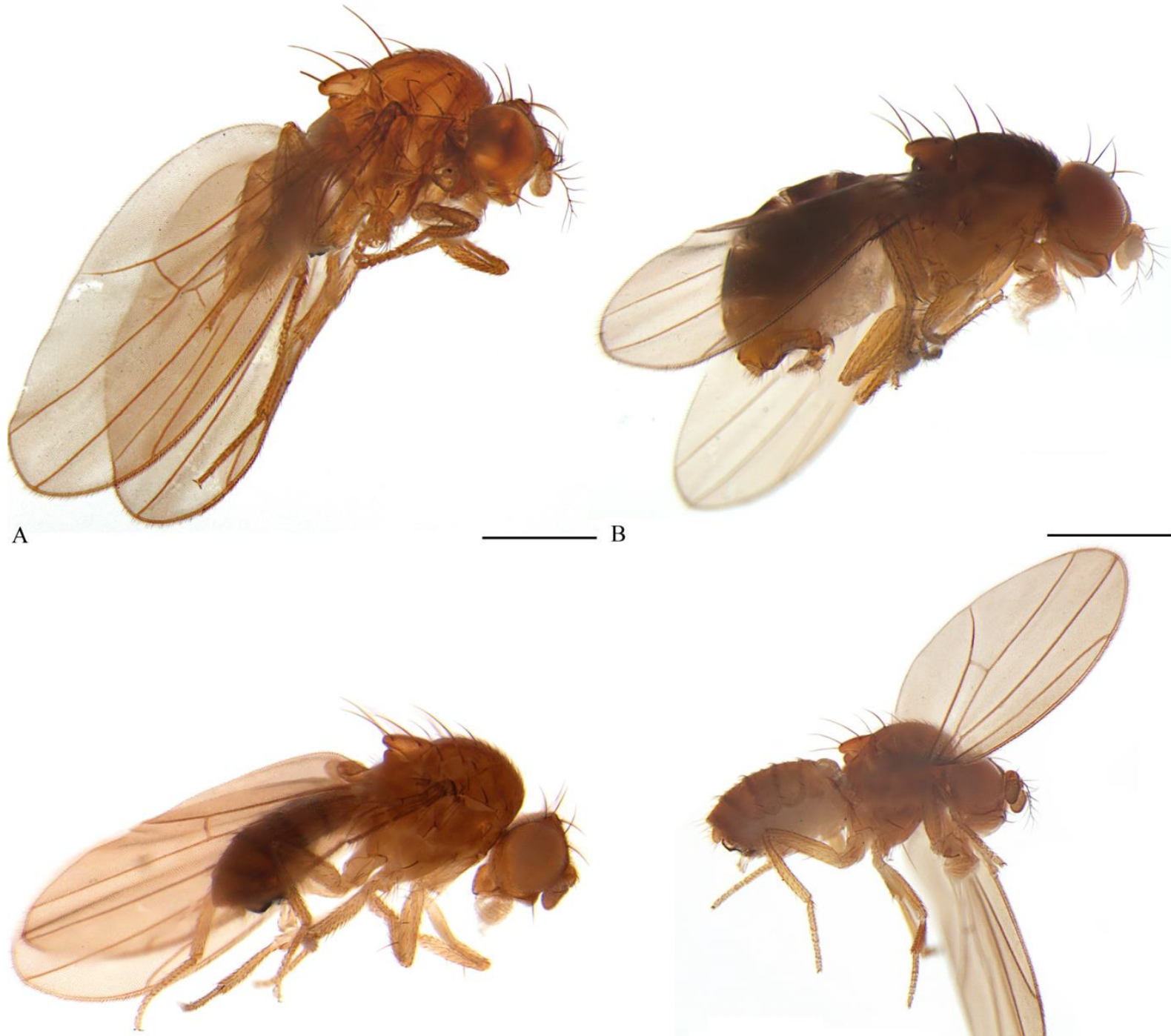

$\mathrm{C}$

D
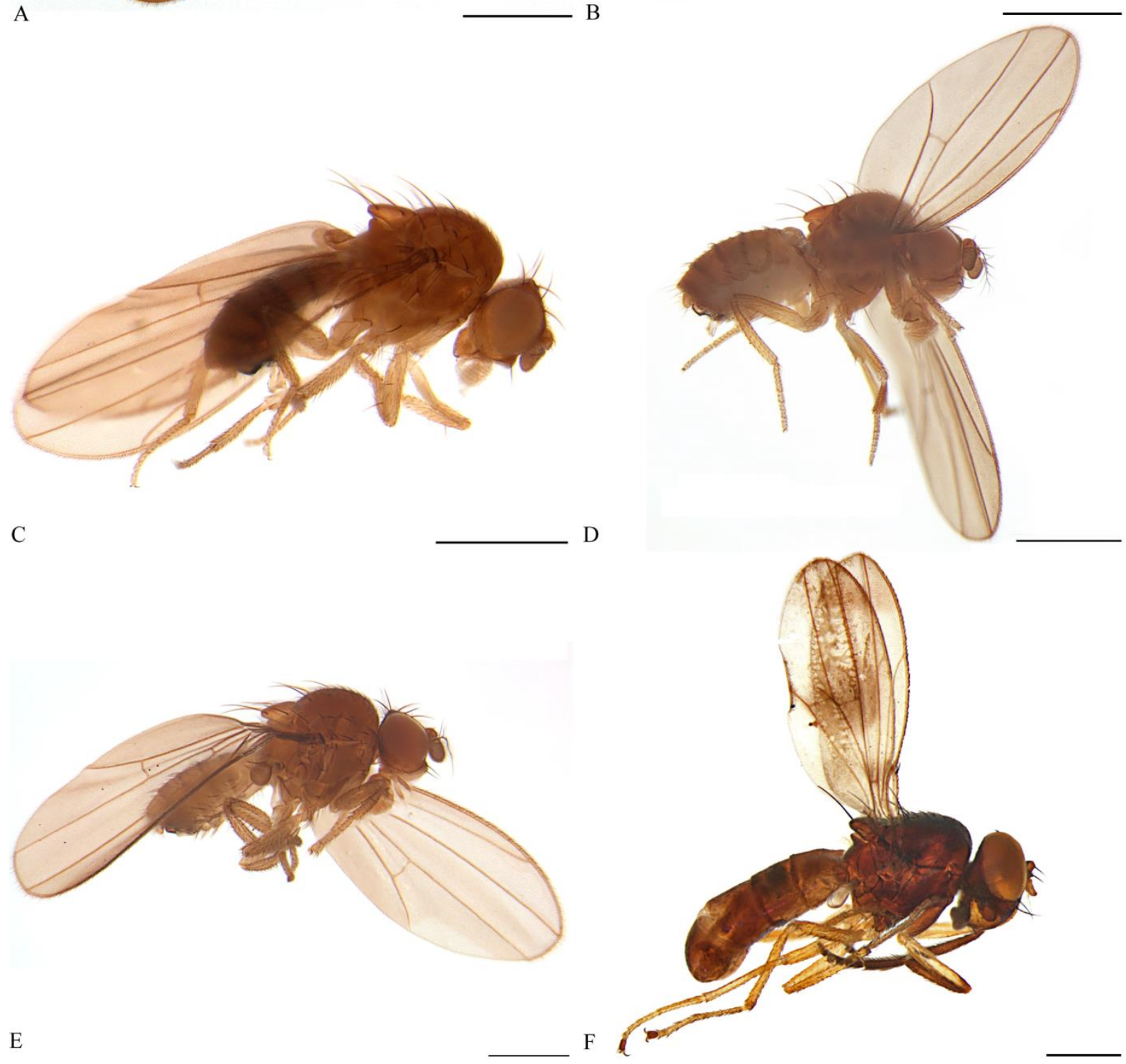

E F

Figure 33. New Brazilian species of Cladochaeta holotypes in lateral habitus. A. C. sp. 7, nov. sp. B. C. sp. 8, nov. sp. C. $C$. sp. 9 , nov. sp. D. $C$. sp. 10 , nov. sp. E. $C$. sp. 11 , nov. sp. F. $C$. sp. 12 , nov. sp. Scale bars: $0.5 \mathrm{~mm}$. 

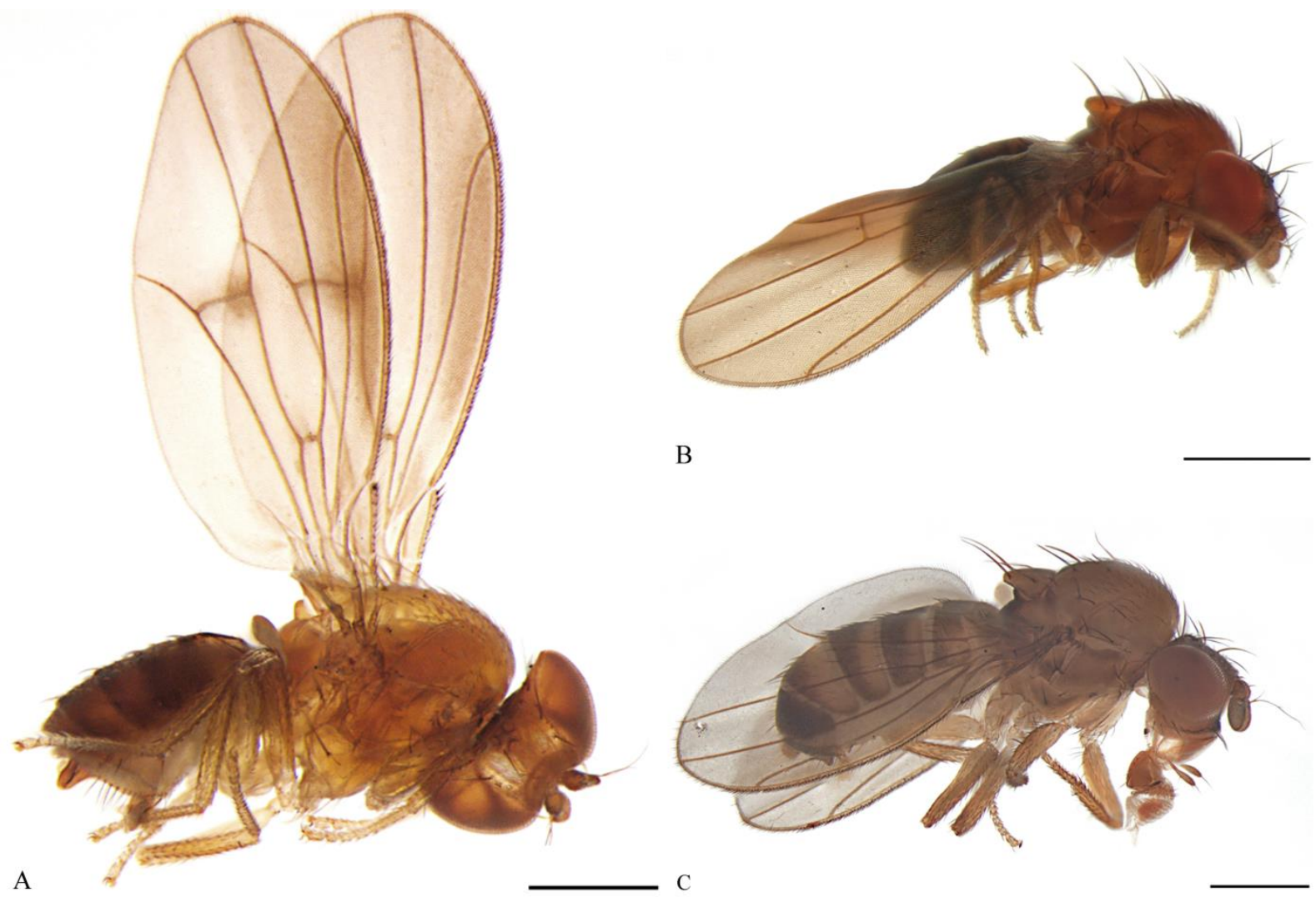

B

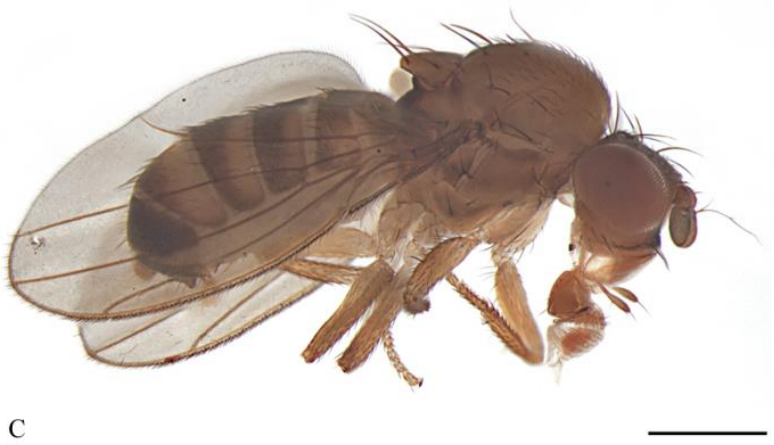

Figure 34. New Brazilian species of Cladochaeta holotypes in lateral habitus. A. C. sp. 13, nov. sp. B. C. sp. 14 , nov. sp. C. C. sp. 15 , nov. sp. Scale bars: $0.5 \mathrm{~mm}$. 

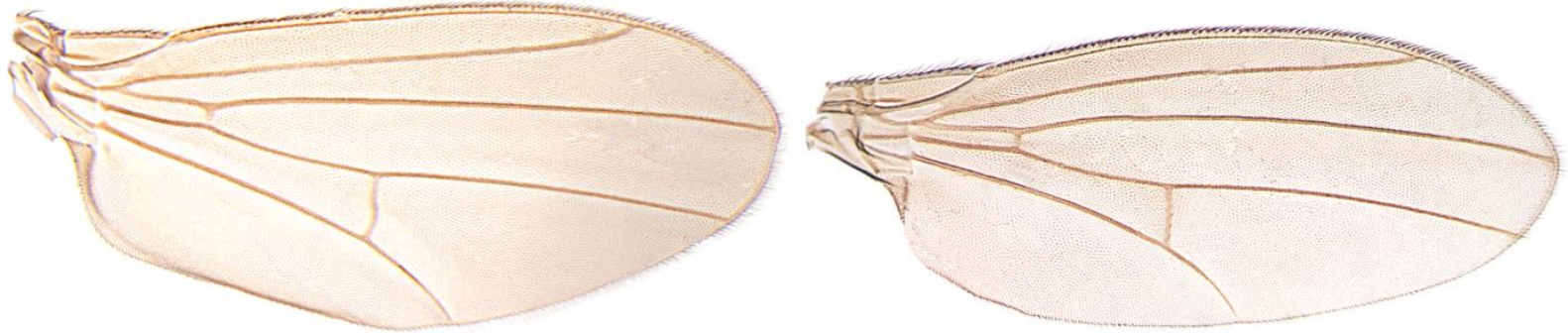

A

B
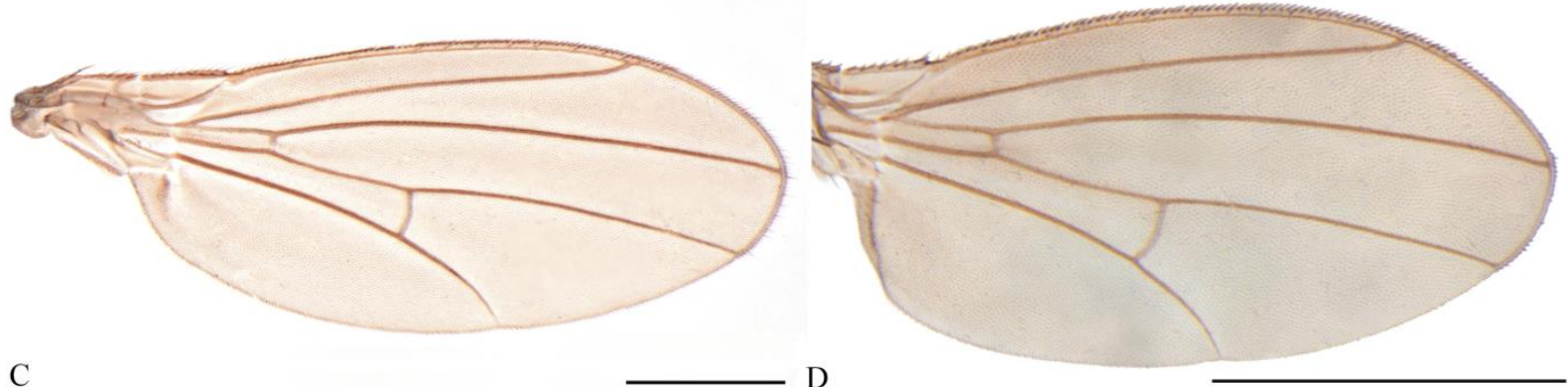

$\mathrm{C}$

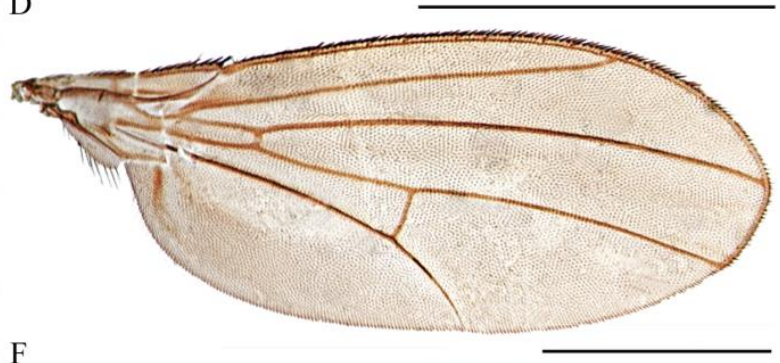

E

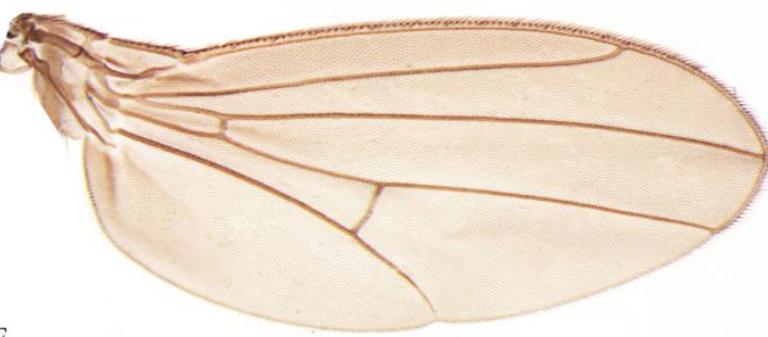

F
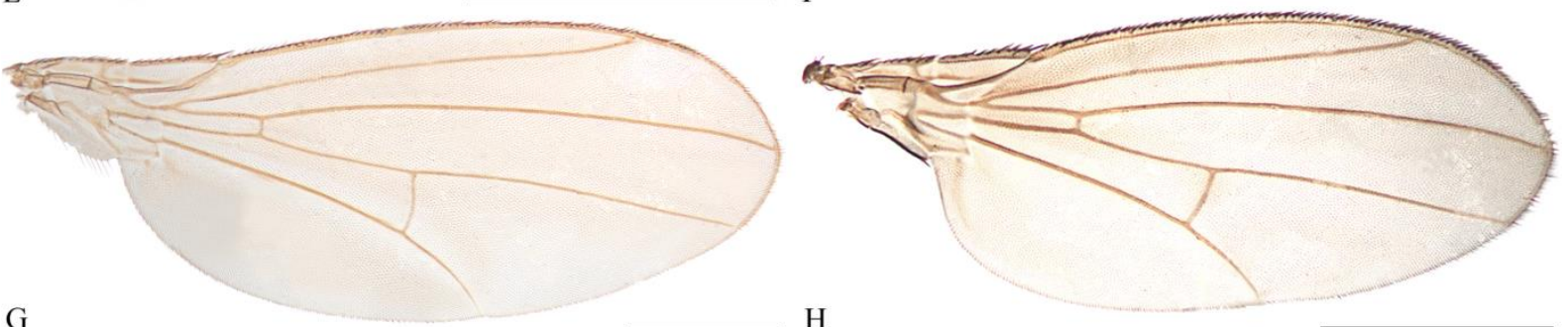

G

$\mathrm{H}$
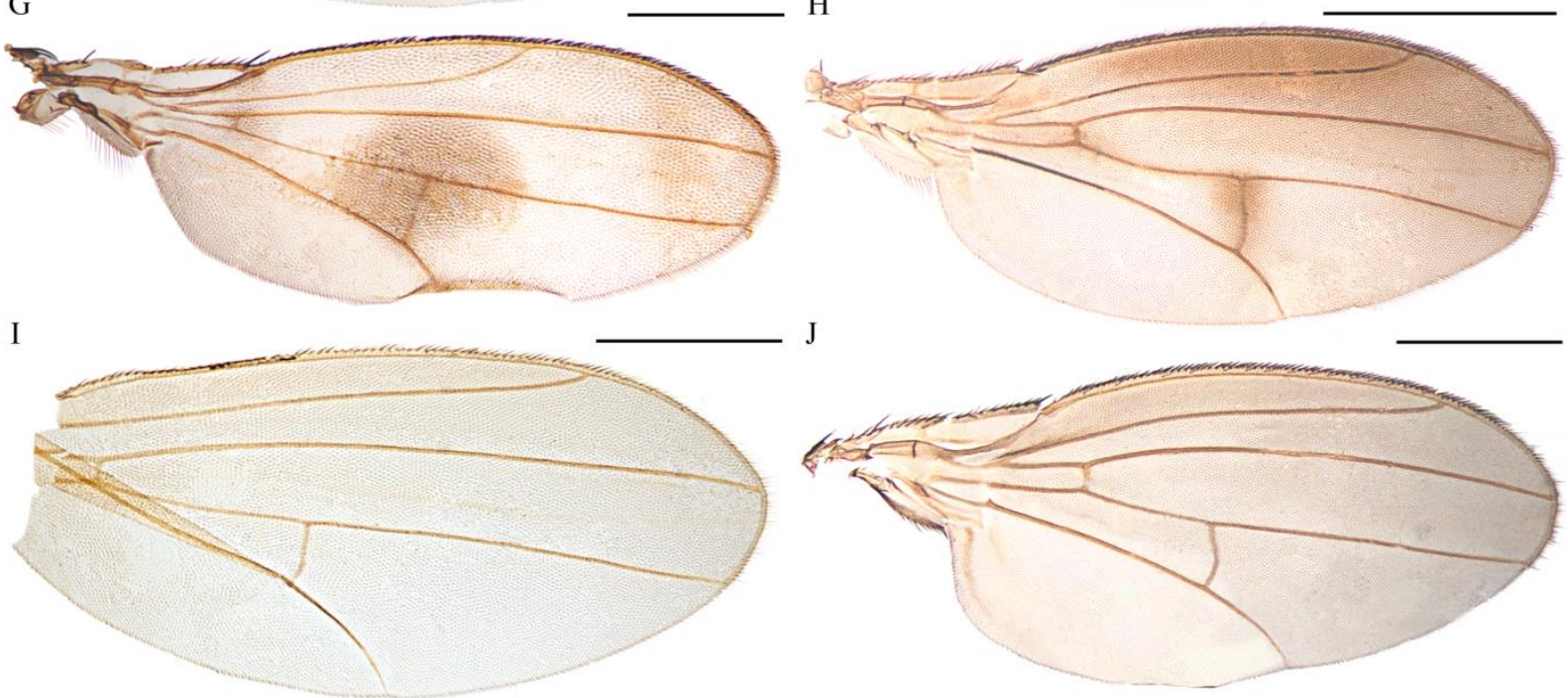

J

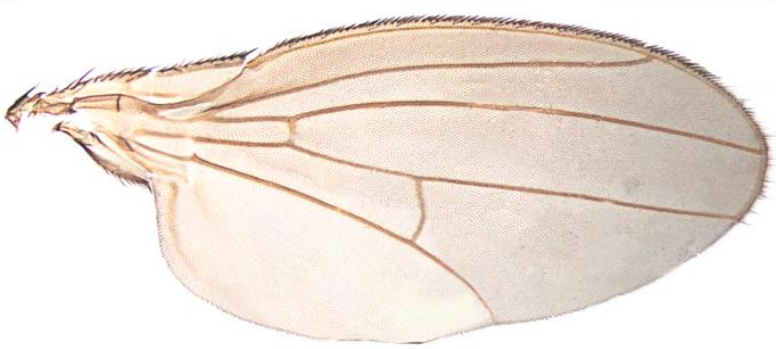

K

L

Figure 35. Wings of the new Brazilian species of Cladochaeta, holotypes. A. C. sp. 1, nov. sp. B. C. sp. 2 , nov. sp. C. $C$. sp. 3 , nov. sp. D. $C$. sp. 4 , nov. sp. E. $C$. sp. 5 , nov. sp. F. $C$. sp. 6, nov. sp. G. $C$. sp. 7 , nov. sp. H. $C$. sp. 8 , nov. sp. I. $C$. sp. 12 , nov. sp. J. $C$. sp. 13 , nov. sp. K. $C$. sp. 14 , nov. sp. L. $C$. sp. 15 , nov. sp. Scale bars: $0.5 \mathrm{~mm}$. 


\subsection{Distributional map of the genus Cladochaeta in Brazil}

The geographic distribution of the genus in Brazil is presented in Fig. 36. Each marker represents one locality, being possible that more than one species occur in that locality. To access this information (i.e., each locality or coordinate), check the section "material examined" presented in the descriptions of each new species.

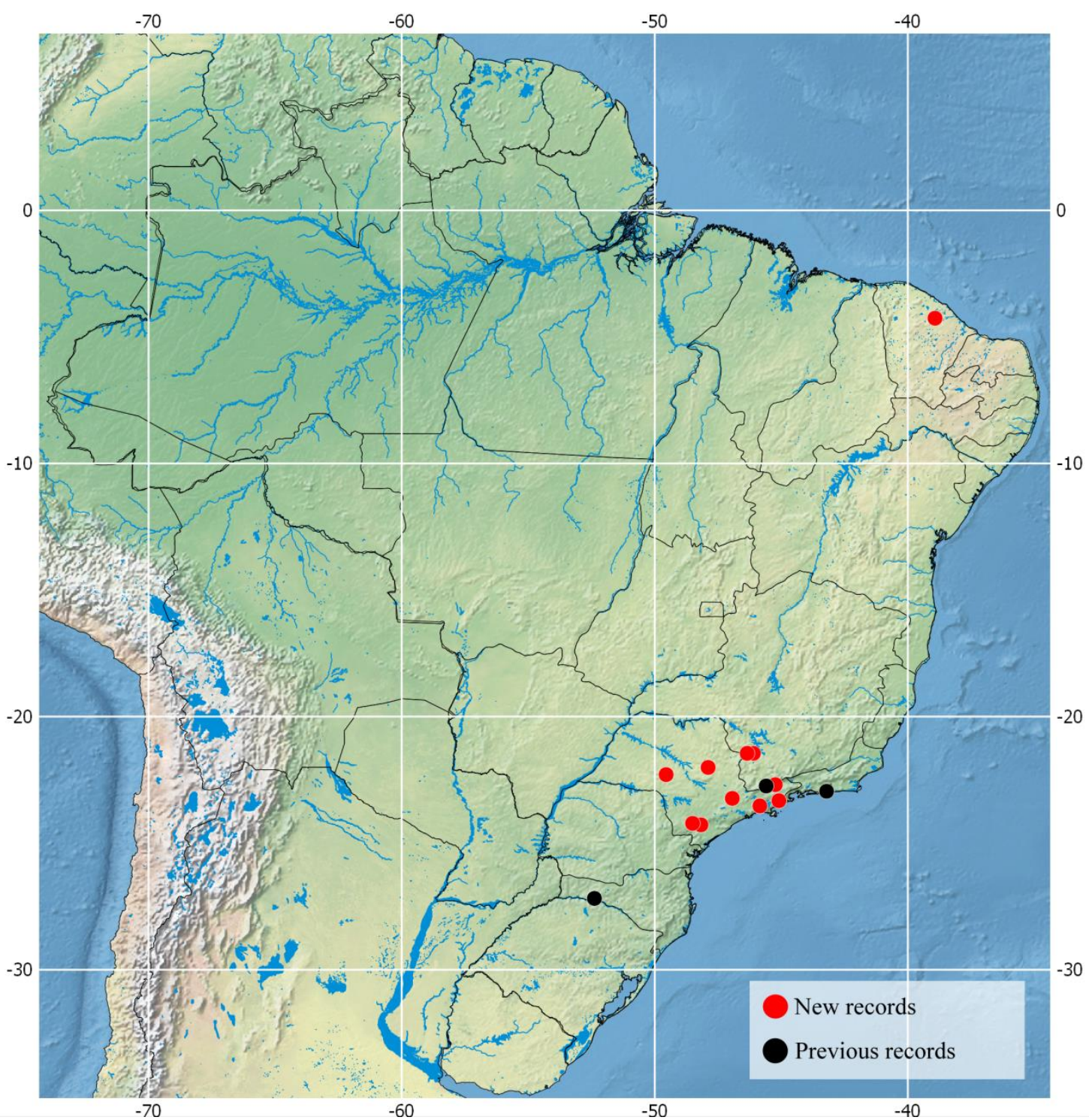

Figure 36. Distributional map of Cladochaeta in Brazil. Black marks represent the occurrence of species previously described. Red marks represent the collecting points of the species described here. 


\subsection{Identification key to Brazilian species of Cladochaeta based on adult males (except for C. travassosi)}

1. Abdominal tergites with light bluish metallic reflections (Figs. 32 D, 32

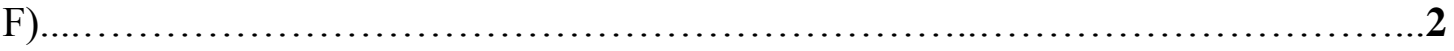

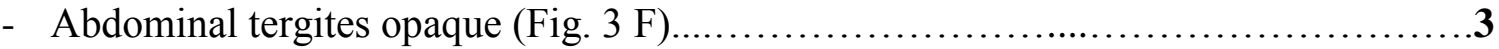

2. Dark brown species, oral margin dark (Fig. 7 B); conical aedeagus, without folds (Fig. 8 D); surstylus bilobed with usual setae (Fig. 8 C)

C. sp. 4, nov. sp.

- Light brown species, oral margin whitish (Fig. $11 \mathrm{C}$ ); conical aedeagus with two dorsolateral folds; surstylus not bilobed (Figs. 12 A-D)

C. sp. 6, nov. sp.

3. Mid and hind legs with several long setae (Grimaldi \& Nguyen, 1999, Fig. 138); paraphyses heavily sclerotized with hook-shaped long projections (as seen in Figs. 20 A-F, 22 A-F) C. armata (Frota-Pessoa, 1947)

- Legs with usual setation 4

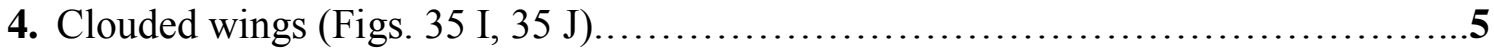

- Wings hyaline or infuscated (Figs. 35 A-H, 35 K-L) .............................

5. Wing macula starting on the apex of $R_{1}$ and extending to the apical portion of $M$ (Vilela \& Bächli, Fig. 143 A); arista with 5 dorsal and one ventral branches. 7 pairs of huge spinelike setae on tergites 4,5 and 6 C. bomplandi (Malloch, 1934)

- Wing without macula in such position; variable arrangement of aristal branches, without spinelike setae on tergites

6. Surstylus with 5 distinctive laterally flattened setae (Vilela \& Bächli, 1990, Fig. 7 A-B); wing with a very light infuscation over costal edge, apical third of wing and over $\mathrm{r}-\mathrm{m}$ and dm-cu, arista with 4 dorsal and one ventral branches

C. minuta (Duda, 1925)

- Without the above combination of characters.

7. Arista with 8 dorsal branches, no ventral branch; head higher than wide in lateral view; surstylus long distally triangular, with 3 anterior and 1 posterior strong setae (Fig. 24 C, 24 F)

C. sp. 12, nov. sp.

- Arista with only the dorsal basal branch (Fig. 26 B). Head as high as wide in lateral view, clavate surstylus (Figs. 26 A-F). C. sp. 13, nov. sp.

8. Arista with 3-4 dorsal and 1 ventral branches; apical fork present (Fig. 26 A) 
- Arista with a dorsal basal long and a minute median branches; no apical fork. (Fig. 31. A-D)

C. sp. 15, nov. sp.

9. Bilobed surstylus, with three-branched setae on distal lobe (Fig. 16 AE)

- Simple or bilobed surstylus, with no three-branched setae 10

10. Paraphyses absent; heavily sclerotized and conical aedeagus (Figs. 10 A-F; 14 A-F; 29 A-F.

- Paraphyses present; undistinguishable or membranous aedeagus .13

11. Arista with 3 dorsal and one ventral dorsal branches C. sp. 5, nov. sp.

- Arista with 4 dorsal and one ventral branches .12

12. Anterior reclinate fronto-orbital setae distinguishable from other orbitals (Fig 28 B); clavate simple surstylus (Fig. 29 A-F)

- Anterior reclinate fronto-orbital setae indistinguishable from other orbitals (Fig. 7 B); bilobed surstylus (Fig. $14 \mathrm{~F}$ )

C. sp. 7, nov. sp.

13. Crossvein dm-cu straight (Fig. 35 B) C. sp. 2, nov. sp.

- Crossvein dm-cu sinuous or bent, even slightly, in the middle .14

14. Arista with 4 dorsal and one ventral branches; paraphyses with 7 projections united by a broad dorsal bridge (Figs. 6 A-C). C. sp. 3, nov. sp.

- Arista with 3 dorsal and one ventral branches; paraphyses with less than 7 projections.

15. Ventral branch opposite to d-3; paraphyses with 5 projections forked on apex (Fig. 18 A-D). C. sp. 9, nov. sp.

- Ventral branch between d-3 and apical fork; paraphyses with less than 5 projections (Figs. 2 A-C, 20 A-F, 22 A-F).

16. Veins $R_{2+3}$ and $M$ convergent. C. sp. 11, nov. sp.

- Veins $\mathrm{R}_{2+3}$ and $\mathrm{M}$ divergent. .17

17. Anterior reclinate fronto-orbital seta present (Fig. 1 B); paraphyses flattened laterally, united by a broad bridge on dorsal half, left paraphyses longer than right paraphyses (Figs. 2 A-C)

C. sp. 1, nov. sp.

- Anterior reclinate fronto-orbital seta absent (Fig. 19 B); paraphyses sinuous, united by a dorsal bridge, with simple apex (Figs $20 \mathrm{~A}-\mathrm{F})$ C. sp. 10, nov. sp. 


\section{Discussion}

\subsection{Species richness in Cladochaeta and morphospecies known only from females}

The description of 15 new species of Cladochaeta raises the species richness of the genus from 124 to 139, and the number of Brazilian species from four to 19 (adding to $C$. armata [Frota-Pessoa, 1947], C. bomplandi [Malloch, 1924], C. minuta [Duda, 1925] and C. nebulosa Coquillett, 1900). Furthermore, there are at least other 16 Brazilian different morphospecies known only from females (Tab. 1). As can be seen from the map in Fig. 36, however, there are huge portions of Brazil that remain unsampled. Even in the areas that have been sampled, it is largely probable that are more species to be described. This points to Grimaldi \& Nguyen's (1999) assessment of the overall species richness of the genus.

We decided not to formally describe species known only from females, as they do not present sufficient morphological information to diagnose species or be associated to males. In other words, females can indeed be assigned to groups of species, but in some cases they could fit in the general morphology of more than one species.

Table 1 is a compilation of information on the distribution of these morphospecies. As stated before, some of these females may be conspecific with the species described above only based on males, but no positive association can be established at the time. As happens with other groups of insects, proper association between males and females may be addressed rearing the species, with specimens collected in copula or with molecular markers - with due care with the problem of paralogy and pseudogenes. A molecular description of the species for the sake of barcoding may be undertaken in the future. 
Table I. Undescribed female morphospecies of Brazilian Cladochaeta. (Brazilian states: MG = Minas Gerais, SP = São Paulo).

\begin{tabular}{|c|c|c|c|c|c|c|c|c|c|c|c|}
\hline & $\begin{array}{l}\text { Bertioga } \\
\text { (SP) }\end{array}$ & $\begin{array}{c}\text { Campos do } \\
\text { Jordão (SP) }\end{array}$ & $\begin{array}{l}\text { Cabo } \\
\text { Verde } \\
\text { (MG) }\end{array}$ & $\begin{array}{c}\text { Gália } \\
\text { (SP) }\end{array}$ & $\begin{array}{l}\text { Iguapé } \\
\text { (SP) }\end{array}$ & $\begin{array}{c}\text { Ribeirão } \\
\text { Grande (SP) }\end{array}$ & $\begin{array}{l}\text { Salesópolis } \\
\text { (SP) }\end{array}$ & $\begin{array}{c}\text { São } \\
\text { Carlos } \\
\text { (SP) }\end{array}$ & $\begin{array}{c}\text { São Luís do } \\
\text { Paraitinga (SP) }\end{array}$ & $\begin{array}{l}\text { Serra do } \\
\text { Japi (SP) }\end{array}$ & $\begin{array}{l}\text { Total number of } \\
\text { specimens per } \\
\text { species }\end{array}$ \\
\hline Cladochaeta sp. 17 & & & & & & & & & & 3 & 3 \\
\hline Cladochaeta sp. 18 & & & & & & & & & & 2 & 2 \\
\hline Cladochaeta sp. 19 & & & & & & & 1 & & & & 1 \\
\hline Cladochaeta sp. 20 & & & & & & 1 & & & & & 1 \\
\hline Cladochaeta sp. 21 & & & & & & 1 & & & & & 1 \\
\hline Cladochaeta sp. 22 & & & & & & & & & 3 & 1 & 4 \\
\hline Cladochaeta sp. 23 & & & & & & & & & 1 & & 1 \\
\hline Cladochaeta sp. 24 & & & & & & & & & 1 & & 1 \\
\hline Cladochaeta sp. 25 & & & & 1 & & & & & & & 1 \\
\hline Cladochaeta sp. 26 & & & & & & & & & & 1 & 1 \\
\hline Cladochaeta sp. 27 & & & & & & 1 & & & 2 & 1 & 4 \\
\hline Cladochaeta sp. 28 & & & 1 & & & & & & & & 1 \\
\hline Cladochaeta sp. 29 & & & & & & & & & 2 & & 2 \\
\hline Cladochaeta sp. 30 & & & & & & 1 & & & & & 1 \\
\hline Cladochaeta sp. 31 & & 2 & 2 & & & 6 & & 0 & 68 & 6 & 84 \\
\hline Cladochaeta sp. 32 & & & 1 & 0 & 1 & 2 & & 1 & 80 & 2 & 87 \\
\hline Cladochaeta sp. & & & & 1 & & & 2 & & 5 & 6 & 14 \\
\hline $\begin{array}{l}\text { Total number of } \\
\text { morphospecies }\end{array}$ & & & & & & & & & & & 209 \\
\hline
\end{tabular}


In most cases, females show differences in external morphology between the morphospecies and even in the female terminalia. Nevertheless, in some cases, as Cladochaeta sp. 31 and Cladochaeta sp. 32, for example, it would not be easy delimit the species based only on females, since most characters that would more clearly separate them from each other (e.g., aristal branching, bands on pleuron etc.) seem to have intraspecific variation and some overlap between the morphospecies. In this particular case, there is one known male (C. sp. 3, nov. sp.) with a very distinctive terminalia (Figs. 6 A-C) and external features that match the aforementioned species complex. In other cases, male and females show similar external morphology, but are from different localities (e.g., C. sp. 2, nov. sp. and C. sp. 23) bringing some uncertainty to the association between them. For the time being, the study of variation of female external morphology between specimens from different localities seems to add to the estimatives of the richness of the genus, but should not be assigned to described species.

The distributional map (Fig. 36) shows large intermediary portions of the country with no records for the genus eventhough samples of different additional Brazilian localities were analyzed with no Cladochaeta records (e.g., Carreiro Castanho, Manaus and Novo Airão, in the State of Amazonas; Cacaulândia, Campo Novo de Rondônia, Monte Negro, and Porto Velho in the State Rondônia; Chapada dos Guimarães and Poconé in the State of Mato Grosso; Aquidauana, Corumbá, Porto Murtinho, Rio Verde, Serra da Bodoquena and Taboco in the State of Mato Grosso do Sul). Several techniques usefull for collecting Cladochaeta were used in these localities-light traps, Malaise traps, and sweeping-but were not succesfull as in other localities. Cladochaeta species are known to occur in the Amazon Forest in other South American countries-e.g., C. abbrevifusca Grimaldi \& Nguyen, 1999 from Coroico, Bolivia; C. erecta Grimaldi \& Nguyen, 1999, C. ptyelophila Tsacas, 1993, and C. spectabilis from Província del Napo, Ecuador; C. sororia (Williston, 1896) and undescribed females by Grimaldi \& Nguyen (1999) in Madre de Dios, Peru. Certainly the collecting effort in many of these areas were not enough to properly sample the species of Cladochaeta in these areas.

\subsection{Male terminalia sclerites and homology}

It is well established in the literature that male terminalia characters are highly informative to species diagnoses in general, although there are some exceptions (see, e.g., 
Ament \& Amorim, 2010 and also some of the species described here). This seems to be the case of Cladochaeta, since most external morphological characters of the genus are almost indistinguishable, as previously discussed. Animals with internal fertilization often show a pattern of rapid and divergent evolution of genital traits that could be explained by the lockand-key, sexual selection or pleiotropy hypothesis (Arnqvist \& Thornhill, 1998). Arnqvist (1998) presents several evidences towards the evolution of genital traits by postmating sexual selection mechanisms. His results show that in taxa with polyandrous females, the male genitalia has a highly divergent evolution and does not influence any external morphological traits. This seems to be the case in Cladochaeta. It is possible to observe these feature across the genus, i.e., relatively low external morphology variability with extremely high variability in the male terminalia. This can be observed mainly on the paraphyses and aedeagus, which composes the intromittent organ, but also on the surstylus and, in a lesser degree, on the shape of epandrium, hypandrium and cerci.

Specially due to this level of variability, it is a major challenge to trace the homology of male terminalia sclerites to a detailed level, not only in this genus, but also between structures of different Drosophilidae genera of Drosophilidae. According to Grimaldi (1990), the y-shaped keeled hypandrium and the pair of long and narrow setose paraphyses are synapomorphic for Cladochaeta. The most controversial structures in Cladochaeta are the surstyli, the gonopods and the complex of paraphyses + aedeagus.

The first point concerns the homology of the surstylus. Grimaldi (1990) considered the surstylus of Cladochaeta as the projections linked to the dorsal portion of the phallapodeme, by the assumed decasternum. Vilela \& Bächli (1990), however, inferred that the decasternum is absent in most Cladochaeta species except C. sororia (Williston, 1986), in which they mention a membranous decasternum. Grimaldi \& Nguyen (1989), while redescribing this species, do not mention a decasternum. In fact, the decasternum doesn't appear in any of their descriptions. In none of the Brazilian species described here a decasternum could be recognized, what made us assume that this structure is absent in Cladochaeta. If the decasternum originally connects both surstyli and is absent in Cladochaeta, it seems difficult to state that the surstylus in Cladochaeta is homologous to the surstylus of other drosophilids.

Grimaldi \& Nguyen (1999) mention that the paraphyses of Cladochaeta were incorrectly interpreted as surstyli in Grimaldi (1990); what was referred to as surstyli by Grimaldi (1990) should actually be the paraphyses - and vice-versa. In addition, several other Drosophilidae have rows of "peg prensisetae" on the mesal surface of the surstyli, which are 
entirely absent in Cladochaeta, this being a synapomorphy of the genus. It is well established in the literature that the surstyli would be an extension of the epandrium and, therefore, associated to it (Cumming \& Wood, 2009). This is not so clear in Cladochaeta, where the assumed surstylus is placed between the epandrium and hypandrium.

In Drosophilidae and other acalyptrate families there is a pair of structures associated to the distal portions of the hypandrium named gonopods (McAlpine, 1981; Grimaldi 1990). According to McAlpine (1981) and Cumming \& Wood (2009), the gonopods are a pair of segmented clasping arms that arise posterolaterally on S9 and are divided in the gonocoxite (basal) and gonostylus (distal). The gonopods are separated from each other and from the hypandrium at the Diptera ground plan. The gonocoxites become fused to the hypandrium several times independently within the Diptera (Cumming \& Wood, 2009). In presenting the revised epandrial hypothesis, Cumming et al. (1995) stated that in the Eremoneura the hypandrium and the gonocoxites are fused and in Cyclorrapha the gonostylus are articulated directly to the hypandrium. The gonostylus in the ground plan of the Cyclorrapha are dorsally directed and clasp against the hypandrium. In the Schizophora, however, it is reduced and modified, articulating ventrally against the hypandrium. That being the case, it would be questionable that the so called gonopods in Drosophilidae are homologous to the gonopods of the Diptera ground plan. If it is, it's possible that what is called surstylus in Cladochaeta, is in fact a gonopod, therefore Cladochaeta lacks a true surstylus. Grimaldi \& Nguyen (1999) in their descriptions refer to surstyli and gonpods in a variaty of arrangement-sometimes only one of them, sometimes together in the same species. This is a pending issue in terms of homology of the male genitalia sclerites in the genus and a sound solution depends on a study across the Ephydroidea.

A second point concerns the complex of the intromitent organs, the paraphyses and the aedeagus. According to Grimaldi (1990), the paraphyses are usually small lobes with apical setae, connected to the basal portion of the aedeagus. The Cladochaetini has a reduced aedeagus, placed between both paraphyses and posterior to the phallapodeme, always with a membranous distiphallus. Grimaldi \& Engel (2005), while describing the extreme diversity of paraphyses in Cladochaeta, mentioned that it may or may not be homologous to the parameres. The parameres, assumed as a synonym of the paraphyses by Cumming \& Wood (2009), are presumably present in all Brachycera as the parameral sheath, a structure that encapsulates the apex of the aedeagus. 
In the Eremoneura ground plan, the parameral sheath is completely fused to the aedeagus to form a modified intromitent organ named the phallus (Cumming et al., 1995; Cumming \& Wood, 2009). The phallus is further divided into basiphallus, epiphallus, distiphallus, and acrophallus. In Cladochaeta it is a challenge to clearly define which parts of the intromitent organ are the paraphyses or the aedeagus itself. The paraphyses, as interpreted by Grimaldi \& Nguyen (1999), are heavily sclerotized hooks with very complex and variable shapes within the genus. Despite the variation, they are almost always united by a dorsal bridge and never have setae. However, giving a special attention to this complex of structures within the species of Cladochaeta is possible to notice that the supposed paraphyses and aedeagus occur in a large range of shapes. They can appear as a single conical structure, which could be interpreted as a fusion of both or the loss of one of them. In other cases, the structure presents several hook-shaped arms in different numbers and a variety of directions, making it difficult to discern which portion is either the paraphyses or the aedeagus. Finally, it is not always possible to observe the distiphallus, a character that could be useful to identify the aedeagal portion (although the name distiphallus is used to refer to the phallus itself and may be not be used in the same sense when paramerers and aedeagus are separated structures). These points raised seem enough to show how complex it is to fully homologize these structures between the species of Cladochaeta and between Cladochaeta species and the general acalyptrate male terminalia sclerite pattern.

\subsection{Groups of species and relationships within the genus Cladochaeta}

When Grimaldi \& Nguyen (1999) proposed the ten species groups for Cladochaeta, they consider that conducting a phylogenetic analysis of the genus at that time would be premature. The knowledge on the genus diversity was still incipient, what would lead to a limited taxonomic sampling.

Even with the increase in the taxonomic knowledge of the genus brought about by the present study, it is still premature to implement a formal phylogenetic analysis. We prefer even not formally indicating the connection of the new Brazilian species described here to the groups of species in the genus (see comments under the descriptions of species for considerations of possible relationship issues). When a phylogenetic analysis can be performed, both phylogeny and fitting the species to their groups would be achieved at the same time. 


\subsection{The already described species of Cladochaeta from Brazil}

Up to date, there were 4 species of Cladochaeta assigned to Brazil (e.g., C. armata [Frota-Pessoa, 1947], C. bomplandi [Malloch, 1924], C. minuta [Duda, 1925] and C. travassosi [Frota-Pessoa, 1947]). Grimadi \& Nguyen (1999) did not have access to the types of $C$. armata, but redescribed it, based on specimens from Nova Teutônia, Santa Catarina State, collected by Fritz Plaumann. However, observing the illustrations available in each publication is possible to notice some diffrences concerning the apical portions of paraphyses. The terminalia described and illustrated by Frota-Pessoa (1947) has these portions single (condition similar to $C$. sp. 10, nov. sp., see Figs. 20 E-F), while the description and illustration of Grimaldi \& Nguyen (1999) refers to a forked condition (similar to C. sp. 11, nov. sp., see Figs. 22 E-F). It's not possible to make many consirations about $C$. travassosi species based only on the illustrations Frota-Pessoa (1947). Being that, we opt to not redescribe these species in an attempt to clarify this situation in the future, in a revisional context, since we did not have access to the type material. 


\section{Conclusions and prospects}

This study was a first effort to broadly understand the Brazilian fauna of Cladochaeta, previously known from only very few species. It corroborates the previsions about the great species richness in Brazil and makes possible to understand and recognize some patterns within the group. It releases the first key to species and photographs of Cladochaeta, which will be certainly helpful in future taxonomic studies.

The great number of females not assigned to any of the formally described species strongly suggest that the assessment of the species richness would have been more efficient if a molecular technique of association with males was used. This would later allow associating immature with adults. Rearing Cladochaeta from spittle bugs would add up important information on the biology and taxonomy of the genus. The geographic sampling of the genus we had in hands for this study was mainly based in material from the Atlantic Forest. Expansion of collecting effort in other biomes will certainly increase the number of known species from the country. Despite some problems concerning strict homology of male terminalia sclerites, the conclusions in Grimaldi (1990) and Grimaldi \& Nguyen (1999) are sound and solve most problems on male terminalia morphology of Cladochaeta and of the Drosophilidae as a whole. A detailed study of morphology and homology of small parts of the terminalia will solve some issues concerning homology, besides resulting in characters for a phylogenetic study for the genus.

Another key issue in terms of progress of the taxonomy of the group is the clarification of the generic limits between Cladochaeta and Diathoneura. It is not entirely clear if both genera are monophyletic sister groups or if either them is paraphyletic in relation to the other genus. This has implications for the understanding of some issues of homology, but as well would have impact for the understanding of the position of the Cladochaetini in the context of the system of the drosophilids as a whole. 


\section{References}

Ainslie, C. N. 1906. Guests of spittle insects. The Canadian Entomologist, 38: 44.

Ament, D. C. \& Amorim, D. S. Five new species of Coniceromyia Borgmeier (Diptera: Phoridae) from the Atlantic Forest, Brazil. Zootaxa, 2421: 35-48.

Arnqvist, G. \& Thornhill, R. 1998. Evolution of animal genitalia: patterns of phenotypic and genotypic variation and condition dependence of genital and non-genital morphology in water strider (Heteroptera: Gerridae: Insecta). Genome Research, 71: 193-212.

Ashburner, M. 1981. Entomophagous and other bizarre Drosophilidae. In Ashburner, M., Carson, H. L. and Thompson, J. N. (Eds.), The genetics and biology of Drosophila 3a: 395-429. New York: Academic Press.

Bächli, G. 2015. TaxoDros: The database on Taxonomy of Drosophilidae. V1.04; Database 2015/03. Electronic Database accessible at http://www.taxodros.unizh.ch. (last access in $26 / 05 / 2015$ ).

Baerg, W. J. 1920. An unusual case of parasitism on Clastoptera obtusa Say (Hemip., Cercopidae; Dip., Drosophilidae). Entomological News, 21: 20-21.

Brown, B.V. (2009) Introduction. In: Brown, B.V. Borkent, A., Cumming, J.M., Wood, D.M., Woodley, N.E. \& Zumbado, M.A. (Eds.), Manual of Central American Diptera. Volume 1. NRC Research Press, Ottawa, pp. 1-7.

Coquillett, D. W. 1900. Report on a collection of dipterous insects from Puerto-Rico. Proceedings of the United States National Museum, 22: 249-270.

Cryan, J. R. \& Svenson, G. J. 2010. Family-level relationships of the spittlebugs and froghoppers (Hemiptera: Cicadomorpha: Cercopoidea). Systematic Entomology, 35: 393-415.

Cumming, J. M; Sinclair, B. J; Wood, D; M. 1995. Homology and phylogenetic implications of male genitalia in Diptera - Eremoneura. Entomologica Scandinavica, 26: 120-151.

Cumming, J.W. \& Wood, D.M. (2009) Adult morphology and Terminology [Chapter 2]. In: Brown, B.V., Borkent, A., Cumming, J.M., Wood, D.M., Woodley, N.E. \& Zumbado, M.A. (Eds.), Manual of Central American Diptera, Volume 1. NRC Research Press, Ottawa, Ontario, Canada, pp. 9-50

DeSalle, R.; Grimaldi, D. A. 1991. Morphological and molecular systematic of the Drosophilidae. Annual review of ecology and systematic, 22: 447-475. 
Duda, O. 1924. Beitrag zur Systematik der Drosophiliden unter besonderer Berücksichtigung der palärktischen u. orientalischen Arten (Dipteren). Archiv für Naturgeschichte, 90(A)3: 172-234.

Duda, O. 1925. Die costaricanischen Drosophiliden des Ungarischen National-Museums zu Budapest. Annales historico-naturales Musei nationalis hungarici, 22: 149-229.

Frota-Pessoa, O. 1947. Revisão do gênero Clastopteromyia (em cuja sinonímia é colocada Diathoneura), com descrição de 9 espécies novas (Drosophilidae-Diptera). Summa Brasiliensis Biologia, 1: 181-221.

Gottschalk, M. S.; Hofmann, P. R. P.; Valente, V. L. S. 2008. Diptera, Drosophilidae: historical occurrence in Brazil. Check List, 4: 485-518.

Grimaldi, D. A. 1990. A phylogenetic, revised classification of genera in the Drosophilidae (Diptera). Bulletin of the American Museum of Natural History, 197: 1-139.

Grimaldi, D. A. \& T. Nguyen. 1999. Monograph on the spittlebug flies, genus Cladochaeta (Diptera: Drosophilidae: Cladochaetini). Bulletin of the American Museum of Natural History, 241: 1-326.

Grimaldi, D. A. 2010. Drosophilidae. In: Brown, B. V.; A. Borkent; J. M. Cumming; D. M. Wood; N. E. Woodley e M. A. Zumbado (Eds.). Manual of Central American Diptera. NRC Research Press, Ottawa, Ontario, Canadá. Vol. 2

Grimaldi, D. A. \& Engel, M. S. The insects. In:Grimaldi, D. A. \& Engel, M. S. (Eds.). Evoltion of the Insects. Cambridge University Press, New York, New Youk, U.S.A.

.Malloch, J. R. \& McATEE, W. L. 1924. Flies of the family Drosophilidae of the district of Columbia Region, with Keys to genera, and other notes, of broader application. Proceedings of the Biological Society of Washington, 37: 25-42.

McAlpine, J. F. 1981. Morphology and terminology - adults. In J. F. McAlpine (ed.), Manual of Neartic Diptera. Research Branch Agriculture Canada monogr. 27. Ottawa: Minister Supply and Services Canada. Vol. 1.

McAlpine, J. F. 1989. Phylogeny and classification of the Muscomorpha, pp. 1397-1518. In: B. V. Peterson, G. E. Shewell, H. J. Teskey, J. R. Vockeroth e D. M. Wood (Eds.), Manual of Nearctic Diptera. Biosystematic Research Centre, Ottawa. Vol. 3.

Okada, T. 1977. Family Drosophilidae. In: Evenhuis, N.L. (Ed.), Catalog of the Diptera of the Australasian and Oceanian regions, 609-638.

Okada, T. 1984. New or Little Known Species of Drosophila (Lordiphosa) with Taximetrical Analyses (Diptera, Drosophilidae). Kontyu, 52: 565-575. 
Okada, T. 1989. A Proposal of Establishing Tribes for the Family Drosophilidae with key to Tribes and Genera (Diptera). Zoological Science, 6: 391-399.

Remsen, J. \& O'Grady, P. 2002. Phylogeny of Drosophilinae (Diptera: Drosophilidae), with comments on combined analysis and character support. Molecular Phylogenetics and Evolution, 24: 249-264.

Sturtevant, A. H. 1921. The North American species of Drosophila. Carnegie Institution of Washington, 301: 1-150.

Thompson, V. \& Mohd-Saleh, N. 1995. Spittle maggots: studies on Cladochaeta fly larvae living in association with Clastoptera spittlebug nymphs. American Midland Naturalist, 134: $215-225$.

Tsacas, L. \& Couturier, G. 1993. Une nouvelle espèce de Cladochaeta de l'Équateur inquiline des nynphes de Cephisus erythrocephalus [Diptera, Drosophilidae; Homoptera, Aphrophoridae]. Revue Francaise d'Entomologie, 15: 85-90.

Van der Linde, K; Houle, D; Spicer, G. S.; Steppan, S. J. 2010. A supermatrix-based molecular phylogeny of the family Drosophilidae. Genetics Research, 92: 25-38.

Vilela, C. R. \& Bächli, G. 1990. Taxoomic studies on Neotropical species of seven genera of Drosophilidae (Diptera). Mitteilungen der Schweizerischen Entomologischen Gesellschaft, 63: 1-332.

Wheeler, M. R. 1952. The Drosophilidae of the Neartic Region, exclusive of the genus Drosophila. University of Texas Publication, 5204: 162-218.

Wheeler, M. R. \& Takada, H. 1971. Male genitalia of some representative genera of American Drosophilidae. University of Texas Publication, 7103: 225-240.

Wheeler, M. R. 1981. The Drosophilidae: a taxonomic overview. In: Ashburner, M., Carson, H. L. and Thompson, J. N., Jr (Eds.). The Genetics and Biology of Drosophila, 3a: 1-97. London: Academic Press.

Yassin, A. 2013. Phylogenetic classification of the Drosophilidae Rondani (Diptera): the role of morphology in the postgenomic era. Systematic Entomology, 38: 349-364. 